\title{
Henri Sée
}

(1864-1936)

\section{La France \\ économique et sociale au XVIII ${ }^{\mathrm{e}}$ siècle}

Troisième édition, 1946

Librairie Armand Colin, Paris.

Première édition : 1925

Un document produit en version numérique par Jean-Marc Simonet, bénévole, Courriel : Jean-Marc_Simonet@uqac.ca

Dans le cadre de la collection: "Les classiques des sciences sociales" Site web : $\underline{\text { http://classiques.uqac.ca/ }}$

Une collection développée en collaboration avec la Bibliothèque Paul-Émile-Boulet de l'Université du Québec à Chicoutimi

Site web : http://bibliotheque.uqac.ca/ 


\section{Politique d'utilisation de la bibliothèque des Classiques}

Toute reproduction et rediffusion de nos fichiers est interdite, même avec la mention de leur provenance, sans l'autorisation formelle, écrite, du fondateur des Classiques des sciences sociales, Jean-Marie Tremblay, sociologue.

Les fichiers des Classiques des sciences sociales ne peuvent sans autorisation formelle:

- être hébergés (en fichier ou page web, en totalité ou en partie) sur un serveur autre que celui des Classiques.

- servir de base de travail à un autre fichier modifié ensuite par tout autre moyen (couleur, police, mise en page, extraits, support, etc...),

Les fichiers (.html, .doc, .pdf, .rtf, .jpg, .gif) disponibles sur le site Les Classiques des sciences sociales sont la propriété des Classiques des sciences sociales, un organisme à but non lucratif composé exclusivement de bénévoles.

Ils sont disponibles pour une utilisation intellectuelle et personnelle et, en aucun cas, commerciale. Toute utilisation à des fins commerciales des fichiers sur ce site est strictement interdite et toute rediffusion est également strictement interdite.

\section{L'accès à notre travail est libre et gratuit à tous les utilisa- teurs. C'est notre mission.}

Jean-Marie Tremblay, sociologue

Fondateur et Président-directeur général,

LES CLASSIQUES DES SCIENCES SOCIALES. 
Cette édition électronique a été réalisée par Jean-Marc Simonet, ancien professeur des Universités, bénévole.

Courriel : Jean-Marc_Simonet@uqac.ca

À partir de :

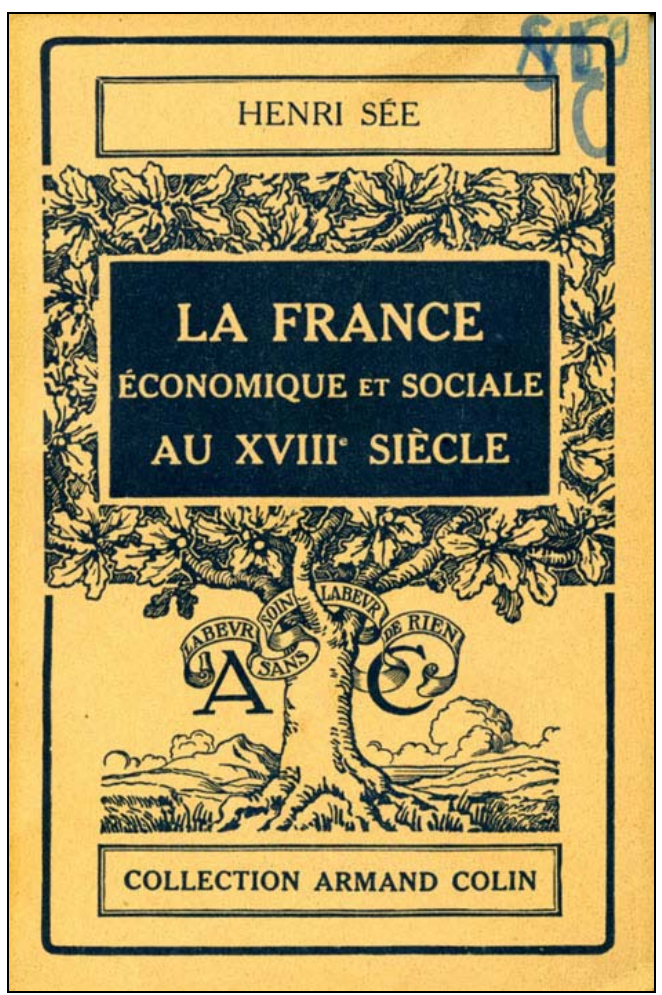

Henri Sée

Historien français

(1864-1936)

\section{La France économique et sociale au $\mathrm{XVIII}^{\mathrm{e}}$ siècle}

Troisième édition, 1946

Librairie Armand Colin, Paris, (première édition : 1925), 197 pages.

Polices de caractères utilisées :

Pour le texte: Times New Roman, 14 et 12 points.

Pour les notes de bas de page : Times New Roman, 10 points.

Édition électronique réalisée avec le traitement de textes Microsoft Word 2008 pour Macintosh.

Mise en page sur papier format : LETTRE (US letter), 8.5’’ x 11'’)

Édition numérique réalisée le 3 juin 2010 à Chicoutimi, Ville de Saguenay, province de Québec, Canada

\section{f. Fait avec}




\title{
Table des Matières
}

\author{
Introduction.
}

Chapitre Premier. La propriété foncière. Sa répartition. La population de la France.

La propriété des classes privilégiées. — La propriété paysanne. — La population de la France. — L'infinie variété des poids et des mesures. — Ouvrages à consulter.

\section{Chapitre II. Les paysans et l'agriculture.}

Les mainmortables. - Les diverses classes. Fermiers et métayers. - Les journaliers et les domestiques. - Le régime seigneurial. — Portée du régime et aggravation de l'exploitation seigneuriale. — La fiscalité royale. L'exploitation agricole. - L'industrie rurale. — Le mode de vie des paysans. - Les crises et la misère. - Épidémies, mendicité et assistance. - Les troubles agraires. - L'état moral. - L'enseignement. L'administration paroissiale. — La question paysanne et l'opinion publique. - Importance prépondérante de la question paysanne. - Ouvrages à consulter.

\section{Chapitre III. Le clergé.}

L’ordre du clergé. - Nombre des ecclésiastiques. — Les propriétés et la richesse du clergé. - Les charges du clergé. - Le haut clergé et la noblesse. - Le clergé régulier. - Le haut clergé séculier. - Mode de vie du haut clergé. - Les évêques administrateurs. - Le bas clergé. - La vie du bas clergé d'après un contemporain. - Relations du bas clergé avec le haut clergé. - Les ressentiments du bas clergé. - Les curés et les élections aux États généraux. — Ouvrages à consulter.

\section{Chapitre IV. La noblesse.}

Les sources de la noblesse. - Les réformations de la noblesse. — Nombre des nobles. - Les privilèges de la noblesse. — Plusieurs catégories dans la noblesse. Les présentés à la cour. — La noblesse de cour. — Le train de vie de la haute noblesse. - Les pensions royales. - Les conséquences de la vie mondaine. - La noblesse provinciale. La diversité des conditions. La moyenne noblesse. - La noblesse pauvre. — La noblesse et les paysans. — La noblesse et les idées nouvelles. - La noblesse et l'opinion publique. 
— Les nobles n’ont pas conscience de leurs intérêts collectifs. — Ouvrages à consulter.

Chapitre V. Noblesse parlementaire et noblesse administrative. Origines de la noblesse parlementaire. - Grandes familles parlementaires. - Valeur personnelle des parlementaires. - Esprit conservateur des parlementaires. - Le rôle social des parlements. - La noblesse administrative. Les intendants. Les conseillers d'État. — Ouvrages à consulter.

Chapitre VI. La petite industrie. Les métiers et les corporations.

Prédominance de la petite industrie. - Les corporations. Métiers libres et jurandes. - L'apprentissage. — Les compagnons. — L'accès à la maîtrise. — L’administration de la communauté. Les jurés. — Les confréries. — Le véritable rôle des communautés de métiers. - Hiérarchie légale des métiers. - Conséquences économiques du régime des jurandes. - Accentuation de l'organisation corporative. - Ruine financière des corporations. Les projets de réforme. — La réforme de Turgot. — Ouvrages à consulter.

\section{Chapitre VII. L’évolution commerciale au XVIII ${ }^{\mathrm{e}}$ siècle.}

Les voies de communication. - Les moyens de transport. - Décadence des foires. Progrès du crédit. - Les tendances libérales de la politique commerciale. Les traités de commerce. - Le commerce avec les pays d'Europe. - Le commerce du Levant. — Le grand commerce maritime et colonial. La compagnie des Indes. - Le commerce avec les Antilles. Les ports français au XVIII ${ }^{\mathrm{e}}$ siècle, p. 122. - Grand épanouissement du commerce au XVIII ${ }^{\mathrm{e}}$ siècle. — Ouvrages à consulter.

\section{Chapitre VIII. L'évolution industrielle au XVIII ${ }^{\mathrm{e}}$ siècle.}

Progrès de l'administration industrielle. - Les manufactures et leurs monopoles. - La réglementation. - Les progrès de l'industrie dans la première moitié du XVIII ${ }^{\mathrm{e}}$ siècle. — Les nouvelles doctrines économiques. - Affaiblissement du régime réglementaire. - Extension de l'industrie rurale. - L'emprise du capitalisme commercial sur l'industrie. — Les origines de la concentration industrielle. — Les progrès du machinisme. — Les mines de houille, grandes exploitations capitalistes. — La petite industrie, toujours prédominante. — Ouvrages à consulter.

\section{Chapitre IX. Les classes ouvrières et marchandes.}

I. Les artisans.

Leur mode de vie. - Leur condition n'est pas uniforme. - Artisans perdant leur indépendance économique. 
II. Les marchands, les négociants, les directeurs de manufactures. Diversité des conditions. — Le mode de vie de la bourgeoisie commerçante. III. Les compagnons.

Les diverses catégories. - Condition de vie. - L'organisation ouvrière. Les compagnonnages. - Les grèves. - L'attitude des pouvoirs publics. Il n’y a pas encore de question ouvrière. — Ouvrages à consulter.

Chapitre X. Les gens de finances.

Les banquiers. - Les officiers des finances. — Les fermiers généraux. Rôle social des financiers. - La nouvelle génération des fermiers généraux. — Ouvrages à consulter.

Chapitre XI. Haute et moyenne bourgeoisie.

Les professions libérales. - Bourgeois vivant noblement. - Les anoblis et le patriarcat urbain. - Le train de vie. - La culture intellectuelle. - Sentiments révolutionnaires de la bourgeoisie. — Ouvrages à consulter.

Chapitre XII. La misère et l'assistance.

La misère dans les campagnes. - La misère dans les villes. - Impuissance de la charité. — L'assistance de l’État. — Ouvrages à consulter.

Chapitre XIII. Les vœux des diverses classes sociales en 1789.

Accord des trois ordres. - Les dissentiments entre les ordres. - Dissentiments parmi les privilégiés. - Les diverses classes du tiers état. - Les vœux d'ordre économique. — Ouvrages à consulter.

\section{Conclusion.}

Bibliographie générale. Appendice bibliographique. 


\section{Introduction}

Si l'on veut vraiment comprendre le caractère de la société contemporaine, il importe de se représenter la vie économique et sociale de l'ancienne France et particulièrement de la France du XVIII ${ }^{\mathrm{e}}$ siècle. Rien n'est, en effet, plus instructif que la méthode comparative, qui nous fait percevoir clairement les ressemblances et surtout les contrastes.

Bien que cent cinquante ans seulement - c'est-à-dire une brève période dans l'histoire de l'humanité - nous séparent de l'époque que nous nous proposons de décrire, il semble, au premier abord, que la France d'aujourd'hui ne ressemble que de très loin à la France de Louis XVI. On se l'explique aisément : dans l'intervalle, l'ancien régime s'est écroulé, la Révolution a transformé toutes les institutions politiques et sociales; puis, une profonde révolution économique a modifié, en France comme dans tout le monde civilisé, les conditions de notre existence matérielle et de notre mode de vie.

\section{I}

Un fait nous apparaît tout d'abord, c'est que la Révolution a bouleversé toutes les anciennes institutions juridiques. Dans la France du XVIII ${ }^{\mathrm{e}}$ siècle, les classes sociales, au sens où nous les entendons aujourd'hui, ne se manifestent que pour un observateur attentif aux réalités de la vie économique. Ce sont les distinctions juridiques qui frappent surtout quiconque n'observe que la surface des choses. On distingue essentiellement trois ordres : le clergé, la noblesse, le tiers état, entre lesquels se dressent les barrières de privilèges séculaires.

Les privilèges du clergé et de la noblesse, tel est l'un des traits qui caractérisent la société du XVIII ${ }^{\mathrm{e}}$ siècle. Clergé et noblesse exercent un droit prééminent sur toute la propriété foncière ; les droits seigneu- 
riaux de toutes sortes qu'ils imposent aux paysans, par qui le sol est mis en valeur, constituent l'un de leurs principaux revenus. Clergé et noblesse échappent aussi à la plupart des impôts, des charges fiscales, qui retombent sur les classes populaires et contribuent à accroître leur misère. Enfin, la plupart des fonctions de l'État sont l'apanage des ordres privilégiés, de la noblesse surtout, et l'on comprend que l'une des grandes revendications du tiers état, en 1789, ait été précisément l'admission de tous à toutes les charges et fonctions.

Les fonctions ecclésiastiques, il est vrai, en théorie du moins, semblent accessibles aux roturiers comme aux nobles. Mais, en réalité, toutes les dignités du haut clergé, les sièges épiscopaux, les abbayes, les riches bénéfices ecclésiastiques sont réservés — et de plus en plus exclusivement, à mesure que l'on approche de la Révolution — aux membres de la noblesse, et surtout de la noblesse de cour.

Les barrières juridiques, qui séparent les diverses classes, se dressent même de plus en plus hautes, à mesure que l'ancien régime approche de son terme. On verra plus loin que le fossé se creuse, de plus en plus profond, entre les nobles et les roturiers. La noblesse, bien que continuant à se recruter dans la classe des enrichis, dans le monde de la finance surtout, tend à devenir une caste fermée. Les réformations de la noblesse, accomplies à l'époque de Louis XIV, bien qu'ayant été surtout des mesures fiscales, ont retranché de la noblesse des familles de récente extraction, surtout les familles qui continuent à se livrer au commerce, ou les gentilshommes trop pauvres pour faire valoir leurs droits.

\section{II}

Cependant, c'est au XVIII ${ }^{\mathrm{e}}$ siècle que se préparent les profondes transformations qui caractériseront l'époque contemporaine et changeront la face de tout le monde social. Le capitalisme, sous sa forme commerciale du moins, apparaît déjà puissant, et voici qu'il commence à exercer une profonde emprise sur l'industrie elle-même. Les négociants, " contrôlant » de plus en plus activement l'industrie rurale, ouvrent la voie à la grande industrie capitaliste. Dans les métiers urbains, dans les métiers textiles du moins, ils parviennent souvent aussi à soumettre à leur domination économique les artisans, autrefois indé- 
pendants, à les transformer en salariés. L'ancienne organisation du travail ne répond plus aux besoins nouveaux ; les corporations de métiers, à la fin du siècle, même après l'échec de la réforme de Turgot, sont bien condamnées.

L'introduction du machinisme dans l'industrie, encore restreinte à quelques fabrications, surtout aux filatures de coton, ainsi que la concentration industrielle, qui se manifeste dans certains centres de l'industrie drapière et dans la fabrication des toiles peintes, annoncent aussi les temps nouveaux.

Mais ce n'est encore qu'un début. On vit encore, en grande partie, sur les anciennes pratiques économiques. Malgré les progrès du réseau routier, les voies de communication restent toujours insuffisantes ; les moyens de transport se sont modifiés, mais ne se sont pas profondément transformés depuis le début des temps modernes. Le commerce maritime fait de grands progrès au XVIII ${ }^{\mathrm{e}}$ siècle, il accroît sensiblement la richesse nationale, mais la navigation n'a guère changé depuis le $\mathrm{XVII}^{\mathrm{e}}$ siècle ; le tonnage reste faible et on n'a guère de bateaux dont la capacité dépasse 400 ou 500 tonneaux.

N'est-ce pas encore un fait significatif que, dans la bourgeoisie de la plupart des villes, la première place soit occupée par les hommes de loi, avocats ou procureurs, ou encore par les gens de finance, employés de la ferme générale ou receveurs des impositions royales ? C'est seulement dans les grands ports que les négociants jouent un rôle de premier plan.

En un mot, pour qui considère l'évolution économique, la grande transformation ne s’opérera qu'au siècle suivant ; la France de la monarchie censitaire, jusqu'aux approches de 1848, conservera encore bien des traits de la France de l'ancien régime.

\section{III}

Enfin, un caractère permanent de l'histoire économique et sociale de la France se manifeste dans toute sa force au XVIII ${ }^{\mathrm{e}}$ siècle : c'est la persistance et l'affermissement de la propriété paysanne. Cette propriété, on le sait, s'est peu à peu constituée au moyen âge, sous le couvert des tenures vilaines. Le paysan, dès la fin du moyen âge, af- 
franchi totalement du servage dans la plupart des régions de la France, est bien propriétaire de la terre qu'il cultive, puisqu'il la transmet à ses héritiers ou peut la vendre, l'échanger. Seulement, cette propriété est grevée des charges du régime seigneurial, lourdes surtout par suite des pratiques et des abus de ce régime. On peut cependant se demander si la persistance du régime seigneurial jusqu'à la Révolution n’a pas contribué à la consolidation de la propriété paysanne, hypothèse admissible si l'on considère qu'en Angleterre, où le régime seigneurial est si affaibli dès la fin du moyen âge, la propriété paysanne finit par être presque entièrement éliminée au profit de l'aristocratie foncière.

Quoi qu'il en soit, il suffira que la Révolution abolisse radicalement le régime seigneurial pour que la propriété paysanne devienne pleinement autonome. Ce n'est pas que tous les paysans soient propriétaires ; il en est beaucoup qui n'ont que très peu de terre ou pas du tout, qui constituent, par le fait même, un véritable prolétariat rural ; mais ce n'est qu'une minorité parmi les habitants des campagnes. En tout cas, le régime agraire de la France a un caractère profondément original, qui distingue notre pays de la plupart des contrées de l'Europe, si bien qu'à l'époque contemporaine, la France restera un type de démocratie rurale ; dans l'Europe occidentale, elle sera le seul grand État où l'équilibre ne sera pas rompu au profit du développement industriel. Voilà en quoi le présent se rattache étroitement au passé.

La constitution de la propriété foncière, telle qu'elle existe au $\mathrm{XVIII}^{\mathrm{e}}$ siècle, nous explique aussi la raison pour laquelle, en France, les progrès de l'agriculture ont été beaucoup plus lents que dans les contrées où la grande propriété noble a éliminé la propriété paysanne. La France est aussi le pays des petites exploitations. Les propriétaires, nobles ou bourgeois, ne se livrent pas au faire-valoir direct ; ce sont les paysans eux-mêmes qui cultivent tout le sol. Or, ils ont trop peu de ressources pour réaliser de véritables améliorations agricoles ; ils s’en tiennent aux pratiques anciennes, et ces pratiques ont encore pour effet le maintien des landes et prés, dont la jouissance collective est considérée comme absolument nécessaire aux besoins des masses paysannes. Les grands défrichements, malgré quelques notables efforts, ne pourront s'exécuter ; on ne pourra qu'imparfaitement mettre en valeur les terres incultes. En un mot, la nouvelle économie rurale ne triomphera vraiment que dans la seconde moitié du $\mathrm{XIX}^{\mathrm{e}}$ siècle ; 
jusque vers 1840, l'agriculture française ressemblera encore beaucoup à ce qu'elle était sous l'ancien régime.

On voit donc que la vie économique du XVIII ${ }^{\mathrm{e}}$ siècle est destinée à se prolonger au-delà de la Grande Révolution. Celle-ci aura surtout pour effet l'abolition des privilèges juridiques, qui séparaient le tiers état des ordres privilégiés. Cette abolition aura, d'ailleurs, sa répercussion sur l'évolution économique elle-même ; elle contribuera, — mais à un moindre degré que les progrès du capitalisme —, à opérer une nouvelle répartition des classes sociales, fondée sur leur rôle économique. Remarquons, d'autre part, que l'application des sciences à l'industrie, qui commence à se manifester au XVIII ${ }^{\mathrm{e}}$ siècle, le triomphe de la vapeur, en attendant celui de l'électricité, la révolution accomplie par les nouveaux moyens de transport (chemins de fer et navigation à vapeur) auront pour effet de reculer dans le passé le monde de l'ancien régime, en bouleversant toutes les conditions de la vie matérielle.

Voilà pourquoi le $\mathrm{XVIII}^{\mathrm{e}}$ siècle peut paraître si lointain à nos contemporains. Il est très proche de nous cependant, si nous considérons que tout ce qui constitue la vie contemporaine trouve son origine à cette époque. Puis, dans l'histoire de la France, dans l'histoire économique et sociale surtout, il subsiste des traits permanents qui donnent à notre pays une physionomie toute spéciale, non moins que la nature de son sol et sa configuration physique. Ainsi s'explique un phénomène en apparence paradoxal : dans la contrée qui, à plusieurs reprises, a donné le signal de la révolution à une grande partie de l'Europe, le présent se rattache peut-être plus fortement encore au passé que dans des pays dont l'attitude a été singulièrement plus conservatrice.

\section{IV}

Quelques mots sont nécessaires pour justifier le plan que nous avons suivi, et qui, au premier abord, pourrait surprendre le lecteur.

Le plus souvent, lorsque l'on trace le tableau de l'ancienne société française, on adopte une classification d'ordre juridique ; on distingue essentiellement les trois états : le clergé, la noblesse, qui sont les or- 
dres privilégiés, puis les roturiers que l'on englobe dans une seule catégorie, le tiers état.

Cette classification a le grave défaut de ne pas reposer sur la vie économique, qui contribue plus que quoi que ce soit à déterminer la condition des classes sociales. Considérons, par exemple, le tiers état ; il comprend des classes profondément distinctes en réalité : la haute bourgeoisie (hommes de loi, titulaires d'offices, gens de finance), les négociants et marchands, les artisans et ouvriers, enfin les paysans.

Bien que les distinctions juridiques exercent encore une grande influence sur l'état social au XVIII ${ }^{\mathrm{e}}$ siècle, il nous semble plus rationnel d'édifier notre classification sur les diverses formes de la propriété, de distinguer essentiellement les classes qui vivent de la propriété foncière, de l'économie rurale, et celles qui tirent leurs moyens d'existence de l'économie urbaine, de la propriété mobilière, de l'activité commerciale et industrielle. Et, comme phénomènes économiques et faits sociaux exercent les uns sur les autres une action réciproque, nous étudierons toujours concurremment les deux ordres de questions, véritablement inséparables.

Quand on traite un sujet dans lequel les recherches érudites sont souvent encore à peine ébauchées, où le travail de synthèse semble parfois encore prématuré, il faudrait pouvoir, à chaque pas, indiquer ses références. Un ouvrage dans le genre de celui-ci ne le permettait pas ; aussi avons-nous indiqué, pour chaque chapitre, les ouvrages essentiels qui permettront aux lecteurs de s'initier peu à peu aux questions dont nous n'avons pu donner qu'un aperçu ${ }^{1}$.

Table des matières

Note sur la troisième édition :

Pour conserver à cet ouvrage toute sa valeur d'instrument de travail, nous avons tenu à mettre au courant la bibliographie. Quand il n’a pas été possible, pour des raisons typographiques, de compléter les bibliographies existantes, nous les avons rejettées dans un appendice, comme on l'avait déjà fait pour la $2^{\mathrm{e}}$ édition en 1933. Cette mise au point a été faite par M. H. HAUSER. 


\section{Chapitre premier}

\section{LA PROPRIÉTÉ FONCIÈRE. SA RÉPARTITION. LA POPULATION DE LA FRANCE.}

Nous décrirons en premier lieu les classes qui vivent directement de la propriété foncière, de la terre, soit qu'elles tirent leurs ressources de leur travail agricole (les paysans), soit qu'elles vivent de l'exploitation des paysans, ou, si l'on aime mieux, des revenus que les cultivateurs sont obligés de fournir à ceux qui sont les propriétaires éminents du sol : le clergé et la noblesse.

La première question qui se présente consiste donc à se rendre compte de la répartition de la propriété entre ces trois classes sociales. Sans doute, il ne saurait être question de statistiques précises ; on peut seulement, grâce aux rôles d'impôts et notamment de vingtièmes, comme l'a fait M. Loutchisky, grâce aussi aux nombreux terriers du $\mathrm{XVIII}^{\mathrm{e}}$ siècle, arriver à des évaluations approximatives, il est vrai, mais qui ne laissent pas d'être instructives et de correspondre sensiblement à la réalité des choses.

Le pourcentage, que l'on lira plus loin, n'a pas de valeur absolue ; il pourra être critiqué dans le détail ; il pourra être modifié par de nouvelles études. Cependant, comme il repose sur d'immenses dépouillements de rôles d'impôts, dont M. Loutchisky n'a pu toujours donner le détail, il semble légitime de l'adopter provisoirement; il a, dans l'ensemble, croyons-nous, une réelle valeur, en dépit des critiques dont il a pu faire l'objet.

La propriété des classes privilégiées. - On voit que la noblesse possède une portion importante du sol, mais plus faible qu'on ne le croit ordinairement. Dans son État des classes agricoles à la 
veille de la Révolution, Loutchisky aboutit aux conclusions suivantes: dans l'Artois, la noblesse détient $29 \%$ du territoire ; en Picardie, 33 $\%$; en Bourgogne, $35 \%$; dans le Limousin, $15 \%$; dans la HauteAuvergne, $11 \%$; dans le Quercy, $15 \%$; dans le Dauphiné, $12 \%$; dans les Landes, $22 \%$; dans le Béarn, $20 \%$; dans le pays toulousain, $28 \%$; dans le Roussillon, $32 \%$; dans l'Orléanais, environ $40 \%$. Dans la Haute-Bretagne et en Normandie, et, d'une façon générale, dans l'Ouest de la France, la propriété noble semble beaucoup plus étendue que dans les autres régions ; elle joue un rôle des plus importants dans les environs de Paris et surtout à proximité de Versailles.

Contrairement à ce que l'on a longtemps pensé, le clergé possède infiniment moins de terre que la noblesse. Le Nord de la France constitue, à cet égard, une exception. Si, dans le Hainaut et le Cambrésis, le clergé détient $40 \%$ de la propriété, si, dans l'Artois, la propriété ecclésiastique comprend un cinquième ou un quart du territoire, dans le Laonnois, 29 \%, et en Picardie, 18 \%, par contre, plus on avance vers l'Ouest ou vers le Midi, et plus la proportion devient faible :

En Bourgogne, 11 et $13 \%$; dans le Berry, $19 \%$; en Touraine, $10 \%$; en Auvergne, 3,5 \% ; en Bas-Limousin et en Quercy, $2 \%$; dans le pays toulousain, $4 \%$; dans le Roussillon, 2,5 \% ; en Béarn, 1,5\% ; dans les Landes, $1 \%$; dans le pays de Rennes, 3,4 \%.

Au total, on peut se ranger à l'opinion de M. G. Lecarpentier, qui attribue au clergé, en moyenne, seulement $6 \%$ du territoire de la France. La richesse du clergé, on le verra plus loin, provient en grande partie de ses propriétés urbaines et de la perception de la dîme.

Remarquons qu'une grande partie des biens nobles et ecclésiastiques consiste en bois et en forêts, que cette propriété est, en général, très morcelée, ce qui rend impossible toute grande exploitation agricole, à la mode anglaise. Il n'est pas inutile d'indiquer, quand nous parlons de propriété noble ou ecclésiastique, que nous entendons uniquement ce que l'on appelle le domaine proche des seigneuries, qui est le plus souvent loué à des fermiers ou à des métayers. Mais les seigneurs exercent aussi un droit de propriété éminent sur les terres qui dépendent de leurs fiefs et notamment sur les tenures paysannes, 
car, parmi celles-ci, il y en a fort peu qui soient en alleux, c'est-à-dire qui soient pleinement autonomes.

La propriété paysanne. - Il n'en est pas moins vrai qu'on doit considérer les tenures paysannes comme de véritables propriétés héréditaires, puisqu'elles passent aux héritiers du tenancier ou peuvent être cédées par lui ; elles sont seulement grevées de redevances et de droits perçus par le seigneur. Les paysans possèdent donc une notable partie du sol, mais dont la proportion varie très sensiblement d'une région à l'autre. C'est dans les provinces de l'Ouest qu'elle semble être la plus faible: en Normandie, en Bretagne, dans le Poitou, on peut l'évaluer seulement à un cinquième ; dans le Nord, en Picardie, en Artois, dans la région qui formera le département du Nord (Flandre, Hainaut et Cambrésis), ainsi que dans l'Orléanais et en Bourgogne, à un tiers; dans le Languedoc, dans le Limousin, à $50 \%$; en Dauphiné, aux deux cinquièmes. Dans la seconde moitié du XVIII ${ }^{\mathrm{e}}$ siècle, la propriété paysanne, loin de diminuer, semble, en certaines régions, s'être accrue sensiblement: M. Loutchisky a pu le constater pour la généralité de Soissons, où les paysans ont acquis quatre fois plus de terre qu'ils n'en ont vendu, ainsi que pour le Limousin où, de 1779 à 1791, leur gain a été de 4000 arpents. Il est vrai que, dans le Nord, M. Lefebvre croit pouvoir établir que la propriété paysanne n’a guère augmenté depuis 1770 ; seul, le nombre des propriétaires s'est accru au XVIII ${ }^{\mathrm{e}}$ siècle, sans doute par l'effet des successions. Quoi qu'il en soit, comme les paysans constituent $90 \%$ du nombre des propriétaires, leurs propriétés sont souvent très petites ; le morcellement de la propriété paysanne est un fait incontestable, et d'une très grande portée.

Beaucoup de paysans ne détiennent que d'infimes parcelles de terre, surtout dans le Nord de la France. M. G. Lefebvre établit que, dans le Cambrésis, 60 à 70 \% des occupants possèdent moins d'un hectare, et un cinquième, moins de 5 hectares. Or, comme, pour vivre de la culture de ses terres, il faut avoir au moins 5 hectares, la plupart des paysans doivent s'occuper, soit comme fermiers - s'ils ont quelques avances -, soit plus souvent encore comme travailleurs agricoles. En Flandre, en Cambrésis, en Hainaut, comme en Artois, en Picardie, en Normandie et, dans une certaine mesure, en Bretagne, il y a donc un 
véritable prolétariat rural, que le chômage ou la disette réduit à la misère, et qui est, au XVIII ${ }^{e}$ siècle, la grande source de la mendicité et du vagabondage. Les propriétaires aisés et les gros fermiers ne constituent qu'une petite minorité des populations rurales, et c'est surtout cette classe qui profitera, à l'époque de la Révolution, de l'abolition du régime seigneurial et de la vente des biens nationaux.

Quant à la bourgeoisie, elle possède une portion de la propriété foncière qui est loin d'être insignifiante, tout au moins dans les environs des villes, et surtout des grandes villes ; dans les environs de $\mathrm{Pa}-$ ris, leur propriété effective est plus considérable encore. Dans le Nord, par exemple, c'est 16 ou $17 \%$ de la superficie que détiennent les bourgeois.

Ce régime de la propriété foncière donne à la France du XVIII ${ }^{\mathrm{e}}$ siècle une physionomie toute particulière ; il la distingue notamment de l'Angleterre, où la grande propriété noble a peu à peu éliminé la petite propriété paysanne, grâce aux enclosures ; il la distingue aussi de la plus grande partie de l'Europe centrale et surtout de l'Europe orientale, où la grande propriété noble n'a cessé de s'étendre et de se fortifier au cours des temps modernes. Ce phénomène a donné à la société française un caractère original et a exercé une notable influence sur toute son évolution historique.

L'évolution agraire de l'Angleterre, telle qu'elle se dessine depuis la fin du moyen âge, peut sans doute nous faire comprendre les raisons pour lesquelles la propriété paysanne s'est conservée et fortifiée en France. En Grande-Bretagne, les progrès de l'industrie lainière ont incité les seigneurs à transformer les terres de culture en pâturages, à accroître leur domaine proche au moyen des enclosures. Et, en même temps, la précarité plus grande des tenures que l'on observe dès le moyen âge, ainsi que l'affaiblissement du régime seigneurial, ont facilité cette transformation ; les lords n’ont pas intérêt à maintenir des tenures paysannes qui ne leur rapportent que de faibles revenus. Enfin, l'aristocratie, qui s'empare du pouvoir politique, à la suite des révolutions du XVII ${ }^{\mathrm{e}}$ siècle, a les mains libres pour s'emparer de toute la terre. En France, rien de semblable. Le capitalisme commercial et industriel a été plus tardif et moins intense. Les seigneurs sont de plus en plus soumis à l'autorité du pouvoir royal, qui s'opposerait à de trop graves empiétements ; puis, jouissant de droits seigneuriaux étendus et 
souvent lucratifs, ils n’ont pas intérêt à détruire le régime des tenures paysannes, dépendant de leurs fiefs, de telle sorte que la petite propriété paysanne doit peut-être sa persistance et ses progrès au maintien du régime seigneurial. Et, lorsque la Révolution détruira ce régime, elle deviendra pleinement autonome.

La population de la France. - Il est un autre élément dont il est nécessaire de tenir compte, lorsqu'on étudie la vie économique et sociale d'une époque, c'est la population; il serait fort important de connaître sa masse et sa densité, ainsi que le rapport de la population urbaine à la population rurale. Malheureusement, en ce qui concerne le XVIII ${ }^{\mathrm{e}}$ siècle, nous ne possédons que des données bien insuffisantes, des évaluations dénuées de valeur scientifique. Parfois, pour telle ou telle région, certains documents nous donnent le nombre de feux ; mais il est difficile de savoir si le mot feu désigne un ménage ou une unité fiscale. Les évaluations données par les mémoires des intendants, rédigés vers 1700 , sont tout à fait approximatives. C'est seulement à partir de 1770 que le gouvernement a fait faire des relevés des mariages, naissances et décès d'après les registres paroissiaux. Turgot se proposa même de créer une véritable statistique de la population.

C'est d'après ces «mouvements de la population » que Necker, dans son Administration des finances (de 1784), estime la population de la France à 24 millions d'habitants, que Calonne, dans l'État de la population du royaume, présenté à l'Assemblée des notables, en 1787, l'évalue à 23 millions. D'après ces documents, on voit que la population totale des villes ne dépasse guère 2 millions, que la province ne possède qu'une seule ville de plus de 100000 habitants: Lyon (135 000) ; les grands ports comptent parmi les villes les plus peuplées : tels, Marseille, Bordeaux, Nantes, Rouen. Mais la plupart des centres urbains ont moins de 20000 habitants ; des capitales de province, comme Dijon et Grenoble, seraient considérées aujourd'hui comme de fort petites villes, avec leurs 21000 et 23000 habitants. Enfin, le mouvement de la population montre que celle-ci s'est accrue sensiblement à la fin de l'ancien régime, excepté cependant en Bretagne. Un autre fait intéressant apparaît : une très forte natalité, mais dont les effets sont contrebalancés par une grande mortalité générale, qui s’explique par la fréquence des épidémies, et aussi par une énorme 
mortalité infantile. Quoi qu'il en soit, en 1789, la France est un des pays les plus peuplés de l'Europe, beaucoup plus que l'Angleterre et que l'Allemagne ; on s'explique ainsi, en partie, le rôle qu'elle joue à cette époque.

A considérer les éléments mêmes de la population, on voit qu'elle est assez stable. L'émigration n'existe guère. Il est vrai que la révocation de l'Édit de Nantes a fait fuir, à la fin du XVII siècle, peut-être 100000 protestants, presque tous d'ailleurs habitants des villes et appartenant aux classes industrielles et marchandes (les paysans huguenots, convertis seulement en apparence, n'ont guère quitté le royaume). Mais, au XVIII ${ }^{\mathrm{e}}$ siècle, à part quelques centaines de familles percheronnes et mancelles, qui ont été coloniser le Canada, il n’y a pas eu, à proprement parler, d'émigration. Quant à l'immigration des étrangers, elle ne contribue pas à accroître sensiblement la population : elle comprend surtout des Irlandais, fuyant les persécutions anglaises, des négociants hollandais ou hanséates. Elle a cependant une importance économique assez notable : à Nantes, à Bordeaux, par exemple, bien des familles de négociants proviennent de l'étranger. A Marseille aussi, des familles grecques et arméniennes viennent accroître le contingent de la classe commerçante.

L’infinie variété des poids et des mesures. - Il nous faut encore signaler un phénomène qui a pesé très fortement sur toute la vie économique et sociale de l'ancien régime : c'est l'infinie variété des poids et des mesures, dont nous avons de la peine à nous rendre compte, depuis que la Révolution, en établissant le système métrique, a fait au chaos succéder l'ordre et une admirable simplicité.

Les mesures de superficie étaient relativement simples. Cela ne veut pas dire qu'elles ne fussent très variées, très diverses suivant les régions. Les documents de l'époque mentionnent surtout l'arpent et le journal. L'arpent était toujours subdivisé en 100 perches, mais la longueur de la perche était très variable, si bien que l'arpent de Paris équivalait à 34 ares, celui de Poitou, à 42, celui des Eaux et Forêts, à 51. Le journal usité en Bretagne valait environ 48 ares. La boisselée (proportionnée à la contenance d'un boisseau) pouvait valoir, dans une même région, soit 15 ares, soit 10, soit même 7. 
Les mesures de capacité sont encore plus variées. La capacité du boisseau, par exemple, dans une seule province comme le Poitou, peut osciller de 65 à 10 litres. Chaque seigneurie, haute ou moyenne, a, en effet, le droit « de poids, de mesures, d'étalonnage ». Chacune a aussi intérêt, pour accroître ses rentes, à étendre la capacité de ses mesures. Une lettre insérée dans les Affiches du Poitou, de 1775, déclare :

«J'oubliais de vous marquer que le boisseau de Civray ne devait peser qu'environ 40 livres, qu'il n'avait que ce poids en 1709, et qu'il s'est successivement accru de trois à quatre livres ; on observe du reste des augmentations analogues à Aulnay, Chiré, Beauvoir, etc. »

On verra plus loin à combien d'abus donne lieu cette incertitude des mesures. Les multiples du boisseau (setier, muid, minot, charge, etc.) connaissent la même variété. Le litre, la pinte, la barrique, la velte ne sont pas plus fixés. Pour la mesure des étoffes, on se sert de l'aune ; elle donne lieu aussi à beaucoup d'abus. Enfin, rien de varié comme les poids usités avant la Révolution : la livre, l’once, etc. n’ont nulle part exactement la même valeur. On comprend alors combien ce système entrave toutes les transactions, et l'on s'explique aisément que les écrivains du XVIII ${ }^{\mathrm{e}}$ siècle, puis les cahiers des États Généraux de 1789 aient réclamé l'unification des poids et mesures avec autant d'insistance que l'unification des coutumes. La Révolution française devait donner satisfaction à ce double vœu et établir un système si rationnel qu'il a servi de modèle à tous les pays civilisés.

Table des matières

\section{Ouvrages à consulter}

Loutchisky, L'État des classes agricoles en France à la veille de la Révolution, Paris, 1911.

- La Propriété paysanne en France à la veille de la Révolution, principalement dans le Limousin, Paris, 1912.

— Quelques Remarques sur la vente des biens nationaux, 1914.

REBILLON A., La Situation économique du clergé à la veille de la Révolution dans les districts de Rennes, Vitré et Fougères (Coll. des Doc. économiques de la Révolution), 1913. 
SÉE H., Les Classes rurales en Bretagne du $\mathrm{XVI}^{\mathrm{e}}$ siècle à la Révolution, Paris, 1906.

- Esquisse d'une histoire du régime agraire en Europe aux $\mathrm{XVIII}^{\mathrm{e}}$ et XIX ${ }^{\mathrm{e}}$ siècles, Paris, 1921.

LECARPENTIER G., La Vente des biens ecclésiastiques pendant la Révolution, Paris, 1908.

LEVASSEuR E., La Population française, t. I, 1889.

MATHOREZ, Les Etrangers en France, 2 vol. parus, Paris, 1921.

Lefebvre G., Les Paysans du Nord pendant la Révolution française, Lille, 1924.

BRUtAils G.-A., Recherches sur l'équivalence des anciennes mesures de la Gironde, Bordeaux, 1912.

RAVEAU Paul, L'Agriculture et les classes paysannes dans le Haut-Poitou au XVI ${ }^{e}$ siècle, Paris, 1926.

FAVRE Adrien, Les Origines du système métrique, Paris, 1931.

SÉE H., Les Essais de statistiques démographiques en Bretagne à la fin de l'Ancien régime (dans Etudes sur la vie économique en Bretagne, 1772-an III, Paris, 1930).

LOUTCHISKY, Régime agraire et populations agricoles dans les environs de Paris, à la veille de la Révolution (Revue d'Histoire moderne, 1933). 


\section{Chapitre 2}

\section{LES PAYSANS ET L’AGRICULTURE.}

Avant d'étudier les classes qui vivent de la propriété foncière, il semblerait logique de décrire d'abord l'agriculture. Mais, à l'époque qui nous occupe, c'est la condition juridique de ces classes qui est l'un des facteurs essentiels de la production du sol. Les faibles progrès de l'agriculture, sous l'ancien régime, s'expliquent, en grande partie, par la situation qui est faite à la classe qui seule exploite le sol, aux paysans. Nous commencerons donc par décrire la condition juridique de la population agricole ; on comprendra mieux alors les raisons pour lesquelles, avant la Révolution, il n’y a pas eu de transformation profonde de l'agriculture.

Les paysans français, dans les deux derniers siècles de l'ancien régime, semblent plus favorisés que leurs congénères du reste de l'Europe, car ils sont, pour la plupart, personnellement libres et propriétaires.

Les mainmortables. - Le servage ne s'est conservé que dans quelques régions, dans celles précisément où il était le plus dense au moyen âge, surtout dans le Nord-Est (Franche-Comté et Lorraine) et aussi, mais en groupes moins compacts, dans quelques pays du centre (Berry, Nivernais, Marche, Auvergne). Le nombre total des serfs, semble-t-il, ne dépasse par un million.

D'ailleurs, ce sont moins des serfs, au sens du moyen âge, que des mainmortables. On distingue la mainmorte personnelle et la mainmorte réelle, prédominante dans l'Est de la France. Dans le premier cas, les enfants, s’ils n’habitent pas avec leurs parents, ne peuvent hériter aucun de leurs biens, même mobiliers ; dans le second cas, le paysan 
n'est soumis à la mainmorte que pour les biens mainmortables qu'il occupe (les choses se passent ainsi dans les bordelages du Nivernais).

Il est vrai que la mainmorte s'est conservée jusqu’à la Révolution, en dépit de l'énergique campagne que Voltaire a entreprise en faveur des serfs du Mont-Jura.

En 1779, Necker abolit bien la mainmorte sur le domaine royal, et, dans tout le royaume, le droit de suite ; mais les seigneurs n'imitèrent pas l'exemple que leur donnait le gouvernement. La mainmorte persista donc jusqu'à la Révolution ; toutefois, elle ne constitue plus qu'une exception ; l'immense majorité des paysans est personnellement libre.

Les diverses classes. Fermiers et métayers. - Les paysans dont la personne est pleinement affranchie ne forment pas cependant une classe uniforme, car ils ne possèdent pas tous la même quantité de terre. Il en est qui peuvent vivre exclusivement de la culture de leurs champs : ils constituent une sorte d'aristocratie paysanne, la classe des laboureurs. Ce sont eux surtout qui arrondissent leurs terres, qui tirent parti des afféagements, des défrichements, et qui, à l'époque de la Révolution, profiteront de la vente des biens nationaux. Mais la plupart des paysans ne possèdent pas une quantité de terre suffisante pour en vivre. S’ils ont quelques avances, ils deviennent fermiers ou métayers ; les plus pauvres s'engagent comme journaliers ou domestiques. Bien des paysans propriétaires joignent à la culture un métier d'appoint, sont marchands, meuniers, aubergistes ou artisans (maçons, charpentiers, tailleurs, tisserands surtout) ; ainsi s'explique l'extension de l'industrie rurale. La classe des travailleurs agricoles, des journaliers, n'a jamais eu l'importance qu'elle a prise en Angleterre.

C'est que les grandes exploitations n'existent pas en France. Les nobles ne font pas valoir eux-mêmes les terres de leur domaine proche, ne les afferment pas non plus à des entrepreneurs capitalistes, à des farmers, comme en Angleterre.

Ce sont des paysans qui cultivent, à titre de fermiers ou de métayers, l'immense majorité des terres appartenant aux classes privilégiées. Rien de variable comme l'étendue des exploitations agricoles. Il 
y en a qui comprennent une étendue équivalant à dix ou vingt hectares ; mais il en est d'autres qui ne sont que des closeries, contenant seulement quelques pièces de terre. Il $\mathrm{y}$ a donc des fermiers aisés, et d'autres qui sont misérables. Mais on peut dire qu'en règle générale, le morcellement des exploitations est tout aussi marqué que le morcellement de la propriété.

Le bail à moitié fruits ou métayage — assez rare aujourd'hui semble, au XVIII ${ }^{\mathrm{e}}$ siècle, le mode de location le plus répandu, surtout dans les provinces les plus pauvres, où les paysans n'ont ni avances, ni cheptel ; il est prédominant dans les pays du Centre et du Midi ; il affecte environ la moitié des terres louées en Bretagne et en Lorraine. Le métayer doit livrer au propriétaire, — qui lui a fait des avances de semence et de cheptel —, la moitié de la récolte, quelquefois même davantage dans le bail à détroit, tel qu'il est usité en Haute-Bretagne, puisqu'à la redevance en nature se surajoute, en ce cas, une redevance en argent. Le métayer est donc souvent misérable, comme le constate Arthur Young, dans ses Voyages en France :

« Des tenanciers n’ayant guère à offrir que leurs bras sont bien plus à la merci du propriétaire que s'ils avaient quelque richesse ; ils ne se contenteraient pas dans leurs entreprises d'un profit moindre que l’intérêt de leur capital. »

Et A. Young déclare encore que beaucoup de métayers sont dans une telle misère, qu'en attendant la prochaine récolte, ils doivent emprunter au propriétaire le pain dont ils ont besoin.

Les conditions faites aux fermiers paraissent sensiblement meilleures. Leur bail, conclu pour trois, six ou neuf ans, leur impose le payement d'une somme d'argent fixe, à laquelle s'ajoutent, il est vrai, des redevances en nature et surtout des corvées de charrois et même de labours. Le fermage est prédominant dans le Nord de la France, où les exploitations agricoles sont plus considérables qu'ailleurs: tel est le cas de l'Artois, de la Picardie, du Vexin, de la Beauce. C'est aussi en ces pays que souvent, dans la seconde moitié du XVIII ${ }^{\mathrm{e}}$ siècle, on opéra la réunion des fermes. Ces réunions, très avantageuses pour les propriétaires, dont elles augmentaient les revenus, eurent la conséquence fâcheuse d'évincer bon nombre de fermiers, les moins aisés, et d'accroître l'antagonisme entre les riches cultivateurs et les pauvres. 
Les cahiers de 1789 le montrent nettement. Ce qui aggrava encore la condition des fermiers, ce fut la hausse très rapide du prix des fermes, surtout dans la seconde moitié du siècle. Il est vrai que, dans la même période, les prix des denrées s'élevèrent aussi ; mais ce n'était qu'une compensation insuffisante, car, tandis que la hausse des prix n'était que de 40 ou $50 \%$, les fermages souvent s'élevèrent de $100 \%$; les propriétaires parvinrent ainsi à accroître notablement leurs revenus.

Notons encore quelques modes de location particuliers à certaines régions ; tel le domaine congéable, en Basse-Bretagne. Le domanier est à la fois propriétaire et fermier. Tandis que le seigneur foncier est propriétaire du fonds, le domanier est propriétaire des édifices et superfices; mais il est à la merci du foncier, qui peut le congédier, à moins qu'il ne lui ait donné l'assurance de lui conserver sa tenure pendant un certain espace de temps (généralement fixé à 9 ans); c’est la baillée, pour laquelle le tenancier doit une commission souvent onéreuse. Le domanier est soumis encore non seulement à la rente convenancière, plus élevée que la rente des autres tenures, mais aussi aux charges seigneuriales et notamment à l'obligation de rendre aveu. Dans les vignes du pays nantais, nous trouvons le mode de location qu'on appelle complant ; le complanteur est propriétaire, non de la terre, mais du plant de vigne ; si celui-ci disparaît, la tenure revient au propriétaire. Citons encore, en Picardie, le droit de marché, d'après lequel les fermiers se considèrent comme locataires perpétuels, et, en Languedoc et en Dauphiné, les locatairies perpétuelles, qui assurent aux tenanciers une sorte d'usufruit à perpétuité.

Les journaliers et les domestiques. - Les paysans, trop dépourvus de terre et d'avances, doivent s'engager comme travailleurs agricoles ou journaliers. Sans doute, cette classe est, en France, beaucoup moins nombreuse qu'en Angleterre. Elle ne laisse pas cependant de former une portion importante de la population agricole, surtout dans des pays comme la Picardie, la Normandie orientale, la Bretagne : certaines paroisses bretonnes, je l'ai montré ailleurs, contiennent une majorité de journaliers.

Les salaires des journaliers varient naturellement suivant les régions ; ils ne semblent pas être bien supérieurs à 7 ou 8 sous pour les 
hommes, 5 ou 6 sous pour les femmes. A la fin de l'ancien régime, ils se sont élevés quelque peu, mais leur hausse a été, comme il arrive d'ordinaire, beaucoup moins sensible que le coût de la vie. Ce sont donc les journaliers qui sont le plus atteints par les crises, les disettes, les épidémies, et ils forment le principal contingent des mendiants et vagabonds, si nombreux dans les campagnes jusqu'à l'époque de la Révolution.

Les domestiques, que l'on emploie surtout dans les fermes importantes, ont une situation moins précaire que les journaliers, puisqu'ils sont loués à l'année, et qu'ils sont logés et nourris. Leurs salaires se sont élevés assez sensiblement au cours du XVIII ${ }^{\mathrm{e}}$ siècle. Les Souvenirs d'un nonagénaire indiquent, pour la fin de l'ancien régime, les chiffres suivants de gages annuels, qui ne semblent pas exceptionnels :

Le premier garçon laboureur
Le charretier
Les touche-bœufs
Le garçon d'écurie
Les servantes

84 à 90 livres

54 à 66 -

30 à $36-$

60 à 66 -

24 à 33 -

et elles reçoivent, en outre, une ou deux paires de sabots et une ou deux aunes de toile.

La nourriture des domestiques consiste surtout en pain, beurre, galettes ; on leur donne quelquefois du lard, rarement de la viande. Leur boisson ordinaire, c'est l'eau, excepté dans les pays vignobles, où on leur fournit de la piquette, faite avec du marc de raisins ou de pommes.

Le régime seigneurial. - On ne saurait comprendre la situation des paysans, si l'on ne déterminait pas le caractère du régime seigneurial. Comme tenancier, comme sujet de la seigneurie, le paysan est soumis à toutes les charges du régime seigneurial. C'est d'abord l'obligation de rendre aveu à chaque mutation, sans compter l'aveu général, auquel les vassaux sont tenus tous les dix, vingt ou trente ans. Quant aux redevances, elles sont certainement moins lourdes qu'au moyen âge. Les redevances personnelles se sont presque toutes transformées en redevances réelles, ne portant que sur les tenures ; la taille a presque complètement disparu. Les corvées se sont transformées le 
plus souvent en redevances pécuniaires, ou bien ne représentent plus que quelques journées de travail par an.

Les redevances qui se sont le mieux maintenues, ce sont celles qui portent sur la terre et sont perçues en argent ou en nature (cens ou rentes). Comme, depuis plusieurs siècles, elles sont d'une fixité remarquable, les rentes en argent, par suite de la diminution de la valeur de l'argent, sont réduites à peu de chose. Les rentes en nature - et notamment le champart - constituent seules une charge appréciable. Les droits de succession (rachat, acapte) ou de mutation (lods et ventes) pèsent assez lourdement sur les tenures roturières. Les banalités du moulin, du four et du pressoir constituent une obligation, gênante et onéreuse. Les péages, les droits de marchés et de foires ralentissent les transactions commerciales, entravent la vente des denrées agricoles. Le droit de chasse semble le plus odieux de tous les monopoles seigneuriaux, car les meutes des nobles et le gibier de leurs garennes ravagent les champs des cultivateurs : on s'en plaint unanimement dans toute la France. Enfin, la justice seigneuriale, qui permet au seigneur d'être juge et partie dans les procès relatifs aux droits qu'il exerce sur ses tenanciers, est l'instrument indispensable de l'exploitation seigneuriale. Nulle part la chose n'apparaît aussi nettement qu'en Bretagne, où « fief » et justice se confondent. S'agit-il de procès civils ou criminels : on se plaint généralement de la mauvaise tenue des tribunaux seigneuriaux et aussi du grand nombre de juridictions, superposées les unes aux autres, que doivent affronter les justiciables.

Aux charges du régime seigneurial il faut joindre la dîme, qui, assez souvent d'ailleurs, est devenue la propriété d'un seigneur laïque (dîme inféodée). Elle prélève une portion importante de la récolte (un dixième ou un treizième), et elle porte, non seulement sur les grains (grosses dîmes), mais aussi sur le lin, le chanvre, les fèves, les fruits (menues dîmes) ; elle enlève donc souvent au paysan une plus forte part de son revenu que l'ensemble des rentes seigneuriales: par exemple, dans le Bordelais, $14 \%$, tandis que les rentes seigneuriales n'en représentent que $11 \%$. Notons, d'ailleurs, que les nobles se plaignent presque aussi vivement de la dîme ecclésiastique que les paysans; on s'explique alors qu'on en ait décrété l'abolition dès le début de la Révolution. 
Il importe de remarquer que le régime seigneurial n'a pas eu la même intensité dans toutes les régions de la France. Très rigoureux en Bretagne, assez âpre en Lorraine, encore assez dur en Auvergne, dans le pays d'Autun, dans la généralité de Bordeaux, il semble bien moins lourd dans le Maine, en Normandie, en Champagne ; dans l'Orléanais, en Angoumois, dans la Flandre maritime, il paraît encore plus atténué.

Portée du régime et aggravation de l'exploitation seigneuriale. - Pour apprécier la portée du régime seigneurial, il faut tenir compte, non seulement des charges elles-mêmes, mais encore des abus et des vexations auxquels elles donnent lieu. Ainsi, les banalités ne sont si insupportables qu'à cause des exactions des meuniers, qui exigent plus que le taux ordinaire et trompent sur le poids de la farine. Pour la reddition des aveux, on perçoit des sommes indues, et souvent on les fait recommencer sous prétexte que les déclarations sont erronées; c'est ce qu'on appelle l'impunissement. A côté des corvées, on exige, surtout en Bretagne, des corvées extraordinaires, qui se sont développées au cours des XVII ${ }^{\mathrm{e}}$ et XVIII ${ }^{\mathrm{e}}$ siècles. Quant aux rentes, ce qui accroît leur lourdeur, c’est la façon dont elles sont perçues. La « solidarité des rentes » oblige les tenanciers à acquitter la quote-part des insolvables ; on exige des amendes pour tout retard dans le paiement ; on laisse aussi les rentes s'arrérager pendant des quinze et vingt ans, puis on en exige le paiement en bloc, ce qui cause une grande gêne au paysan. La perception des rentes en nature provoque des abus encore plus graves. Y a-t-il retard dans leur livraison : on doit les acquitter en argent, à l'appréci, au prix du marché ; or, souvent les apprécis sont fixés d'une façon arbitraire ; on prend le prix du marché au moment où les grains se vendent le plus cher. Les tenanciers ont aussi à souffrir des fraudes sur les mesures qui servent à mesurer les grains et qui sont extrêmement variables d'une localité à l'autre.

Il semble bien que les charges seigneuriales se soient aggravées à la fin de l'ancien régime, qu'il se soit produit ce qu'on a appelé la « réaction féodale ». Cette réaction ne se manifeste pas par la création de droits nouveaux, mais bien par l'élévation arbitraire des droits existants et surtout par le rétablissement de droits tombés en désuétude. Dans la seconde moitié du XVIII ${ }^{\mathrm{e}}$ siècle, on procède souvent à la réfec- 
tion des terriers, onéreuse pour les vassaux, qui se plaignent de l'activité vexatoire et des exactions des « commissaires à terriers ».

On s’explique aisément la raison de la réaction seigneuriale, si l'on songe que les seigneurs, ayant de plus en plus besoin de se procurer de l'argent, s'efforcent de tirer tout ce qu'ils peuvent de leurs droits seigneuriaux, comme de leurs fermages. En fait, les comptes seigneuriaux montrent que les revenus des propriétaires privilégiés se sont notablement accrus dans les vingt dernières années de l'ancien régime.

Voilà aussi la raison pour laquelle les seigneurs s'efforcent de mettre en valeur les parties encore improductives de leur propriété, portent atteinte aux droits d'usage des paysans, tentent de leur enlever la jouissance collective des bois, landes et terres vagues dont ils ont besoin pour l'affouage, pour l'engrais de leurs terres, pour la pâture de leur bétail. Afin de restreindre les usages des habitants, les seigneurs ont un moyen légal : conclure avec eux des traités de cantonnement ou de triage, qui leur réservent les deux tiers ou le tiers des terres vagues, traités qui se multiplient après 1750 . Mais souvent aussi ils procèdent par usurpation brutale, usant même de manœuvres frauduleuses. Les terres, ainsi libérées des usages, sont afféagées par les seigneurs, moyennant des "droits d'entrée » et des redevances. Ces afféagements profitent aux bourgeois et aux paysans aisés, mais sont fort nuisibles aux pauvres, qui ne peuvent se passer des usages ; ils mettent souvent aux prises, dans les campagnes, ces deux classes et les dressent en deux camps hostiles. Partout on constate ces entreprises des seigneurs, mais elles ont une grande intensité surtout dans les provinces où le régime seigneurial reste fort, comme la Bretagne, dans les régions forestières comme la Lorraine, ainsi que dans les pays de montagnes, comme la Haute-Auvergne ou le Dauphiné, où abondent les communaux. Toutes ces usurpations et tous ces abus sont d'ailleurs favorisés par les Parlements, dont les membres possèdent souvent d'importantes propriétés rurales (c'est le cas notamment en Bretagne et en Dauphiné), et profitent de leur autorité pour imposer à leurs vassaux des charges injustifiées.

Il y a donc eu, à la fin de l'ancien régime, aggravation de l'exploitation seigneuriale. Bien qu'il s'agît surtout du rétablissement de droits en désuétude et de l'exagération de pratiques abusives, les 
paysans étaient convaincus qu'ils étaient victimes de graves innovations et qu'ils n'avaient jamais été aussi durement exploités. Ainsi s'expliquent les revendications véhémentes qu'ils expriment dans les cahiers de paroisses de 1789, comme dans les pétitions adressées au Comité féodal de l'Assemblée constituante. Ainsi s'expliquent les troubles agraires, qui, après le 14 juillet, accompagnent la Grand'Peur, qui se manifesteront encore avec intensité en 1790 et 1791, et qui ne cesseront véritablement que lorsque la Convention aura radicalement aboli le système seigneurial.

La fiscalité royale. - La fiscalité royale aggrave singulièrement la condition des paysans. Ce sont eux seuls qui paient la taille, et même les nouveaux impôts (capitation et vingtièmes), auxquels les nobles doivent être soumis, retombent presque entièrement sur les populations rurales. Il faut se représenter aussi le système de répartition des impôts, très défectueux, très injuste, ainsi que tous les vices du mode de perception ; les notables des paroisses, chargés de cette perception, sont obligés de payer la quote-part des défaillants.

Il serait intéressant de déterminer la portion du revenu prélevée par l'impôt. Mais on n'a à cet égard que peu de données précises. Dans le Bordelais, d'après $M$. Marion, les impôts prélèveraient 36 \% du revenu ; dans le Limousin, où la taille est tarifée, l'impôt absorbe un tiers du revenu sur les bonnes terres et quatre cinquièmes sur les médiocres ; en Saintonge, le total des impôts équivaut au quart du prix de la ferme.

Le franc-fief constitue aussi une lourde charge qui pèse sur les terres nobles possédées par des propriétaires roturiers, car il enlève à ces derniers une année de revenu tous les vingt ans, une année aussi à chaque succession. N'oublions pas non plus les nouvelles prestations datant du XVIII ${ }^{\mathrm{e}}$ siècle : la corvée des grands chemins, au régime très lourd, à la répartition injuste, qui ne porte que sur les paysans, bien qu'ils ne se servent qu'assez peu des routes; les logements des gens de guerre et les charrois militaires ; enfin, la milice, qui n'est pas en soi un service très lourd, mais qui ne pèse que sur les paysans et, en vertu de son régime d'exemptions, sur les moins aisés d'entre eux. 
Tous les contemporains sont frappés de la charge accablante que les impôts infligent aux paysans.

L'exploitation agricole. - Peu de grandes propriétés ; prédominance des petites exploitations; la culture entre les mains de paysans peu aisés; voilà des conditions peu favorables aux progrès de l'agriculture. En fait, elle est généralement assez arriérée, surtout si on la compare à l'agriculture anglaise.

Un trait caractéristique, c'est la grande quantité de terres incultes et de landes qui subsistent, surtout en Bretagne, où elles occupent les deux cinquièmes de la superficie, et dans les pays de montagnes, comme le Roussillon, le Massif Central, les régions alpestres ; la proportion, il est vrai, en est bien plus faible dans l'Ile-de-France, en Picardie, en Flandre, en Alsace. Les terres incultes jouent un rôle considérable dans l'économie rurale de l'époque : beaucoup de paysans, qui n'ont pas de pâturage, envoient paître leur bétail sur les landes communes et se servent de leurs produits pour la litière de leurs animaux et surtout comme engrais.

Pour comprendre les pratiques agricoles de l'ancien régime, il faut, comme le fait Marc Bloch en un récent ouvrage, distinguer les champs ouverts, que l'on trouve surtout dans le Nord, l'Est et aussi le Midi de la France, et le régime des enclos, prédominant dans tout l'Ouest bocager, ainsi que dans le Massif Central. La première catégorie est caractérisée par un réseau très menu de parcelles, ce qui entraîne le morcellement des biens, et, par suite, l'assolement forcé et la vaine pâture. Ce qui distingue, au contraire, le régime des enclos, c'est que chaque cultivateur est maître de son assolement et que la vaine pâture y est inconnue.

Les procédés de culture restent très primitifs, et les progrès sont très lents, excepté dans les régions les plus riches et les plus fertiles. Les bâtiments d'exploitation sont mal aménagés ; l'attirail de culture est insuffisant ; les instruments agricoles, très rudimentaires, ne semblent guère supérieurs à ceux dont on usait au moyen âge. Aussi presque partout la culture intensive est-elle inconnue. Le système de la jachère est d'un usage constant, excepté en Flandre, en Alsace et dans une partie de la Normandie. Même en Picardie, la terre se repose un 
an sur trois; en Bretagne, la terre est laissée en jachère un an sur deux, souvent même deux ans sur trois, et certaines terres " froides » ne se labourent que tous les sept ou huit ans, ou même tous les vingt ans. La prairie artificielle fait à peine son apparition.

Les paysans, menés par l'esprit de routine et disposant de peu de capitaux, n'apportent pas grand soin à la culture ; ils ne labourent pas assez profondément, ils sarclent les blés avec négligence, font des semailles trop tardives et usent de mauvaise semence. Presque partout on manque de bon fumier ; comme la ferme en fournit peu, on use surtout de feuillage et de fougères qu'on laisse pourrir. Ainsi s'explique le faible rendement des récoltes : il ne dépasse guère 5 ou 6 pour 1, en Bretagne, 3 ou 4 en Limousin, tandis qu'exceptionnellement, en Flandre, il s'élève à 11.

Un autre trait caractéristique, c'est que, presque dans toute la France, le froment est considéré comme une culture de luxe et que le seigle prédomine, à l'exception cependant du pays toulousain, de l'Angoumois, de la zone côtière de la Bretagne. Sur les terres pauvres, on cultive surtout le blé noir, qui fournit aux paysans leur principale nourriture sous forme de galette. Dans le Centre et le Midi, le maïs joue un grand rôle. Le lin et le chanvre sont des cultures plus répandues qu'aujourd'hui, par suite de l'extension de l'industrie rurale et domestique. Le gouvernement, craignant que la vigne ne prenne la place des céréales, s'est efforcé, au cours du XVIII ${ }^{\mathrm{e}}$ siècle, d'en restreindre la culture ; celle-ci cependant est florissante et rémunératrice dans le Midi et surtout dans le Bas-Languedoc. Quant à l'exploitation forestière, ruinée par une mauvaise administration, par les abus des usagers, elle laisse fort à désirer, et le développement des forges, des mines et surtout des fonderies accroît le déboisement, de plus en plus inquiétant. L'élevage, qu'il s'agisse de l'espèce bovine ou de l'espèce chevaline, reste très médiocre, bien que l'on constate un certain progrès dans la seconde moitié du XVIII ${ }^{\mathrm{e}}$ siècle.

Incurie des grands propriétaires ; inertie des paysans, découragés par les charges qui les accablent ; insuffisance des voies de communication et surtout mauvais état des chemins de traverse ; entraves au commerce des denrées agricoles et à la liberté des cultures : autant de raisons qui expliquent le faible développement de l'agriculture. 
Il y a bien eu, dans la seconde moitié du XVIII ${ }^{\mathrm{e}}$ siècle, des tentatives d'améliorations agricoles, mais c'est presque exclusivement le gouvernement qui en a pris l'initiative.

Sous l'influence des économistes, et surtout des physiocrates, l'agriculture devient l'une des préoccupations prédominantes de l'administration royale, qui, à tout instant, envoie aux intendants des mémoires et des instructions pour recommander de meilleurs procédés de culture. Un premier comité d'agriculture est créé en 1761, et Bertin, qui, de 1761 à 1783, apparaît comme un vrai ministre des affaires économiques, prend toute une série de mesures tendant à accroître la production du sol. Vers la fin de l'ancien régime, à la suite de la sécheresse de 1785, on crée un Comité d'administration de l'agriculture, qui comprend parmi ses membres des hommes très distingués, comme savants, comme agronomes, comme économistes, tels que Lavoisier, le botaniste du Tillet, l'économiste Dupont de Nemours, l'inspecteur des manufactures Lazowski, le duc de la Rochefoucauld-Liancourt. Ces personnages se livrèrent à des enquêtes intéressantes et rédigèrent des mémoires fort instructifs, mais l'activité du Comité ne dura que deux ans, de 1785 à 1787.

Dès 1761, Bertin s’était appliqué à créer, dans chaque généralité, une Société d'Agriculture (les États de Bretagne en avaient fondé une dès 1757). Ces Sociétés se livrèrent à des enquêtes intéressantes, leurs membres rédigèrent des mémoires, firent même des expériences ; mais au bout de quelques années, elles entrèrent en sommeil et ne purent exercer une grande action sur les progrès de l'agriculture. L'immense majorité des cultivateurs restait fidèle aux pratiques traditionnelles, surtout par manque de capitaux et d'avances. C'est seulement dans les pays riches du Nord-Ouest que l'on constate des progrès un peu sensibles : les prairies artificielles s'y développent, et on y introduit de nouvelles cultures.

Il est vrai que, dans tout le royaume, on voit s'accroître la quantité des terres productives. Les déclarations royales de 1764 et de 1766 encouragent par des exemptions d'impôts les dessèchements des marais et le défrichement des terres incultes. En fait, d'importants dessèchements sont entrepris en Picardie, en Normandie, en Bretagne, en Vendée. On défriche un peu partout beaucoup de terres incultes. Cependant, à la veille de la Révolution, le plus gros de la besogne restait 
à accomplir. C'est que la masse de la population, ayant besoin pour son usage des landes, se montrait hostile aux dessèchements et aux défrichements, réfractaire aussi, pour la même raison, aux partages des biens communaux, que le gouvernement s'efforçait d'encourager, et qui furent, en fait, bien peu nombreux avant la Révolution, comme on le voit notamment par les documents qu'a publiés Georges Bourgin.

Partages de communaux, défrichements et dessèchements ne semblaient avantageux qu'aux grands propriétaires et aux paysans aisés. Eux seuls aussi se montrèrent favorables aux efforts que tenta le gouvernement, pendant les vingt dernières années de l'ancien régime, pour restreindre la vaine pâture et le droit de parcours, si nuisibles à l'agriculture : on dut se contenter d'une série de mesures partielles, applicables seulement aux régions où la réforme semblait la plus urgente, et qui n'eurent pas d'ailleurs une pleine efficacité.

C'est qu'il eût fallu, en effet, opérer toute une redistribution des terres, analogue au système des enclosures, qui, à ce moment même, était pratiqué en Angleterre. Il n’y avait pas à y penser en France.

L'industrie rurale. - Un indice de l'insuffisance de la production agricole, c'est encore, au $\mathrm{XVII}^{\mathrm{e}}$ siècle et surtout au $\mathrm{XVIII}^{\mathrm{e}}$, l'extension de l'industrie rurale, qui fournit un appoint important aux moyens d'existence des cultivateurs. Tel est notamment le cas de la Bretagne et du Bas-Maine. En Bretagne, l'industrie de la toile est exclusivement rurale et domestique ; ceux qui s'y emploient, ce sont de petits propriétaires, des fermiers (qui souvent font travailler leurs domestiques), des journaliers qui fabriquent la toile pendant les mois de chômage. Les salaires des tisserands sont fort médiocres et les profits vont surtout aux fabricants, c'est-à-dire aux marchands qui recueillent les produits fabriqués et avancent souvent la matière première.

Dans les régions où l'agriculture est plus prospère, comme la Normandie orientale, la Picardie, la Flandre, les paysans qui pratiquent l'industrie rurale sont ceux qui possèdent trop peu de terres pour vivre de leur culture. Dans la Normandie orientale, le Parlement de Rouen, dès 1722, nous montre les paysans abandonnant la culture de la terre pour filer ou carder le coton, et il se plaint du dommage qui en 
résulte pour l'agriculture. Il n'est aucun village normand qui n'ait ses fileuses et ses tisserands ; 180000 personnes sont ainsi occupées par la « manufacture » de Rouen.

La Picardie nous présente un spectacle à peu près analogue.

Dans ces dernières provinces, où l'industrie a, en quelque sorte, essaimé des villes vers les campagnes, l'artisan rural est plus étroitement soumis qu'ailleurs à la classe des négociants, qui concentrent ses produits et qui lui fournissent, non seulement la matière première, mais même, en bien des cas, les métiers. Ici, l’industrie rurale se présente vraiment comme le premier stade de l'évolution qui aboutira au triomphe de la grande industrie capitaliste. Dans les campagnes de la Haute-Normandie, dans celles du pays de Troyes, les métiers de la fabrication cotonnière nuisent gravement aux artisans et aux ouvriers urbains, qui reprochent aux fabricants de les réduire à la misère. Grâce aux perfectionnements techniques, le métier de tisserand est à la portée d'artisans peu habiles, sans éducation professionnelle, qui ne touchent que de faibles salaires, ce qui incite encore davantage les négociants à utiliser leur main-d'œuvre.

Le mode de vie des paysans. — L'existence matérielle du paysan est encore assez misérable, même à la fin de l'ancien régime. Son habitation est tout à fait insuffisante. La plupart des maisons sont bâties en torchis, couvertes de chaume ; une seule chambre basse, sans plancher ; de petites fenêtres, sans vitres. En Bretagne, et surtout en BasseBretagne, on a pu dire que le paysan vivait "dans l'eau et dans la boue ». C'est là l'une des causes principales des épidémies, encore si fréquentes. Cependant, comme aujourd'hui, les conditions de l'habitation varient d'une région à l'autre. C'est dans le Nord de la France que la maison paysanne semble le plus confortable.

D’ailleurs, il ne faut jamais manquer de distinguer les paysans aisés et les pauvres, surtout lorsqu'on considère le mobilier et les vêtements. Chez les uns, c'est un mobilier simple, primitif, mais convenable, une vaisselle suffisante, beaucoup de linge, une garde-robe assez bien montée ; les pauvres, au contraire, peuvent à peine satisfaire les besoins les plus rudimentaires. Chez les uns, l'inventaire après décès (c'est notre principale source de renseignements) évalue parfois le 
mobilier à plus d'un millier de francs ; chez les autres, souvent il ne l'estime qu'à 50 ou même 20 livres. Les pauvres ne disposent guère que d'un ou deux coffres, d'une table, d'une huche, d'un banc, d'un lit mal garni ; chez les paysans aisés, on trouve des lits bien garnis, des armoires, toutes sortes d'ustensiles de ménage, des écuelles de bois et de terre, de la faïence, des verres. Dans les vêtements, on constate aussi une grande diversité : il en est de cossus et il en est de misérables. Les vêtements de travail sont presque toujours en toile; beaucoup de paysans n'ont que des sabots ou même, dans le Midi, marchent pieds nus : les droits sur les cuirs rendent les souliers trop chers.

L'alimentation du paysan est presque toujours grossière, souvent insuffisante. La viande n'apparaît que rarement sur sa table. Parfois, il mange du lard ; excepté dans les pays où le vin est abondant, il ne boit guère que de l'eau ; en Bretagne, il ne boit du cidre que dans les années d'abondance. Le fond de l'alimentation, c'est le pain, la soupe, les laitages, le beurre ; jamais de pain de froment ; seulement du pain de seigle ou d'avoine, souvent de mauvaise qualité ; dans les pays les plus pauvres, la galette ou la bouillie de blé noir ou encore de châtaigne ou de maïs. Le froment et même le seigle servent surtout à acquitter les redevances ou les fermages, sont vendus pour l'exportation, lorsque celle-ci est autorisée. La culture de la pomme de terre, qui sera une si précieuse ressource pour l'alimentation paysanne, n'est encore pratiquée que dans de rares régions, dans les cantons fertiles comme certaines parties de la côte bretonne.

Les vêtements sont souvent misérables ; la description de Besnard dans ses Souvenirs d'un nonagénaire, semble bien correspondre à la réalité :

« Les vêtements des paysans pauvres, - et presque tous l'étaient plus ou moins -, étaient encore plus chétifs, car ils n'avaient que les mêmes pour l'hiver et pour l'été, qu'ils fussent d'étoffe ou de toile ; et la paire de souliers très épais et garnis de clous, qu'ils se procuraient vers l'époque du mariage, devait, moyennant la ressource des sabots, servir tout le reste de la vie. »

Les femmes «portaient un manteau court de gros drap ou cadi noir, auquel tenait un capuchon destiné à envelopper la tête et le cou dans le cas de pluie ou de froid ». - Cette description correspond bien aux renseignements que nous fournissent les inventaires. 
Les crises et la misère. - D'ailleurs, si l'on veut se rendre compte du mode de vie des paysans, il faut toujours distinguer les époques normales et les périodes de crises, provoquées par les guerres étrangères et les mauvaises récoltes.

Au XVIII ${ }^{e}$ siècle, les crises ont été moins graves, sinon moins fréquentes qu'au XVII ${ }^{e}$. Certaines provinces avaient supporté directement le poids de la guerre : telles la Lorraine et la Bourgogne, qui subirent des ravages terribles, surtout pendant la première moitié du XVII ${ }^{\mathrm{e}}$ siècle ; dans le pays dijonnais, comme le montre M. Gaston Roupnel, des villages entiers sont dépeuplés, les champs redeviennent incultes.

Même sous le gouvernement personnel de Louis XIV, qu'on proclame souvent si prospère, la misère sévit durement sur les campagnes, dans toutes les régions de la France. Déjà, en 1675, Lesdiguières, gouverneur du Dauphiné, écrivait :

«Il est assuré, et je vous parle pour en être bien informé, que la plus grande partie des habitants de cette province n'ont vécu pendant l'hiver que de glands et de racines, et que présentement on les voit manger l'herbe des prés et l'écorce des arbres. »

Après 1685, la misère ne fait que s'accroître. En 1687, Henri d'Aguesseau et Antoine Lefèvre d'Ormesson, chargés d'une enquête dans le Maine et l’Orléanais, déclarent :

« Il n’y a presque plus de laboureurs aisés ; il n’y a plus que de pauvres métayers qui n'ont rien; il faut que les maîtres leur fournissent les bestiaux, qu'ils leur avancent de quoi se nourrir, qu'ils payent leur taille, et qu'ils prennent en payement toute la portion de leur récolte, laquelle même quelquefois ne suffit pas... Les paysans vivent de pain fait avec du blé noir ; d'autres, qui n'ont pas même du blé noir, vivent de racines de fougère bouillies avec de la farine d'orge ou d'avoine et du sel... On les trouve couchés sur la paille ; point d'habits que ceux qu'ils portent qui sont fort méchants ; point de meubles, point de provisions pour la vie ; enfin, tout y marque la nécessité. »

Dès 1684, l'ambassadeur de Venise déclare : « J'ai vu de mes yeux des terres, qui jadis comptaient 700 et 800 feux, réduites à moins de 30 par le continuel passage des gens de guerre. » 
Dans les quinze dernières années du règne de Louis XIV, la détresse des campagnes ne fait que s'accroître ; c'est une véritable famine qui désole la France, pendant l’hiver de 1709.

Il est nécessaire de rappeler ces faits pour montrer qu'il y a eu, à ce point de vue, une indéniable amélioration dans les quatre-vingts dernières années de l'ancien régime : au XVIII ${ }^{\mathrm{e}}$ siècle, le théâtre des hostilités se trouve presque toujours au-delà des frontières, et il y a moins de guerres qu'à l'époque du Grand Roi. Toutefois, on signale encore des crises graves : en 1725, 1740, 1759, de 1766 à 1768, de 1772 à 1776, en 1784 et 1785, enfin, en 1789, les subsistances haussèrent de prix dans d'énormes proportions ; en 1785, la sécheresse obligea les cultivateurs à vendre une partie de leur bétail. En 1774 et en 1789, bien des paysans durent se nourrir de navets, de laitage et même d'herbes. En ces années de crises, la misère atteint surtout les journaliers, qui n'ont pour vivre que le travail de leurs bras.

Peut-être cependant ne faudrait-il pas pousser le tableau trop au noir. Il y a des régions où l'agriculture est plus prospère (comme la Flandre, la Picardie, la Normandie, la Beauce), où le paysan est plus à son aise. On s'en rendra mieux compte quand de nouvelles monographies auront été élaborées. Mais, dès maintenant, on en a bien l'impression quand on lit les Voyages en France, d'Arthur Young. L'économiste anglais observe le contraste qui existe entre les diverses régions ; il remarque l'aisance des contrées où la terre est cultivée surtout par de petits propriétaires. Entrant d'Espagne en France, il admire la prospérité du Roussillon :

« Ici, sans traverser un village, une barrière ou même une muraille, vous entrez dans un nouveau monde. Des misérables routes de la Catalogne, vous arrivez sur une splendide chaussée, faite avec la solidité et la munificence qui distinguent les grands chemins de France; au lieu de lits de torrents, vous avez des ponts bien bâtis ; et d'une région sauvage, déserte et pauvre, nous nous trouvons transportés au milieu de la culture et du progrès. »

Tout compte fait, et dans l'ensemble, il paraît y avoir plus de bienêtre - tout relatif encore - dans les campagnes, surtout à partir de 1750. Cependant, le paysan, aux approches de la Révolution, a un sentiment plus vif de sa misère. C'est que peut-être, comme on l'a finement remarqué, « l’allégement même de sa misère lui fait paraître plus 
lourd le poids de ce qui reste ; peut-être est-il dégoûté du présent par les idées et les espoirs nouveaux qui pénètrent dans les campagnes ».

Épidémies, mendicité et assistance. - Une conséquence de la misère et des mauvaises conditions de vie, ce sont les épidémies, très fréquentes, et qui, pour être moins terribles qu'au moyen âge, semblent encore très meurtrières. La rougeole et surtout la variole, le typhus et la fièvre typhoïde font des milliers de victimes : en 1741, en Bretagne, on compta plus de 80000 morts. Chose curieuse : les épidémies sont plus fréquentes et plus redoutables dans les campagnes que dans les villes, comme le remarquent les médecins de l'époque, et notamment le Dr Bagot, de Saint-Brieuc, dans ses Observations médecinales. Et les paysans sont presque dénués de soins médicaux ; c'est seulement à la fin de l'ancien régime que le gouvernement organise l'assistance médicale, distribuant des remèdes et instituant des médecins des épidémies.

On comprend que la mendicité et le vagabondage soient de véritables fléaux, contre lesquels le gouvernement reste impuissant. C'est surtout dans les campagnes que mendiants et vagabonds sont nombreux ; dans les époques de crises, beaucoup de journaliers, réduits à la misère, accroissent la quantité de ces misérables ; beaucoup d'entre eux se réfugient dans les villes, pensant y trouver plus de secours. Mais les villes souffrent parfois autant de la misère que les campagnes.

C’est que, contre la misère, la charité privée est impuissante. L'assistance publique, en progrès dans les villes, est devenue, par contre, de plus en plus insuffisante dans les campagnes. Hôpitaux et aumôneries, autrefois assez nombreux, y ont peu à peu disparu ; pour donner un exemple, dans les pays de Rennes, Fougères et Vitré, il ne subsiste plus d'hôpitaux, à la fin de l'ancien régime, que dans 3 paroisses sur 140. Pour nourrir les pauvres, on ne trouve, en général, que de maigres fondations. Le clergé paroissial a pitié des misérables; mais souvent il a peu de ressources, et les riches abbayes ne s'acquittent guère de leurs devoirs de charité. L'État se voit donc obligé de s'occuper de l'assistance ; un effort sérieux a été tenté par des ministres réformateurs comme Turgot et Necker ; on a créé des 
ateliers de charité pour faire subsister les pauvres, on a fondé des bureaux d'aumônes. Mais, à la veille de la Révolution, l'œuvre d'assistance n'a encore que peu de résultats efficaces et la question se pose, tout à fait urgente, à l'Assemblée constituante, qui institue un Comité de mendicité.

Les troubles agraires. - Les populations rurales le plus souvent supportent passivement les charges qui pèsent sur elles. Chose curieuse, il n'y eut d'insurrections véritables que sous le règne de Louis XIV, ce roi dont, prétend-on, l'autorité s'imposait si fortement, et précisément dans les années les plus prospères de ce règne. Les paysans s'insurgent contre l'établissement d'impositions nouvelles ou contre l'aggravation de contributions anciennes. Dès 1662, c'est le Boulonnais qui s'agite; Louis XIV, en dépit des anciens privilèges, avait voulu y imposer, comme il le dit dans ses Mémoires, " une très petite somme », ce qui " produisit un mauvais effet » : 6000 personnes prirent les armes, et la révolte fut durement réprimée. En 1664, en Béarn et en Bigorre, lorsque la gabelle y est introduite, éclatent des troubles qui se prolongent pendant plusieurs années ; tout le pays se soulève. Dans le Vivarais, en 1670, le bruit absurde se répandait qu'un édit taxait la naissance des enfants, les habits et les chapeaux neufs. Toute la campagne des environs d'Aubenas (une vingtaine de paroisses) s'insurge sous la conduite d'Antoine du Roure.

Quand, au moment de la guerre de Hollande, Colbert dut créer de nouveaux impôts (papier timbré, augmentation des gabelles, monopole sur le tabac, etc.), les campagnes de la Guyenne s’agitent, en 1675, et le gouvernement, pour réprimer l'insurrection, mobilise plus de 200 compagnies. Au même moment, et pour les mêmes raisons, une partie de la Basse-Bretagne s'insurge. Un certain nombre de paroisses rédigent ce que l'on a appelé le Code paysan, véritable programme de revendications, qui annonce déjà les cahiers de 1789. L'insurrection commence, en effet, à prendre le caractère d'une jacquerie qui s'attaque à la noblesse. Comme nous le montre l'historien qui a consacré une excellente étude à la révolte du papier timbré, M. Jean Lemoine, la répression fut terrible: on ne faisait que pendre des paysans révoltés, les troupes tuaient et volaient. Toutes ces insurrections semblent bien avoir été spontanées. Ainsi que l'a dit très juste- 
ment Ernest Lavisse, " entre ces " émotions ", qui se produisent pour les mêmes causes dans le même moment, il n'y a pas d'entente ; Bretagne et Guyenne, Rennes et Bordeaux agissent chacun de son côté, ne se connaissent pas; les feux épars ne se sont pas réunis en un incendie général ».

Il est intéressant de remarquer qu'au XVIII ${ }^{\mathrm{e}}$ siècle, à une époque où l'on considère qu'il y a décadence de l'autorité royale, on ne perçoit aucune insurrection paysanne analogue aux troubles qui ont marqué le règne du Grand Roi. Les campagnes restèrent généralement calmes, soit que l'état économique fût meilleur qu'au XVII ${ }^{\mathrm{e}}$ siècle, comme tendrait à le prouver l'accroissement très notable de la population, soit que l'administration provinciale fût plus fortement organisée et que la police fût plus sérieuse. C'est seulement à la veille de la Révolution que des émeutes sont suscitées par la crainte de la famine, provoquées par l'exportation des grains ; et cependant le gouvernement prend des mesures pour prévenir les disettes ou en parer les effets, achetant des grains, subventionnant les importateurs de blé, faisant des distributions de grains gratuites ou à bas prix. Des troubles agraires graves n'éclateront qu'à l'époque révolutionnaire, au lendemain du 14 juillet, puis après la nuit du 4 août, quand les paysans voudront obtenir l'abolition du régime seigneurial abhorré, dont on leur a fait espérer la suppression.

L'état moral. - Il est encore plus malaisé de se représenter la situation morale des paysans que leur vie matérielle. Comment déterminer avec précision le caractère collectif d'une classe aussi nombreuse, et dont la condition économique est loin d'être uniforme?

Cependant, il apparaît clairement que ces hommes, si peu indépendants, dont l'existence est souvent si misérable, qui sont si mal nourris et dépourvus de tout bien-être, manquent souvent de courage au travail, d'énergie, d'initiative. C'est vrai surtout des pays pauvres comme la Bretagne. Et telle est l'impression générale des administrateurs et des voyageurs qui ont parcouru cette province au XVIII siècle. A entendre l'intendant des Gallois de la Tour, dans son mémoire de 1733, il est un assez grand nombre de régions où la population est industrieuse, ou tout au moins laborieuse ; mais ailleurs, et notamment 
dans les cantons les plus pauvres, les habitants sont "fainéants ", ivrognes, grossiers, "sans industrie ", négligent la culture et l'élevage. Vers la fin de l'ancien régime, un observateur intelligent, M. de Brémontier, note l'imprévoyance des paysans bretons :

« Le laboureur ne travaille que pour lui. Sa prévoyance ne va point au-delà de son nécessaire ; il s'endort sur ses besoins futurs, et il s'en rapporte constamment à une Providence toujours juste, qui le condamne souvent à des privations méritées par sa négligence ; alors il est au comble du malheur. »

La Révolution, en allégeant les charges des paysans qu'elle a délivrés du régime seigneurial, en les faisant profiter de la vente des biens nationaux, c'est-à-dire en accroissant leur propriété, contribuera à les rendre actifs et énergiques ; Besnard, dans ses Souvenirs, en note un exemple bien typique sur les terres de l'ancienne abbaye de Fontevrault.

Souvent, la brutalité est un trait de caractère du paysan. Les domestiques sont fréquemment maltraités. Les juges des régaires de Tréguier, en Bretagne, déclarent que « le mépris des lois et l'insolence de certains gros paysans de ce canton sont montés à un si haut degré, qu'il n'est pas possible à un domestique de les servir sans courir à chaque instant les risques d'être excédé de coups ou d'invectives, ou les deux à la fois ». Les rixes sont fréquentes, qui mettent aux prises, soit des individus, soit même les habitants de deux villages rivaux. C'est la raison pour laquelle on redoute, en bien des régions, les fêtes villageoises, les "assemblées », occasion de divertissements qui aboutissent trop souvent à des bagarres. Cela est surtout vrai de pays comme la Bretagne, où la population, dispersée dans des maisons ou des hameaux isolés, est peu préparée à la vie sociale.

Ce qui d'ailleurs incite à la violence, c'est l'ivrognerie. Dans les campagnes, on boit moins d'eau-de-vie que de nos jours ; ce que nous appelons l'alcoolisme n'existe pas encore.

N'empêche que bien des cahiers de paroisses, en 1789, demandent qu'on restreigne la quantité des cabarets, qui sont nombreux, non seulement dans les villages, mais aussi le long des routes. 
L'enseignement. - On peut affirmer que la population des campagnes est très inculte et que la grande majorité des paysans ne sait ni lire, ni écrire.

Sans doute, dans certaines régions, notamment dans l'Est et dans le Nord, les écoles sont plus nombreuses. Mais ailleurs, et surtout dans l'Ouest, beaucoup de paroisses ne possèdent pas d'écoles, et les écoles de filles sont encore plus rares. Comme, le plus souvent, aucune fondation n'assure l'entretien de l'école, c'est le curé ou son vicaire, en bien des cas, qui fait la classe, plus ou moins régulièrement. Ce qu'il faut dire, c'est que, l'enseignement dépendant de la charité privée (les petites écoles sont dénommées souvent écoles de charité), cet enseignement est forcément précaire : des écoles restent fermées pendant plusieurs années. D’ailleurs, il ne faut pas se faire d'illusion sur la qualité de l'enseignement primaire ; il ne consiste guère que dans la lecture, l'écriture et le catéchisme. Combien il laissait à désirer, c'est ce que montrent, d'une façon indirecte, le projet attribué à Turgot par le Mémoire sur les municipalités, rédigé par Dupont de Nemours, ainsi que les beaux programmes d'éducation nationale, élaborés par les assemblées révolutionnaires.

En tout cas, sans aucun doute, il y a énormément d’illettrés dans les campagnes. Une preuve, entre beaucoup d'autres, c'est que les cahiers de paroisses de 1789, notamment en Bretagne, ne portent, en général, que très peu de signatures, et il est beaucoup de ces cahiers qui déclarent que "tous ceux qui savent ont signé ", ou encore que "le plus grand nombre ne savent pas signer ». Le procès-verbal de l'Assemblée de Pontivy de 1790 note que, « dans les municipalités de campagne, les maires et officiers municipaux savent à peine écrire ». Les signatures apposées sur les contrats de mariage qui nous ont été conservés sont pour la plupart informes. Enfin, nombreux sont les cahiers de 1789 qui demandent " un maître d'école dont les enfants ont été privés jusqu’ici », qui réclament l'établissement de «bonnes écoles ».

L'administration paroissiale. - Cependant, on perçoit le premier germe d'une vie politique. Les paysans commencent à prendre une conscience plus nette de leurs intérêts collectifs. Ils participent 
activement, en effet, à l'administration paroissiale. Il est vrai que l'assemblée paroissiale, l'ensemble des habitants, perd de plus en plus son autorité, au profit d'un corps restreint de notables, de ce qu'on appelle en Bretagne le "général » de la paroisse. Le général ou conseil de la paroisse comprend le seigneur, son sénéchal ou son procureur fiscal, le recteur, douze délibérants, les deux trésoriers ou marguilliers en exercice. Les délibérants ne peuvent être choisis que parmi d'anciens trésoriers. La masse des habitants n'intervient que rarement dans l'administration.

La paroisse a des officiers, qui exécutent les décisions du général ; ce sont : les greffiers, les bedeaux et surtout les marguilliers ou trésoriers. Ces derniers, qui sont élus pour un an, administrent les fonds et revenus de la paroisse, des confréries, des fondations, convoquent le général, proposent l'ordre du jour de ses délibérations ; ils sont chargés aussi de l'entretien des enfants trouvés, de l'équipement des soldats de la milice, de la gestion des revenus communaux et des taxes extraordinaires. Ils ont une responsabilité financière. Leurs fonctions sont donc pénibles, onéreuses, et l'on comprend que les paysans essaient de s’y soustraire le plus possible.

Les généraux de paroisses sont, à la fois, conseils de fabrique et conseils municipaux ; ils ont donc à gérer une double administration : celle de la fabrique, généralement assez prospère, car elle a un budget bien défini, et celle du "gouvernement extérieur », presque toujours déplorable, car les communautés de campagne, pour satisfaire à leurs besoins temporels, n'ont ni budget, ni recettes régulières, rien que des ressources transitoires, alimentées par des taxes extraordinaires et des expédients ruineux.

Au XVIII ${ }^{\mathrm{e}}$ siècle, l'administration temporelle de la paroisse se développe et se complique, par le fait même des progrès de la fiscalité royale : les fonctions d'assesseurs et de collecteurs des impôts deviennent de plus en plus lourdes ; on crée un syndic militaire pour assurer le logement des gens de guerre, et un syndic de la corvée, assisté de députés, qui dirige le service si pénible de la corvée.

D’ailleurs, les administrations paroissiales sont soumises étroitement à la tutelle de l'État; pour tout acte de la vie municipale, l'autorisation du Gouvernement est indispensable; les syndics sont 
véritablement les agents de l'intendant, qui dispose d'eux pour toutes les besognes administratives. L'autorité du seigneur s'exerce aussi sur les paroisses rurales; n’est-ce pas l'un de ses officiers (sénéchal ou procureur fiscal) qui préside les délibérations du général ? Toutefois, au XVIII siècle, nous voyons les paroisses rurales se défendre assez énergiquement contre les usurpations seigneuriales, protester vigoureusement contre les atteintes portées aux droits d'usage des habitants, engager contre les propriétaires nobles de longs procès qui souvent les endettent fort.

Le mouvement qui tendait à grossir les fonctions temporelles des administrations paroissiales devait aboutir à la séparation définitive du spirituel et du temporel. A cet égard, l'édit du 25 juin 1787, qui établit, dans les campagnes comme dans les villes, des municipalités organisées d'une façon uniforme, a vraiment une grande portée. Dans chaque communauté, on établit un conseil, composé du seigneur, du curé et de 3, 6 ou 9 membres élus, selon le nombre des feux. Ces membres représentent bien l'assemblée paroissiale, car ils sont élus au scrutin secret par tous les habitants payant au moins 10 livres d'imposition foncière et personnelle. Les assemblées générales ne sont plus guère, d'ailleurs, que des assemblées électorales. C'était une véritable organisation municipale, au sens moderne du mot, qui était créée.

Les paysans commencent donc à s'éveiller à la vie politique. Irrités par la réaction seigneuriale, qui marque la fin de l'ancien régime, ils ne craignent pas, en 1789, dans leurs cahiers de paroisse, de faire entendre hautement leurs revendications. Et bientôt, par leurs pétitions, puis par leurs violences (attaques de châteaux, brûlements d'archives), ils forceront la main aux assemblées révolutionnaires, les obligeront à abolir le régime seigneurial, à rendre pleinement autonomes leurs propriétés.

La question paysanne et l'opinion publique. - La réforme édictée par la Convention devait être radicale ; elle résolvait pour toujours la question.

Mais l'agitation révolutionnaire fut préparée par un puissant mouvement d'opinion qui se manifeste surtout dans la seconde moitié du 
$\mathrm{XVIII}^{\mathrm{e}}$ siècle. Les physiocrates considèrent que le régime seigneurial, par toutes ses entraves vexatoires, est nuisible aux progrès de la production agricole. Cependant, leurs revendications, à cet égard, ont un caractère encore abstrait.

Mais voici que les rois de Sardaigne, par leurs édits de 1762, 1771, 1778, affranchissent les paysans savoyards de la mainmorte, ordonnent le rachat des droits seigneuriaux. Voltaire est encouragé ainsi à mener plus activement encore sa campagne en faveur des serfs de Franche-Comté. Dans un de ses mémoires, il rappelle que « le roi de Sardaigne a affranchi toutes les terres de la Savoie de la mainmorte réelle et personnelle ».

Puis, en 1776, paraît le célèbre pamphlet de Boncerf sur les Inconvénients des droits féodaux, secrètement encouragé par Turgot. Malgré son extrême modération, puisqu'il ne demande le rachat obligatoire que pour les successeurs des seigneurs actuels, il est condamné par le Parlement de Paris. Voltaire adhère pleinement aux idées de Boncerf et s'élève vigoureusement contre le Parlement, dénonce son égoïsme :

« Proposer la suppression des droits féodaux, c’est encore attaquer particulièrement les propriétés de Messieurs du Parlement, dont la plupart possèdent des fiefs. Ces Messieurs sont donc personnellement intéressés à protéger, à défendre, à faire respecter les droits féodaux : c'est ici la cause de l'Église, de la noblesse et de la robe. Ces trois ordres, trop souvent opposés l'un à l'autre, doivent se réunir contre l'ennemi commun. L'Église excommuniera les auteurs qui prendront la défense du peuple, fera brûler auteurs et écrits ; et, par ces moyens, ces écrits seront victorieusement réfutés. »

Jean-Jacques Rousseau, de son côté, a beaucoup fait pour rendre populaire la cause des paysans. Dans la Nouvelle-Héloïse, qui a eu un si grand succès, il ne cesse d'opposer au luxe factice de Paris les mœurs simples et saines des campagnards. Saint-Preux, voyageant dans le Valais, admire l'aisance et le bonheur des montagnards : « les denrées y sont abondantes sans aucun débouché au dehors, sans consommation de luxe au dedans, et sans que le cultivateur montagnard, dont les travaux sont les plaisirs, devienne moins laborieux ». 
Le véritable génie de la nation française, Rousseau le cherche, non point à Paris, mais dans les provinces, dans les campagnes reculées.

Le sentiment de la nature, qu'il a tant contribué à répandre, attire aussi l'attention des citadins sur les habitants des campagnes. Le roman, le théâtre commencent à peindre, d'une façon tout idéaliste, un peu fade et très fausse, il est vrai, les mœurs paysannes. Dans les Contes de Florian, il n'est question que de bergers et de bergères. Marie-Antoinette, à Trianon, joue à la fermière. Sans attacher à ces manifestations d'un nouveau " snobisme ", comme l'on dirait aujourd'hui, plus d'importance qu'elles n'en méritent, il faut cependant reconnaître qu'elles révèlent, dans une certaine mesure, les tendances d'une époque.

Importance prépondérante de la question paysanne. - La question paysanne devait, d'ailleurs, forcément se poser dans un pays où, numériquement, la population des campagnes tient une si grande place, dans une région où la grande industrie n'en est encore qu'à ses débuts, où la production agricole prime toutes les autres. Vauban disait déjà que "la vraie richesse d'un royaume consiste dans l'abondance des denrées, dont l'usage est si nécessaire à la vie des hommes qui ne sauraient s'en passer »; il considérait aussi que la grande ressource du pays, c'était sa population et surtout sa population rurale. Au XVIII ${ }^{\mathrm{e}}$ siècle, l'intérêt que les administrateurs éclairés, comme les économistes, portent aux questions agricoles, attire l'attention des contemporains sur la condition de la classe qui, seule, se livre à la culture de la terre. En Angleterre, à la même époque, ce sont les questions commerciales et industrielles qui passionnent surtout l'opinion publique.

Table des matières

\section{Ouvrages à consulter}

Outre les ouvrages de Loutchisky, Sée, Lefebvre, cités au chapitre premier, et les nombreuses éditions des cahiers de 1789 (publiés surtout dans la Coll. des Doc. écon. de la Révolution) :

Sion, Les Paysans de la Normandie Orientale, Paris, 1909. 
Demangeon A., La Picardie, Paris, 1906.

Musset R., Le Bas-Maine, Paris, 1917.

De Calonne A., La Vie agricole sous l'Ancien Régime dans le Nord de la France, $3^{\mathrm{e}}$ éd., 1920 (Mém. de la Soc. des Antiquaires de Picardie).

MARION M., État des classes rurales dans la généralité de Bordeaux, 1902.

SOULGÉ, Le Régime féodal de la propriété paysanne (dans le Forez), Paris, 1923.

GIFFARD A., La Justice seigneuriale en Bretagne, 1900.

AulARD, La Révolution française et le régime féodal, Paris, 1917.

SAgnac Ph. et CARON Pierre, Les Comités des droits féodaux et de législation et l'abolition du régime seigneurial (Coll. des Doc. économiques de la Révolution), 1906.

BRUCHET Max, L'Abolition du régime seigneurial en Savoie, (même collection), 1908.

LETACONNOUX J., Les Subsistances et le commerce des grains en Bretagne au XVIII siècle, 1909.

AfAnASSIEV, Le Commerce des céréales en France au XVIII siècle, Paris, 1894.

TARLÉ, L'Industrie rurale en France à la fin de l'ancien régime, Paris, 1910.

LAUDE, Les Classes rurales en Artois à la fin de l'ancien régime, Lille, 1914.

BOURDAIS F. et DuRAND R., L'Industrie et le commerce de la toile en Bretagne sous l'ancien régime (Comité des travaux historiques, Sect, d'hist. moderne, fasc. VII), 1922.

PoRT Célestin, Souvenirs d'un nonagénaire, Fr.-Yves Besnard, Angers, 1880, 2 vol. in-8 ${ }^{\circ}$.

BABEAU, La Vie rurale sous l'ancien régime, $2^{\mathrm{e}}$ éd., 1885.

BussiÈre, La Révolution dans le Périgord (surtout le t. III), 1903.

SÉE H., La Vie économique et les classes sociales en France au XVIII ${ }^{e}$ siècle, Paris, 1924.

- Les Troubles agraires en Haute-Bretagne (1790-1791) (Bull. d'histoire économique de la Révolution, 1919-1921), Paris, 1924. 


\section{Chapitre 3}

\section{LE CLERGÉ.}

L’ordre du clergé. - Le clergé, bien qu'il comprît les conditions les plus diverses, constituait cependant un ordre bien défini, et même le seul ordre qui existât réellement en France sous l'ancien régime. La discipline particulière à laquelle tous ses membres sont soumis, le célibat auquel ils sont astreints le distinguent du reste des sujets. Le clergé a ses tribunaux particuliers, les officialités, qui, d'ailleurs, au $\mathrm{XVIII}^{\mathrm{e}}$ siècle, n'ont plus guère à juger que les causes purement spirituelles, résultant des sacrements, les infractions des ecclésiastiques à la discipline, et aussi certains procès entre membres du clergé.

Seul, l'ordre du clergé est représenté auprès du roi par une assemblée, «l'assemblée du clergé ». Celle-ci a été instituée, au XVI ${ }^{\mathrm{e}}$ siècle, dans un but fiscal, afin de lui faire voter la contribution que l'Église de France devait donner au roi. Elle se tenait tous les dix ans, pour renouveler l'octroi relatif aux décimes ordinaires, et tous les cinq ans pour voter le «don gratuit». Les députés à l'assemblée générale étaient élus par les assemblées provinciales, qui se tenaient au cheflieu de chaque archevêché et qui se composaient des députés des diocèses suffragants. L'assemblée provinciale désignait deux députés du premier ordre (haut clergé) et deux députés du second (bas clergé) ; mais c'était le premier ordre qui avait toute l'autorité. L’assemblée générale, à partir de Louis XIV, accepta les demandes du roi sans faire réellement d'opposition, bien qu'en réalité elle eût le droit d'élever ou d'abaisser le chiffre du don ; elle répartissait ensuite entre les diocèses la somme qu'ils devaient acquitter. Des bureaux diocésains répartissaient la contribution entre les membres du clergé.

Les assemblées générales s’occupent aussi de la « défense de la foi », demandent l'appui du bras séculier contre les hérétiques, contre 
les protestants, condamnent les livres contraires à la religion, traitent aussi toutes les questions concernant la discipline et l'organisation de l'Église, le maintien de ses privilèges, l'instruction publique (surtout après l'expulsion des Jésuites). On comprend alors l'intérêt que présentent pour l'histoire générale les Procès-Verbaux des assemblées du clergé et les rapports de ses agents. L'assemblée désigne, en effet, deux agents généraux, qui ont pour fonctions de défendre les intérêts de l'ordre et de gérer son administration financière.

Le clergé exerce aussi, même au temporel, une grande autorité. Seul, il est chargé de tenir les registres des baptêmes, mariages et décès (l'état-civil est aux mains de l’Église). Il exerce la haute main sur l'instruction publique et la charité. Les assemblées paroissiales sont étroitement subordonnées aux curés. Ce sont ces derniers qui notifient les édits et publient en chaire un monitoire, chaque fois qu'un crime est commis. En un mot, toute la société laïque dépend encore très étroitement du pouvoir ecclésiastique.

Nombre des ecclésiastiques. - Cet ordre si puissant n'est pas très nombreux. L’Almanach royal indique 135 évêchés et archevêchés, 34658 cures. Mais on peut évaluer le nombre des curés et des vicaires à 60000 environ. Les prélats et chanoines de cathédrales sont 2 800, les chanoines de collégiales, 5 600, sans compter 3000 ecclésiastiques sans bénéfices. Au total, 71000 prêtres séculiers. Il est plus difficile de déterminer le nombre des réguliers, des moines de toutes catégories. Il ne dépassait pas, semble-t-il, 60000 et, à la fin de l'ancien régime, il a été sensiblement réduit.

Les propriétés et la richesse du clergé. - C'est cette petite quantité des ecclésiastiques (environ 1,8\% de la population totale) qu'il faut envisager quand on parle de la richesse du clergé. On sait déjà que la propriété du clergé comprenait tout au plus 5 à $6 \%$ du territoire ; les revenus de cette propriété ne dépassaient pas 80 ou 100 millions. Les dîmes représentaient une somme plus considérable, environ 123 millions. Mais, on le verra plus loin, la répartition de cette fortune était très inégale. 
D’ailleurs, à considérer même les plus riches établissements ecclésiastiques, - évêchés, chapitres, abbayes —, il ne s’agit presque jamais de grands domaines d'un seul tenant. La propriété ecclésiastique est, en général, très morcelée, se composant surtout de fermes isolées. M. Rebillon, dans sa Situation économique du clergé dans les districts de Rennes, Fougères et Vitré, l'a montré de la façon la plus claire. En somme, la propriété rurale d'un évêché et d'un chapitre, comme ceux de Rennes, semble fort peu de chose. Si l'évêque de Rennes a environ 60000 livres de revenus, c'est qu'il touche le produit de nombreuses dîmes. Quant aux abbayes et aux couvents, leur propriété urbaine est plus importante que leur propriété rurale ; à Rennes, ces établissements possèdent une grande partie des immeubles et enserrent, pour ainsi dire, toute la ville. Il semble bien que, dans toute la France, on pourrait constater des faits analogues, même dans des régions comme les pays du Nord, où le pourcentage de la propriété ecclésiastique est plus fort qu'ailleurs.

Les charges du clergé. - Les charges, représentées par les décimes et le don gratuit, semblent bien faibles en proportion de ces recettes. Le décime ordinaire n'est guère que de 400000 livres. Le don gratuit, plus lourd, ne cessa de s'élever à la fin de l'ancien régime : 16 millions en 1773, 30 millions en 1780, 36 millions en 1782 ; en moyenne, 5400000 livres par an. Mais le clergé, pour payer ces sommes, contractait des emprunts. La dette, en 1784, s’élevait à 134 millions. Toutefois, le roi payait une partie des intérêts : 500000 livres jusqu'en 1780 ; puis, un million, et, à partir de 1782, 2500000 livres. D'autre part, le clergé était exempté de toute autre imposition, même de la capitation et des vingtièmes auxquels était soumise, partiellement au moins, la noblesse. Les contributions du clergé, déclare Necker, sont « inférieures de 700000 à 800000 livres à celles dont il serait tenu si, avec les mêmes privilèges que la noblesse, il était assujetti aux formes ordinaires de la répartition ». C'est surtout au XVIII ${ }^{\mathrm{e}}$ siècle que l'État, pressé par le besoin d'argent, tenta de porter atteinte aux immunités pécuniaires du clergé. Machault essaya de le soumettre aux vingtièmes et s'attaqua d'abord au clergé étranger, c'est-à-dire au clergé des provinces réputées étrangères, qui, n’étant pas représenté aux assemblées, semblait devoir céder plus aisément aux exigences de la fiscalité royale. 
Le haut clergé et la noblesse. - $\mathrm{Au} \mathrm{XVII}^{\mathrm{e}}$ siècle, dans les rangs du haut clergé, on trouve encore un certain nombre de roturiers, comme Huet, Fléchier, Bossuet. Au XVIII ${ }^{\mathrm{e}}$ au contraire, le haut personnel se compose presque exclusivement de nobles. Les abbés - presque tous sont à la nomination du roi - sont choisis presque exclusivement dans les rangs de la noblesse. D’ailleurs, 850 abbayes, sur 1 100, sont données, comme on dit, en commende, c'est-à-dire à un bénéficier qui n'exerce pas la fonction et prend pour lui la moitié ou les deux tiers du revenu de l'abbaye.

En un mot, la plupart des anciennes abbayes lucratives sont données à la faveur, et Taine, dans son Ancien régime, a pu dire assez justement: "J'ai compté quatre-vingt-trois abbayes d'hommes possédées par des aumôniers, chapelains, précepteurs ou lecteurs du roi, de la reine, des princes et princesses ; l'un d'eux, l'abbé de Vermont, a 80000 livres de rente en bénéfices. »

Considérons les sièges diocésains : à la fin de l'ancien régime, ils sont tous occupés par des nobles. Tandis qu'à l'époque de Louis XIV, des roturiers, comme Bossuet, pouvaient faire de belles carrières ecclésiastiques, au XVIII ${ }^{\mathrm{e}}$ siècle, un prêtre de grande valeur, l'abbé Beauvais, n’obtient qu'à grand'peine le misérable évêché de Senez, et, en 1789, comme le dit l'abbé Sicard, on ne trouve pas un seul évêque qui soit de condition roturière. Parcourons les listes des évêques et archevêques : on y voit éclater les noms des plus nobles et anciennes familles de France, les Montmorency, Rohan, La Rochefoucauld, Clermont-Tonnerre, Talleyrand-Périgord, si bien que les ecclésiastiques de petite ou même de moyenne noblesse (tel Boisgelin) ne parviennent pas sans peine aux sièges épiscopaux. Appartient-on à la haute noblesse, la carrière est toute tracée, rapide et triomphante : on devient archevêque ou évêque de trente à quarante ans, et même un Luynes et un Rohan ont été sacrés à vingt-six. Dans certaines familles, on voit s'accumuler les dignités ecclésiastiques : Louis de Rohan, évêque de Strasbourg, a succédé à son oncle ; à Rouen, à Beauvais, à Saintes, siègent trois La Rochefoucauld. Ce sont là des bénéfices lucratifs réservés aux cadets des grandes familles; dès l'enfance, on les destine aux grandes dignités de l'Église, on les tonsure, sans se préoccuper de leur vocation ou de leurs aptitudes. 
Le clergé régulier. - Il avait connu, dans la première moitié du $\mathrm{XVII}^{\mathrm{e}}$ siècle, sous l'influence de la contre-réforme, une époque de rénovation. Beaucoup de communautés sont alors créées : en 1602, les frères de Saint-Jean-de-Dieu, voués aux soins des malades ; en 1606, les Ursulines, destinées à l'enseignement ; en 1608, les Capucines ; en 1611, c'est la fondation par Pierre de Bérulle de la congrégation de l'Oratoire pour l'instruction des prêtres. Peu de temps après, sont institués les Filles du Calvaire, les Visitandines, puis les Lazaristes ou prêtres de la mission, les Eudistes, qui doivent se vouer à l'enseignement ; en 1686 encore, Baptiste de la Salle crée la congrégation des Frères des écoles chrétiennes. Dans beaucoup de villes, il y a un pullulement d'ordres religieux, qui possèdent de nombreux immeubles, souvent des quartiers entiers. A Dijon, par exemple, l'on compte une vingtaine d'établissements religieux: l'abbaye SaintEtienne, l'abbaye Saint-Bénigne, la Sainte-Chapelle, la Chapelle-auxRiches, les Pères de l'Oratoire, les Jésuites, les Chartreux, les Cordeliers, les Carmes, les Capucins, les Minimes, les Ursulines, les Visitandines, les Bernardines, les Carmélites, les religieuses du Refuge, les Dames de Saint-Julien, les Jacobines, la maison du Bon-Pasteur, les Lazaristes, etc.

Mais, au XVIII ${ }^{\mathrm{e}}$ siècle, et surtout dans la seconde moitié du siècle, on constate une décadence progressive, surtout au point de vue moral. Dans les anciens ordres contemplatifs ou mendiants, la discipline se relâche singulièrement et le discrédit où on les tient rend leur recrutement difficile. Les prélats eux-mêmes se montrent sévères pour les moines. C'est ainsi que l'archevêque de Tours, Conzié, écrivit, en 1778 : « La race cordière (des Cordeliers) est en cette province dans l'avilissement ; les évêques se plaignent de la conduite crapuleuse et désordonnée de ces religieux. »

L’assemblée du clergé elle-même, en 1765, demanda une réforme du clergé régulier. Le gouvernement, sans faire intervenir l'autorité pontificale dans une question de police intérieure, constitua, en 1766, une commission des réguliers, qui fonctionna jusqu'en 1789. Cette commission supprima plusieurs congrégations, réunit souvent en un seul établissement les moines dispersés dans plusieurs maisons, réduisit le nombre des religieux de 26000 à 17000 . De 1770 à 1789, le 
nombre des Bénédictins tomba de 6434 à 4 300, celui des Franciscains, de 9820 à 6 064. Cependant, le relâchement des mœurs subsista. Et il faut dire aussi que bien des moines étaient gagnés aux idées nouvelles, lisaient les écrits des philosophes, s’imprégnaient de leur doctrine ; c'est surtout parmi eux que se recrutera le clergé constitutionnel, à l'époque de la Révolution.

La décadence est moins sensible dans les communautés nouvelles, surtout dans les communautés de femmes, comme les sœurs de la Charité, de la Sagesse, du Bon Pasteur, qui s'occupent d'œuvres d'enseignement et surtout de charité. Ce sont aussi celles dont la situation matérielle est la moins prospère ; elles possèdent peu de biensfonds, seulement des rentes mobilières, et leurs principales ressources leur sont fournies par des aumônes ou par l'entretien de pensionnaires. $\mathrm{Au}$ contraire, les anciennes abbayes jouissent de revenus souvent considérables.

Le haut clergé séculier. - Les évêques, en bien des cas, disposent d'un pouvoir temporel qui leur confère des dignités et des richesses. On peut en citer un assez grand nombre qui détiennent d'anciennes seigneuries ecclésiastiques. Ainsi, l'évêque de Strasbourg, prince-évêque de Strasbourg et landgrave d'Alsace, possède en cette province de grands domaines qui lui rapportent environ 800000 livres. L'archevêque de Cambrai est duc de Cambrai, et ses domaines sont peuplés de 75000 habitants. L'archevêque de Besançon, comme l'évêque de Strasbourg, est prince d'empire.

Aux évêques et archevêques revient une bonne partie des revenus du clergé. Sans doute, à en croire l'Almanach royal, certains diocèses ne rapportent que quelques milliers de livres (ils sont aussi fort peu étendus). La plupart des évêchés bretons auraient moins de 30000 livres de revenus. Toutefois, il semble que les publications officielles sous-estiment ces revenus. Quoi qu'il en soit, nombre d'évêchés valent à leurs titulaires plus de 40000 livres de revenus : celui de Rennes, près de 60000 ; Condom, 70000 ; Verdun, 74000 ; Beauvais, 96000 ; Strasbourg, le plus opulent, 400 000. La plupart des archevêchés rapportent de 40000 à 70000 livres ; Rouen, 100000 ; Albi, 120000 ; Narbonne, 160000 ; Paris, 200 000. D’ailleurs, les évêques 
possèdent presque tous des abbayes en commende, qui doublent, en général, leur revenu, ou peu s'en faut. Ainsi, Bernis, archevêque d'Albi, touche de ce chef 100000 livres ; Dillon, archevêque de Narbonne, 120000 ; La Rochefoucauld, archevêque de Rouen, 130000. Il est vrai que les prélats sont astreints à payer d'assez nombreuses pensions, ce qui diminue leurs revenus.

Les chapitres, qu'ils dépendent d'une cathédrale ou d'une collégiale, jouissent aussi de privilèges considérables ; beaucoup de chanoines ont de riches prébendes, sans avoir à s'acquitter de lourdes fonctions. Certains chapitres ne s'ouvraient qu'à des nobles, comme ceux de Strasbourg et de Lyon. Les chapitres nobles de femmes, comme ceux de Remiremont ou d'Épinal, n'astreignaient leurs titulaires qu'au célibat temporaire et à l'assistance à quelques messes : « elles répudiaient toutes les gênes religieuses, a-t-on dit, pour n'en garder que les avantages matériels »; c’étaient des "séminaires de filles à marier ». Les privilèges excessifs des chapitres de toute catégorie constituaient l'un des abus contre lesquels l'opinion se prononçait de plus en plus vivement au cours du XVIII ${ }^{\mathrm{e}}$ siècle.

Mode de vie du haut clergé. — Un assez grand nombre d'évêques et d'archevêques mènent un grand train, tiennent table ouverte, ont hôtel à Paris, fastueuse maison de campagne. C'est en grand seigneur que vivait le cardinal de Brienne, dans son domaine de Brienne ; Dillon, à Hautefontaine, en Picardie, menait une vie beaucoup plus amusante qu'épiscopale ; on y chassait trois fois par semaine, on y jouait la comédie. A Saverne, le cardinal de Rohan, évêque de Strasbourg, donnait des fêtes magnifiques, recevant souvent des centaines d'hôtes.

Sans doute, un faste aussi considérable est plutôt exceptionnel. Mais beaucoup de prélats ne s'acquittent que d'une façon fort tiède de leurs fonctions. Ils résident souvent plutôt à Paris que dans leurs diocèses ; en 1764, on constate dans la capitale la présence de plus de quarante évêques, et il n'est guère de moment où on n'en compte une vingtaine. Bien des prélats ne prêchent que rarement, n’administrent les sacrements que de loin en loin, ne font presque jamais de visites pastorales, et confient l'administration de leurs diocèses à des vicaires généraux ou à des suffragants. 
On reproche aussi au haut clergé de ne s’acquitter que médiocrement des obligations attachées à sa charge ou aux dîmes qu'il perçoit. Il ne se soucie que médiocrement de l'entretien du culte et moins encore de ses devoirs de charité. Les gros décimateurs ne soulagent guère les pauvres : le clergé paroissial le constate souvent et le déplore. Cependant, vers la fin de l'ancien régime, des prélats se montrent plus compatissants, font construire de leurs deniers des hôpitaux, se préoccupent de la création de bureaux d'aumônes dans les campagnes. Mais ce n'est, semble-t-il, qu'une minorité.

L'enseignement était à la charge du clergé, qui avait la haute main sur les écoles publiques et privées, nommait les maîtres. Mais les écoles populaires étaient encore peu nombreuses, si on en excepte, jusqu'à un certain point, l'Est de la France. L'instruction y était fort médiocre et, dans les campagnes, les illettrés constituaient la grande majorité de la population.

On ne s'étonnera donc pas que beaucoup de cahiers, en 1789, demandent que les biens ecclésiastiques soient consacrés à l'assistance et à l'enseignement, que les dîmes « soient rendues à leur destination primitive ».

Les évêques administrateurs. - Cependant, vers la fin de l'ancien régime, un certain nombre d'évêques s'intéressent à l'administration temporelle de la région où se trouve leur siège épiscopal. Dans les pays d'États, en Bretagne et plus encore dans le Languedoc, ils participent activement aux assemblées de la province. En ce dernier pays, bien des évêques s'occupent de la construction des routes, de la mise en valeur des terres incultes, de l'entretien des canaux.

Un Champion de Cicé, d'abord comme évêque de Rodez, puis comme archevêque de Bordeaux, se distingue par ses qualités d'administrateur et se trouve tout désigné, à l'époque de la Constituante, pour devenir garde des sceaux. L'archevêque de Toulouse, Loménie de Brienne, avait fait œuvre utile dans son diocèse avant de devenir premier ministre aux derniers temps de la monarchie. Boisgelin, l'archevêque d'Aix, fut aussi un administrateur habile et jouit d'une grande popularité en Provence, à la veille de la Révolution. 
Champion de Cicé et Boisgelin représentent dans le haut clergé la tendance libérale ; ils sont partisans de ce "gallicanisme épiscopal », qui pourra s'épanouir à l'époque napoléonienne, sous le régime du Concordat ; ils formeront comme le lien entre le clergé d'ancien régime et le clergé de la France contemporaine.

Un autre type d'évêque administrateur, mais assez différent de Boisgelin et de Champion de Cicé, c'est J.-F. de la Marche, évêque de Saint-Pol-de-Léon. Il joue un rôle considérable à toutes les sessions des États de Bretagne, où il montre un talent remarquable de tacticien, au grand profit de son ordre; à plusieurs reprises, il s'efforce d'atténuer les dissentiments qui s'élèvent entre la noblesse et le tiers état, entre l'assemblée et le gouvernement royal ; à plusieurs sessions, on le voit présider avec une grande compétence la commission des finances. A la différence de Boisgelin et de Champion de Cicé, il ne fréquente guère la Cour ; pendant vingt ans, il réside d'une façon presque continue dans son diocèse ; il s'occupe en conscience de ses devoirs épiscopaux, faisant régulièrement ses visites pastorales, veillant aux progrès des études ecclésiastiques, à la formation des prêtres, reconstituant, en grande partie de ses deniers, le collège de Saint-Polde-Léon. Il se soucie beaucoup aussi de charité et essaie de créer de nouveaux établissements d'assistance. Sans doute, le cas de Mgr de la Marche n'est pas aussi exceptionnel qu'on pourrait le penser ; mais les prélats, qui se sont acquittés sérieusement de leurs devoirs, ont moins frappé les imaginations des contemporains que les brillants prélats, dont le faste attirait les regards. Puis il ne sont pas gagnés par les idées libérales, ils ne flattent pas l'opinion publique. Mgr de la Marche n'a cessé de se dresser contre le nouvel ordre de choses, d'être hostile à tout projet de réforme ; il sera l'un des plus ardents à repousser la Constitution civile ; dans le monde des prêtres émigrés, à Londres, il représentera le parti des intransigeants, refusera de reconnaître le Concordat et mourra farouchement dans l'exil.

Il ne faut pas, d'ailleurs, se faire illusion sur le libéralisme du haut clergé ; il a protesté presque tout entier contre l'octroi de l'état civil aux protestants ; s'il s'élève contre le despotisme, c'est qu'il sent ses privilèges menacés par les ministres réformateurs. Même à la veille de la Révolution, il se montre toujours aussi hautain à l'égard du bas clergé. 
Le bas clergé. - Le bas clergé était loin de former une classe uniforme. On y distinguait essentiellement les curés, les vicaires, les prêtres habitués.

Parmi les curés, il en est d'aisés, même de riches, surtout les curés des villes, qui trouvent des ressources assurées dans le casuel. Mais beaucoup ne jouissent que du revenu médiocre de quelques dîmes, que leur laissent les gros décimateurs. Dans les districts de Rennes, Fougères et Vitré, $M$. Rebillon a pu établir que 44 recteurs jouissaient d'un revenu inférieur à 1000 livres, 56 recevaient de 1000 à 2000 livres par an, 30, de 2000 à 4000 livres, 14 seulement, plus de 4000 livres. Nombreux étaient les prêtres qui n’avaient pour vivre que leur portion congrue. Fixée pour les curés à 300 livres par la déclaration de 1686, à 500 livres pour les curés, et à 200 pour les vicaires, en 1768, cette portion congrue fut portée, pour les premiers à 750 livres, et à 300 livres pour les seconds, en 1786 ; mais le prix de la vie avait notablement haussé à la fin de l'ancien régime. Les congruistes vivaient misérablement.

Les vicaires, dont la plupart n'avaient aucun espoir d'obtenir une cure, formaient un véritable prolétariat ecclésiastique, sur lequel le plus souvent tombait toute la charge des fonctions paroissiales. Les prêtres "habitués ", vivant de quelques fondations, du produit de quelques messes, étaient encore plus malheureux.

Le bas clergé, si mal rétribué, supporte une bonne partie des décimes ordinaires et extraordinaires que l'ordre doit acquitter. Il y a la plus grande inégalité dans la répartition, non seulement entre le haut et le bas clergé, mais dans les rangs mêmes du bas clergé, bien que les congruistes soient généralement ménagés.

La vie du bas clergé d'après un contemporain. - Un chanoine de l'abbaye de Beauport, située dans le diocèse de Saint-Brieuc, nous a laissé une description très vivante de la situation du bas clergé dans cette partie de la Bretagne :

«Bien différentes des cures de Normandie, la plupart amplement dotées, les 
nôtres étaient généralement pauvres ou médiocres... Il y avait cependant des curés décimateurs, mais en petit nombre, par comparaison aux congruistes, et presque toujours dans de petites paroisses où la valeur de la dîme n'était souvent que l'équivalent de la portion...

«Dans Tréguier, il se trouvait peut-être une dizaine de cures depuis 100 louis jusqu'à 4000 livres. Aussi étaient-elles réputées places de faveur et remplies communément par des nobles ; on les nommait paroisses d'abbés que la Révolution déposséda...

« Saint-Brieuc comptait peu de paroisses où la dîme et le casuel donnassent mille écus au titulaire. On en nommait six ou sept, dont deux occupées par des nobles et deux par des réguliers. Quelques-unes rapportaient 100 louis, 2000 livres, d'autres de 1500 à 1800 livres et celles-ci étaient réputées très bonnes. Les médiocres étaient de 1200 à 1500 l., et le plus grand nombre, de 1000 à 1200 l. Il en était même beaucoup au-dessous de ce même produit. Là où le curé ne touchait que la congrue de 500 l., il fallait, pour doubler la somme, qu'outre les 180 l. auxquelles montaient ses messes à 12 sols, il tirât 320 l. de l'église, soit en tiers d'oblations, objet ordinairement peu considérable, soit en baptêmes de 6 ou 8 sols, en mariages à 40 sols, en droits, sépultures et assistance aux services fixés à 16 sols, ce qui dépendait de l'aisance et de la population des paroisses.

« Tel était, avant la Révolution, le sort de nos curés et la perspective de leurs vicaires. Heureux dans un concours où, après dix ou douze ans de service et de bonne conduite, ils obtenaient une paroisse, il fallait commencer à s'établir et à se meubler, à quoi suffisait à peine le produit de leurs épargnes. S'ils n'en avaient pas, ils contractaient des dettes à payer sur le futur revenu. Des neveux, des nièces, des parents arrivaient au presbytère, car un recteur était de droit curé riche et l'appui naturel des siens. Aussi combien en voyait-on de mal à l'aise, même en d'assez bonnes paroisses, à moins qu'ils n'eussent beaucoup d'ordre et d'économie. »

Relations du bas clergé avec le haut clergé. — Le bas clergé ne participe en aucune façon à l'administration de l'ordre. Dans les assemblées diocésaines réunies pour la répartition du décime, les prêtres des paroisses ne figurent qu'à titre exceptionnel et jamais comme représentants de leurs confrères. Dans les assemblées d’États, en Bretagne et en Languedoc, il ne participent pas à l'élection des députés du clergé.

Les évêques ne montrent que bien rarement des égards aux curés de leur diocèse ; ils estiment qu'ils sont d'une autre race qu'eux ; ils ne les reçoivent jamais à leur table. Un évêque, qui cependant s'est 
montré fort aimable pour ses curés, déclare : « ils sont grossiers, malpropres, ignorants, et il faut bien aimer l'odeur empestée de l'ail pour se plaire dans la société des médiateurs du ciel et de la terre ».

Les ressentiments du bas clergé. - Les curés, à la fin de l'ancien régime, commencent à se révolter contre cette attitude de leurs évêques et à comparer leur sort misérable avec l'opulence de leurs supérieurs. Le curé de Marolles, en Normandie, en 1789, exprime bien les sentiments de beaucoup de ses confrères :

« Nous, malheureux curés à portions congrues, nous, chargés communément des plus fortes paroisses, nous, dont le sort fait crier jusqu'aux pierres et aux chevrons de nos misérables presbytères, nous subissons des prélats qui feraient encore faire par leurs gardes un procès au pauvre curé qui couperait dans leurs bois un bâton, son seul soutien dans ses longues courses par tous chemins... A leur passage, il est obligé de se jeter à tâtons le long d'un talus, pour se garantir des pieds et des éclaboussures de leurs chevaux, comme aussi des roues et peut-être du fouet d'un cocher insolent, puis, tout crotté, son chétif bâton d'une main et son chapeau, tel quel, de l'autre, de saluer humblement et rapidement, à travers la portière du char clos et doré, le hiérarque postiche ronflant sur la laine du troupeau que le pauvre curé va paissant et dont il ne lui laisse que la crotte et le suint. »

Les curés, à plusieurs reprises, osent s’assembler pour rédiger leurs réclamations, pour demander notamment une augmentation de leur portion congrue, comme le firent les curés de Provence et du Dauphiné, en 1779. C’est en vain que les évêques obtiennent du roi, en 1782, une déclaration interdisant aux curés de s’assembler. Le bas clergé se montre de plus en plus hostile au haut clergé, de plus en plus favorable aux revendications du tiers état. Témoin la brochure qui parut à la veille de la Révolution, et qui était intitulée : Les curés du Dauphiné à leurs confrères les recteurs de Bretagne. On y pouvait lire ce passage caractéristique :

« Les évêques sont les chefs de la hiérarchie ecclésiastique, mais, en matière civile et politique, ils ne sont que des citoyens comme nous... Qu'ils nous laissent le droit d'avoir des sentiments à nous... L'intérêt du peuple et celui des curés sont inséparables. Si le peuple sort de l’oppression, les curés sortiront de l'avilissement dans lequel le haut clergé les a plongés. » 
Les curés et les élections aux États Généraux. - Ces sentiments devaient se faire jour au moment de la convocation des États Généraux. Il ne s'est conservé, il est vrai, qu'assez peu de cahiers du bas clergé ; les assemblées diocésaines, où dominait le haut clergé, n’avaient nul intérêt à les garder. Il en subsiste cependant. Tels, ces intéressants cahiers des curés du bailliage d'Auxerre, que M. Porée a publiés. Tels, les cahiers du bas clergé breton, car si, en Bretagne, le haut clergé devait, comme la noblesse, tenir son assemblée électorale à part (à Saint-Brieuc), le bas clergé forma des assemblées diocésaines, dans lesquelles il élut ses députés.

Voici, par exemple, les principales revendications du cahier du diocèse de Rennes :

«Que l'on ne reconnaisse plus dans le clergé d'autres distinctions que celles de la hiérarchie ; par là on verra disparaître une foule d'abus, qui frappent tous les yeux et révoltent tous les esprits. »

Qu'on remédie aux abus qui se sont glissés dans l'élection des évêques et la collation des bénéfices. Mais c’est surtout la question des dîmes qui tient au cœur des curés du diocèse de Rennes :

"Que les dîmes, enlevées aux pasteurs et aux pauvres, leur soient enfin restituées, comme aux seuls qui puissent les posséder légitimement. »

Qu'on dédommage les « communautés régulières » par l'« union des bénéfices simples ». Surtout que l'on pourvoie au sort des recteurs congruistes. En un mot, qu'on procède à une "plus égale répartition des biens ecclésiastiques ".

Qu'on renonce à donner à la faveur les dignités ecclésiastiques : «Que les canonicats et dignités des cathédrales ne soient accordés à l'avenir qu’à ceux qui auront blanchi dans les pénibles travaux du ministère. »

Le clergé du royaume devra renoncer à tous ses privilèges pécuniaires. Mais, si on conserve les décimes, que leur rôle soit communiqué à tous les contribuables, car on ne peut refuser à ceux-ci «ni le droit, ni les moyens de juger les opérations de ceux qui les représentent ». 
En ce qui concerne « les affaires civiles et politiques », le clergé du diocèse de Rennes émet des vœux analogues à ceux du tiers état. Il réclame la périodicité des États Généraux, la suppression des impôts actuels, l'établissement d'une constitution, l'égalité des droits politiques « sans distinction d'ordre ", l'égalité de tous devant « les charges publiques », proportionnellement aux facultés de chacun. Que la liberté individuelle des citoyens soit garantie, " mise à l'abri des lettres de cachet et de tous ordres arbitraires ». Que l'on délivre aussi le commerce « de toutes les entraves de la fiscalité et du monopole ». Comme les cahiers des paysans, le clergé réclame l'établissement dans les campagnes de sages-femmes instruites et capables. Enfin, il demande que "pour régénérer le peuple français, on travaille à perfectionner l'éducation, et dans les villes, et dans les campagnes ».

On comprend alors le rôle que doivent jouer les curés élus aux États Généraux. Ce sont eux qui, en se séparant de l’ordre du clergé, en se réunissant au tiers état, décideront du sort de la Révolution, assureront le triomphe de l'Assemblée Nationale.

Table des matières

\section{Ouvrages à consulter}

Collection des procès-verbaux des assemblées du clergé de France depuis 1560, 1777-1780, 9 vol. in-fol.

CANS, L'Organisation financière du clergé, 1909.

Mention, Documents relatifs aux relations du clergé et de la royauté de 1682 à 1789, 2 vol., 1893-1903.

TAINE H., L'Ancien Régime.

LAVISSE E., Histoire de France, t. IX.

Rebillon A., La Situation économique du clergé dans les districts de Rennes, Fougères et Vitré, 1913 (Coll. Doc. écon. de la Révolution).

KeRBIRIOU L. (Abbé), Jean-François de la Marche, évêque-comte de Léon (17291806), Paris, 1924.

CHAssin, Les Cahiers des curés, Paris, 1882.

Marion M., La Vente des biens nationaux, Paris, 1908.

Dubreuil L., La Vente des biens nationaux dans les Côtes-du-Nord, Paris, 1913.

SicARD (Abbé), L’Ancien Clergé de France, 2 vol., 1893-1894. 
GÉRIN, La Commission des réguliers (Revue des Questions historiques, 18751877).

MAthieu (Cardinal), L'Ancien Régime dans tes provinces de Lorraine et Barrois, $2^{\mathrm{e}}$ éd., 1907.

LÉVY-SCHNEIDER, L'Application du Concordat par un prélat d'ancien régime, Mgr Champion de Cicé, Paris, 1922.

LAVAquery (Abbé), Le Cardinal de Boisgelin, 2 vol., Paris, 1921.

LAVEILlE, Les Revenus du clergé breton avant la Révolution (Revue des questions historiques, oct. 1912).

SÉE H. et LESORT A., Cahiers de doléances de la sénéchaussée de Rennes, t. IV, 1912 (Coll. des Doc. écon. de la Révolution).

PORÉE Ch., Cahiers des curés et communautés ecclésiastiques du bailliage d'Auxerre en 1789, Auxerre, 1927 (Coll. des Documents économiques de la Révolution).

Pocouet Du Haut-Jussé B. (fils), La Vie temporelle des communautés de femmes à Rennes au XVII ${ }^{\mathrm{e}}$ et au XVIII ${ }^{\mathrm{e}}$ siècles (Annales de Bretagne, t. XXXI et XXXII).

DONAT Jean, Une Abbaye cistercienne et son budget au XVIII siècle, Toulouse, 1935.

De VAissière P., Les Curés de campagne de l'ancienne France, Paris, 1933, in$8^{0}$.

Guilhamon H., La Situation matérielle du Haut Clergé quercynois au moment de la Révolution (Coll. des Documents économiques de la Révolution). 


\section{Chapitre 4}

\section{LA NOBLESSE.}

Les sources de la noblesse. - En théorie, le fondement de la noblesse, c'est la naissance. On est noble « de race », quand on peut faire remonter sa noblesse à quatre générations nobles, au moins ; et un gentilhomme est d'autant plus réputé qu'il peut compter un plus grand nombre d'aïeux nobles.

Mais, en fait, la noblesse comprend une quantité plus ou moins considérable d'anoblis. Et il en a toujours été ainsi. A l'origine de la féodalité, l'homme qui a pu s'équiper, servir comme cavalier, quelle que fût son origine, est devenu le vassal d'un chef de guerre. Ses services ont été récompensés par l'octroi d'un fief. Les possesseurs de fiefs ont alors prétendu former une classe fermée ; mais celle-ci devait admettre dans ses rangs des acquéreurs de terres nobles, des hommes qui avaient été anoblis par le prince ou par le roi.

Les lettres de noblesse, qu'on achète le plus souvent à prix d'argent, sont devenues de plus en plus nombreuses à partir du $\mathrm{XVI}^{\mathrm{e}}$ siècle ; sous Louis XIV, la «finance » à payer par l'anobli n'était que de 6000 livres ; et, comme le dit Voltaire, dans l'Essai sur les mœurs, « un nombre prodigieux de citoyens, banquiers, chirurgiens, marchands, domestiques de princes, commis ont obtenu des lettres de noblesse » et ont fait souche de gentilshommes.

Il y a aussi nombre d'offices ou de charges de l'État qui confèrent la noblesse héréditaire : telles, les charges de chancelier, de garde des sceaux, de secrétaire d'État, de gouverneur, de commandant en chef, de président de Cours souveraines. Les offices de la haute magistrature ont fini par conférer la noblesse à leurs titulaires ; c'est ainsi qu'au $\mathrm{XVIII}^{\mathrm{e}}$ siècle, on ne trouve plus guère que des nobles parmi les mem- 
bres des Parlements, et la règle s'établit notamment au Parlement de Bretagne, que les sièges des magistrats ne peuvent être conférés qu'à des gentilshommes. Même des charges à peu près inutiles, comme celles de secrétaires $d u$ roi, qui ne demandaient aucun travail, conféraient la noblesse, et elles étaient fort nombreuses, plus de 900, déclare Necker. Il est vrai qu'elles coûtaient 120000 livres, mais elles permettaient à tout roturier enrichi de pénétrer dans les rangs de la noblesse. Il en était de même des charges de bureau des finances, au nombre de 740. Ajoutons que les offices municipaux, très nombreux, conféraient, en général, la noblesse. La noblesse de robe, la noblesse de cloche, d'abord distinctes de la noblesse d'épée, finissent par se confondre avec elle.

Enfin, on peut devenir noble par l'acquisition d'une terre noble, d'une seigneurie. La possession des droits seigneuriaux confère à la longue la noblesse, bien que l'ordonnance de Blois, de mai 1579, l'ait interdit. Mais, en fait, les roturiers prenaient les noms des fiefs qui leur appartenaient et usurpaient peu à peu la noblesse.

Il y a eu, depuis le moyen âge, une accession plus ou moins lente du tiers état à la noblesse. M. Mireur, dans son Tiers état à Draguignan, montre qu'en cette ville, vers 1789, sur 25 familles fieffées, 18 sortaient de la roture. Souvent, les marchands, quelquefois même les plus riches des artisans, poussent leurs fils aux charges de judicature, qui confèrent la noblesse. Parfois même, des fils de paysans aisés parviennent aux fonctions honorifiques. G. Roupnel, dans sa thèse si intéressante sur les Populations du pays dijonnais, montre bien fortement cet état d'instabilité des familles nobles.

L'ancienne noblesse militaire, puis la noblesse administrative du $\mathrm{XV}^{\mathrm{e}}$ siècle disparaissent en grande partie ; elles sont presque entièrement remplacées par une noblesse nouvelle, en grande partie d'origine parlementaire. Or, la plupart des hauts magistrats descendent de familles de riches marchands de Dijon ou des villes de la province. Au XV siècle et au $\mathrm{XVI}^{\mathrm{e}}$, les barrières entre les diverses classes sociales sont bien plus fragiles qu'elles ne le seront à l'époque de Louis XIV ; depuis le $\mathrm{XVII}^{\mathrm{e}}$ siècle, ces classes tendent de plus en plus à former des castes fermées. 
Les réformations de la noblesse. - Il est vrai qu'à plusieurs reprises, le pouvoir royal essaya de sévir contre les " usurpateurs » de noblesse, en faisant faire des réformations. Il y en eut au XVI ${ }^{\mathrm{e}}$ siècle, et plus fréquemment encore au $\mathrm{XVII}^{\mathrm{e}}$, notamment sous le règne de Louis XIV. Mais ce furent surtout des mesures fiscales. On raya des rangs de la noblesse les gentilshommes qui dérogeaient, c'est-à-dire qui se livraient au négoce, bien que Colbert leur eût accordé, en 1669, le droit de se livrer au commerce maritime sans perdre leur qualité ; on exclut aussi ceux que leur pauvreté empêchait de produire leurs titres et de payer les droits que cette production comportait. Les magistrats, qui composaient surtout les commissions de réformation, étaient, pour la plupart, des membres des Parlements ; ils se montrèrent, notamment en Bretagne, très complaisants à l'égard de leurs confrères et très durs pour les juges des cours subalternes. Pendant ce temps, l'on continuait à conférer, à prix d'argent, des lettres de noblesse. Les réformations eurent surtout pour effet de rendre oisive la noblesse, qui ne pouvait plus trouver qu'à l'armée d'occupation compatible avec sa dignité. Et le fossé se creusa, plus profond, entre la noblesse et le tiers état. Telles sont les conclusions qui se dégagent surtout d'une récente étude, très approfondie, de M. Bourde de la Rogerie sur la réformation de la noblesse en Bretagne. A la fin de l'ancien régime, d'Hozier, par ses verdicts sur les quartiers de noblesse, tient vraiment à sa merci tous ceux qui aspirent à exercer une charge militaire.

En réalité, tous les hommes qui sont parvenus à une notable fortune arrivent à pénétrer dans les rangs de la noblesse, ce qui leur confère des privilèges de toutes sortes, et surtout des privilèges pécuniaires. Aussi Turgot, en 1776, a-t-il pu déclarer très justement que « le corps des nobles ", exempts des charges roturières, comprend « tout le corps des riches », et que " la cause des privilégiés est devenue la cause du riche contre le pauvre ». Tous ces nouveaux nobles, comme il arrive toujours en pareil cas, tiennent encore plus à leurs droits, sont plus entichés de leurs titres honorifiques que les nobles d'ancienne extraction.

Nombre des nobles. - Par tout ce qui précède, on peut comprendre aisément combien il est difficile de fixer le nombre des nobles sous l'ancien régime. L’évaluation la plus vraisemblable, c'est celle 
de l'abbé Coyer dans sa Noblesse commerçante, de 1756, et du marquis de Bouillé, dans ses Mémoires, qui déclarent qu'il y avait 80000 familles nobles comprenant environ 400000 individus. Mais on n'a dressé aucune statistique, et, en l'état de nos connaissances, il est impossible de fixer véritablement un chiffre, comme on a pu le faire pour l'ordre du clergé.

Les privilèges de la noblesse. - Ces privilèges sont nombreux et importants. Tout d'abord, la plupart des nobles sont seigneurs de fiefs et, à ce titre, qu'ils soient riches ou pauvres, ils jouissent des droits seigneuriaux, dont on a décrit plus haut le caractère et la nature. Certains seigneurs, à peu près dépourvus de domaine proche, ne possèdent que ces droits pour vivre et les exigent avec d'autant plus d’âpreté.

Aux droits seigneuriaux se rattachent les prééminences honorifiques, telles que le droit de porter des armoiries, d'avoir un banc seigneurial dans l'église paroissiale, des sépultures particulières ou enfeux. Ces prééminences sont plus importantes qu'on ne se l'imagine ordinairement ; elles suscitent bien des procès entre gentilshommes, mécontentent les paroissiens, et on ne s'étonnera pas qu'à l'époque révolutionnaire les troubles agraires aient souvent débuté par la destruction des bancs seigneuriaux, des armoiries, des girouettes seigneuriales, etc.

Plus importantes encore apparaissent les exemptions de charges fiscales dont jouit la noblesse, c'est-à-dire de la taille, de la corvée des grands chemins, du logement des gens de guerre, etc. Lorsque la royauté, poussée par le besoin d'argent, créa de nouveau impôts, la capitation et les vingtièmes, qui devaient peser sur tous les sujets, on comprend les efforts tentés par les nobles pour s'en exempter, ou, tout au moins, pour n'en acquitter qu'une part infime. En fait, il y eut un rôle spécial de capitation pour les gentilshommes, et ceux-ci, en ce qui concerne les vingtièmes, ne furent pas taxés proportionnellement à leurs revenus, en dépit des vérifications des rôles, qui furent entreprises, surtout à la fin de l'ancien régime.

En matière de justice, les nobles ne doivent comparaître qu'aux sièges des baillis et des sénéchaux, et, quand ils sont accusés d'un 
crime, ce sont les Parlements qui doivent juger leur cas. Condamnés à mort, ils ont le privilège d'échapper à la pendaison : ils ne peuvent être que « décollés ».

Enfin, c'est aux nobles, on le sait, que sont réservés les gros bénéfices ecclésiastiques, les prélatures et aussi les hautes charges militaires. Dans beaucoup de familles nobles, on tonsurait les cadets et on espérait que les bénéfices qui leur seraient conférés resteraient en leur possession, même s’ils renonçaient à la carrière ecclésiastique.

Plusieurs catégories dans la noblesse. Les présentés à la cour. - La noblesse ne forme pas, d'ailleurs, une classe homogène. Parmi les gentilshommes, il y a des privilégiés. Ce sont d'abord ceux qui ont été présentés au roi et à la reine.

«La présentation des hommes, dit M. Carré dans son livre sur la Noblesse de France et l'opinion publique au XVIII siècle, consistait à chasser avec le roi, à monter ses chevaux de chasse, à monter dans ses carrosses. » La femme " admise en présentation » offrait ses joues au roi, à la reine, au dauphin et aux princes. Vers la fin de l'ancien régime, on comptait 4000 familles présentées, représentant environ 20000 personnes. Un règlement de 1760 essaya d'en limiter le nombre en édictant que, pour être présenté, il fallait appartenir à une famille remontant au-delà de l'an 1400. Mais, si on l'avait appliqué rigoureusement, plus d'un tiers des familles admises à la cour auraient dû en être exclues. Louis XV lui-même décida donc, en 1774, que seule la décision royale déciderait de la présentation.

En fait, sous Louis XVI, il y eut plus de présentations que jamais. Beaucoup de gentilshommes de province sollicitèrent cet honneur ; c'est ainsi que Chateaubriand, en 1787, fut présenté à Louis XVI ; il raconte la scène d'une façon pittoresque dans ses Mémoires d'Outretombe.

La présentation n'est pas seulement un honneur. Elle confère des avantages considérables, notamment dans l'armée ; elle permet de briguer les hautes charges militaires ; eût-on tout le mérite du monde, on ne peut dépasser le grade de colonel si l'on n’a pas été présenté : 
«Un lieutenant d’infanterie du nom de Montfalcon, nous raconte M. Carré, bien qu’il ait été remarqué par le maréchal de Ségur, n’arrive à rien, ou peu s'en faut; on le fait chevalier de Saint-Louis, major d'une petite garnison, mais il s’arrête là, parce qu’il n’est pas « présenté ». Or, il découvre chez une tante, aux environs de Nîmes, une liasse de parchemins établissant qu'il descend de l'ancienne famille d'Adhémar ; il accourt à Paris, soumet les pièces à Chérin, qui les déclare authentiques ; il est « présenté », devient colonel ; puis, comme il est souple et fin, d'allures discrètes, avec des airs d'homme du monde, il épouse une riche veuve, dame d'honneur de la Dauphine, et le voici ministre de Louis XVI à Bruxelles. »

On comprend alors que, sous Louis XVI, c’ait été une « fureur », parmi les gentilshommes de province, de se faire présenter. Chérin le déclare nettement dans son livre, publié en 1788, sur La noblesse considérée dans ses divers rapports : «On estime moins un noble par ce qu'il vaut que par le nombre d'années de noblesse qu'il peut prouver... Dans certaines sociétés, on se met sur le pied de ne recevoir que des gens présentés et de fermer impitoyablement sa porte à de bons et honnêtes gentilshommes. » Et c’est encore en 1781 qu’on décida de n'admettre comme officiers que les nobles pouvant prouver quatre quartiers de noblesse. On s'explique alors l’hostilité croissante de la noblesse provinciale contre la noblesse de cour.

La noblesse de cour. — C'est, en effet, à la noblesse de cour que vont les plus grands privilèges, les charges et les pensions lucratives.

Dans cette classe, les fortunes de 100000 à 150000 livres de rente sont fréquentes, et il en est de bien plus considérables. Le duc d'Orléans, petit-fils du Régent, avait, en 1753, trois millions de revenus ; à l'époque de Louis XVI, la maison d'Orléans, unie à celle de Penthièvre, jouissait d'environ 8 millions de rente. On estime les revenus de la maison de Condé, au XVIII ${ }^{\mathrm{e}}$ siècle, à 1500000 livres, ceux des Conti, à 600000 livres. Les ducs de Bouillon et de Mortemart ont 500000 livres de rente; le duc de Chevreuse, 400000 ; le duc de Grammont, 300000 ; le duc de la Trémoille, 200000 ; le marquis de Villette, 150 000. La noblesse de robe compte aussi de grandes fortunes : les Le Pelletier de Saint-Fargeau avaient 600000 livres de rente ; le premier président d'Aligre était riche, dit-on, de 6 à 7 millions ; les 
d’Éprémesnil, Joly de Fleury, Hérault de Séchelles étaient aussi fort opulents.

D'ailleurs, les familles de la haute noblesse redorent souvent leur blason grâce aux fortunes des gens de finance, avec lesquels elles contractent des alliances. Que l'on songe à la richesse d'un Samuel Bernard (33 millions), d'un Bouret (42 millions), d'un Pâris de Montmartel (100 millions), d'un Lenormand de Tournehem (20 millions). Non seulement les filles de financiers épousent des nobles, mais souvent les financiers se font anoblir et font souche de gentilshommes.

Le train de vie de la haute noblesse. - Beaucoup de membres de la haute noblesse mènent un train de vie fastueux, qui les ruine. Les mémoires du temps nous montrent le luxe des habits et des robes, car les vêtements des hommes rivalisent avec ceux des femmes en ornements coûteux. On pense ce que peuvent valoir des habits de drap d'argent et d'or, garnis de point d'Espagne. Des robes de bal sont payées fréquemment 1500, 2000 livres. Et que dire des trousseaux des mariées ? Celui de $\mathrm{M}^{\text {lle }}$ de la Briffe, fille du premier président au Parlement de Bretagne, est estimé plus de 21000 livres en 1781 ; celui de $\mathrm{M}^{\text {lle }}$ Billon, 45000 , en 1787 ; celui de $\mathrm{M}^{\text {lle }}$ de Mondragon, 100000 livres, en 1784.

Les nobles de la cour tiennent à honneur d'avoir les plus beaux chevaux, les carrosses les plus élégants, souvent tapissés de velours et décorés de panneaux peints. Le luxe de la table est surtout l'apanage des magistrats et des financiers. Il faut aussi une domesticité énorme : il n'est pas rare de trouver, dans une maison noble, 30 ou 40 valets, sans compter les femmes de chambre, les maîtres d'hôtel. Enfin, il est de bon ton d'entretenir des maîtresses, à qui l'on donne des pensions fastueuses, sans compter les cadeaux :

« Le prince de Soubise, dit l'acteur Fleury, ne se contentait pas de jeter l'or à pleines mains sous les pas des reines de boudoir, - elles étaient une douzaine -; comme il donnait à chacune le même état de maison, la même livrée, et un équipage en quelque sorte uniforme, on disait, quand on voyait passer les voitures de ses maîtresses : voici la maison Soubise!» 
Quand le président de Rieux, en 1743, congédie la Camargo, il lui fait don de 120000 livres.

Les réceptions de la vie mondaine n'entraînent pas moins de dépenses, qu'il s'agisse de dîner, de bals ou de représentations théâtrales, de chasses. Un souper où le prince de Soubise invite le roi, à Saint-Ouen, en 1749, ne coûte pas moins de 200000 livres. Choiseul, à Paris, puis dans sa retraite de Chanteloup, tient table ouverte ; il reçoit tous les soirs, donne des soupers et des concerts; son train de vie est tel que ses 800000 livres de rente ne lui suffisent pas. A Chantilly, dans l'admirable domaine des Condé, ce sont, à tout instant, des fêtes splendides.

La vie de château est, en effet, tout aussi dispendieuse que l'existence parisienne. On a souvent décrit les splendeurs du château de Sceaux, résidence de la duchesse du Maine, de Chambord, qui appartint au maréchal de Saxe, du château de Pontchartrain, où Maurepas réunit une véritable cour, de Chanteloup. Non moins splendide est le château de Brienne, où le comte de Brienne et son frère, l'archevêque, donnent des fêtes splendides :

« On arrivait au château de Brienne, nous dit M. Henri Carré, par une longue avenue bordée de tilleuls, de lilas et de gazons. Au rez-de-chaussée étaient les pièces d'apparat, salle à manger pour quatre-vingts personnes, grand salon donnant sur l'avenue et les jardins, salle de billard, bibliothèque à galeries circulaires, cabinet d'histoire naturelle, cabinet de physique expérimentale, salle de spectacle pouvant se transformer en salle de bal, si l'on mettait la scène au niveau du parterre ; dans un souterrain, au-dessous, salle de bal pour la domesticité. Au rez-de-chaussée encore, appartement de la comtesse. En avant du château, du côté de la cour d'honneur, deux grands pavillons, divisés en appartements. »

A Brunoy, près de Paris, le financier Pâris de Montmartel a dépensé 10 millions ; à Méréville, en Beauce, le banquier de la Borde, pour faire un parc « à l’anglaise », a englouti 14 millions.

Dans toutes ces résidences, et même dans des maisons des champs moins fastueuses, ce ne sont que fêtes, représentations théâtrales, chasses magnifiques. Le marquis de Mirabeau a pu dire justement, dans son Ami des hommes, que, " par la vie qu'ils mènent dans leurs 
châteaux, les grands seigneurs ruinent les paysans et se ruinent euxmêmes ".

Les plus riches sont mangés de dettes. A leur mort, en 1740 et 1741, le duc de Bourbon et le prince de Carignan doivent chacun 5 millions. Vers 1750, le duc d'Antin doit 900000 livres ; Choiseul, en 1785, laisse 6 millions de dettes. Certains ne peuvent faire face à leurs engagements et font des faillites retentissantes : tel, le prince de Guéméné, qui doit plus de 32 millions. Et bien des magistrats parisiens, comme les premiers présidents de Mesmes et Maupeou, se sont ruinés, parce qu'ils ont voulu vivre comme de grands seigneurs.

Les pensions royales. - On comprend alors que cette haute noblesse cherche à accroître ses revenus en quémandant des pensions. Les princes du sang sont les premiers à en recevoir, et les plus fortes. Le comte de Toulouse, qui a 1700000 livres de revenu, touche cependant 100000 livres sur le Trésor. Le prince de Condé, dont on a vu l'énorme fortune, reçoit 260000 livres par an. Le duc de Chartres, fils du duc d'Orléans, se fait donner, en 1747, une pension de 150000 livres. Sous le règne de Louis XVI, le comte d'Artois et le comte de Provence, pour payer leurs dettes, reçoivent respectivement 37 et 29 millions.

Ne parlons pas des riches pensions qui sont attribuées aux anciens ministres ; elles peuvent, à certains égards, être considérées comme la récompense des services rendus. Mais il était moins légitime que $\mathrm{M}^{\mathrm{me}}$ de Pompadour fît accorder d'importantes pensions aux membres de sa famille ou à ses amis, que le Roi conférât de riches dotations à des filles de gens en crédit, lors de leur mariage. Les Noailles se font accorder pensions sur pensions, sous le règne de Louis $\mathrm{XV}$; la marquise de Lambert, riche de 4 millions, reçoit une pension de 5000 livres en 1745. Sous le règne de Louis XVI, l'amie de MarieAntoinette, la princesse de Lamballe, reçoit des sommes énormes, traitements et pensions.

Les Polignac se montrèrent plus cupides encore. En 1779, le comte de Mercy écrit à la mère de la reine, l’impératrice Marie-Thérèse :

«Depuis quatre ans, toute la famille des Polignac, sans aucun mérite envers 
l’État et par pure faveur, s’est déjà procuré, tant en grandes charges qu'en autres bienfaits, près de 500000 livres de revenus annuels. Toutes les familles les plus méritantes se récrient contre le tort qu'elles éprouvent par une telle dispensation de grâces... »

En fait, les Polignac se sont fait accorder 700000 livres de pensions, sans compter les gratifications.

Lorsqu’à l'époque de la Révolution, le Livre Rouge révélera le chiffre énorme des pensions concédées aux courtisans, on comprend que la haine contre l'ancien ordre de choses se soit accrue et que des cris de colère aient été proférés contre cette aristocratie inutile, contre ces parasites, dont le trésor royal payait les folles prodigalités.

Les conséquences de la vie mondaine. - Cependant, la vie mondaine, que favorisait le faste de la haute aristocratie, a eu indirectement des conséquences révolutionnaires. Elle a pour effet de rapprocher l'ancienne noblesse d'épée de la noblesse de robe et des financiers. Les gens de robe reçoivent les gens de cour. Le premier président de Mesmes, les présidents Chauvelin et Le Pelletier tiennent table ouverte, et les plus grands seigneurs figurent à leurs réceptions. Le président Hénault, marié cependant avec une fille de " finance », est le familier de la duchesse du Maine, fraie avec les Nivernais, les Brancas, les Maurepas. Les Dufort de Cheverny — noblesse de robe - ont des relations avec les personnes de la plus haute noblesse. Le monde des financiers se mêle aussi de plus en plus à l'ancienne aristocratie : on se presse aux réceptions du fermier général de la Popelinière, de $\mathrm{M}^{\text {me }}$ d'Épernay, de Grimod de la Reynière. Les salons de l'aristocratie d'argent groupent, tout à la fois, des nobles d'esprit libre et les écrivains illustres, les "philosophes ", dont les idées vont exercer, au XVIII $^{\mathrm{e}}$ siècle, une si grande influence sur toute la société française. Par ses mœurs, par ses idées, une partie de la haute noblesse parisienne commence à se " déclasser ", précisément à l'époque où la hiérarchie sociale semble plus stricte et plus rigide qu'elle ne l'a jamais été.

La noblesse provinciale. Diversité des conditions. - Si l'on considère la noblesse non présentée, qui vit en province, on observe 
une grande diversité de conditions. C'est que l'étendue et l'importance des propriétés seigneuriales varient à l'infini. Prenons comme exemple la Bretagne. Certaines seigneuries englobent la plus grande partie de plusieurs paroisses : telle, la baronnie de Sens, non loin de Rennes, qui comprend, non seulement toute la paroisse de Sens, mais encore la plus grande partie des paroisses de Vieuxvy et de Romazy ; telle, la seigneurie de la Martinière et Montbarot, dont les dépendances foisonnent dans toute la région située au Nord de Rennes ; telle encore, la seigneurie de Saint-Brice, qui s'est formée par la réunion de sept ou huit terres nobles, car il s'est produit, en certains cas, une concentration de la propriété nobiliaire.

Les moyennes et les petites seigneuries sont infiniment plus nombreuses que les grandes. Il n'est pas rare d'en compter plusieurs par paroisses. C'est ainsi que les paroisses de Tremblay et de Beaucé comprennent, chacune, six terres nobles ; en Landéan, il y en a sept ; en Carentoir, une quinzaine. On comprend que beaucoup de ces seigneuries aient une étendue fort restreinte, ne possédant que deux ou trois métairies. Certaines d'entre elles n'ont qu'un domaine proche d'une vingtaine d'hectares.

Voilà pourquoi la condition économique des propriétaires nobles varie à l'infini. Considérons, en prenant toujours comme exemple la Bretagne, le chiffre des revenus de diverses seigneuries. Il est parfois très élevé. Le marquisat de Romilley, la baronnie de Tiercent valent, l'un et l'autre, 42000 livres de rente ; le comte de la Villetehart a un revenu de 36000 livres, le marquis de Châteaugiron, de 124000. Mais bien plus nombreuses sont les seigneuries dont les revenus sont inférieurs à 10000 livres : la seigneurie de Launay-Quinart ne rapporte que 7500 livres ; celle de Sion, 5500 livres. Beaucoup d'autres ne sont pas estimées à plus de 4000 livres de revenu. Enfin, beaucoup de petites seigneuries produisent à peine 1000 livres : telle la seigneurie de l'Espinaye, dont le domaine proche ne contient que 60 journaux (moins de 30 hectares), et qui ne rapporte que 900 livres. On comprend qu'il y ait une petite noblesse nombreuse et souvent très misérable. Peut-être le fait est-il plus frappant en Bretagne qu'ailleurs ; mais partout il existe une noblesse pauvre, dont l'existence est très pénible. 
La conséquence, c'est que, parmi les gentilshommes, les conditions d'existence varient aussi à l'infini. On peut s'en rendre compte avec précision par les inventaires après décès : les biens mobiliers du marquis de Châteaugiron, en 1762, sont évalués à 112828 livres, et l'inventaire décrit l'installation luxueuse de ce personnage, tant à Rennes qu'à la campagne. Les meubles du château du Gage ne sont estimés qu'à 12734 livres : ils sont confortables, mais simples. Par contre, les manoirs des gentilshommes pauvres ne sont guère mieux meublés que les maisons de paysans.

La moyenne noblesse. - Il y a donc, dans la province française, une noblesse aisée, qui continue à résider sur ses terres, une partie de l'année au moins, mais qui, le plus souvent, possède aussi des hôtels à la ville. Beaucoup de ces nobles mènent une vie mondaine, qui rappelle un peu la vie de cour ou de salon des nobles parisiens. Il y a, pendant l'hiver, dans les villes "capitales ", à Strasbourg, à Dijon, à Rennes, à Poitiers, à Bordeaux, à Toulouse, de brillantes réceptions, que fréquentent les membres des Parlements, les officiers, les hauts fonctionnaires. A Poitiers, dit Henri Carré, « la noblesse raffolait de réunions et de fêtes ". Même dans les petites villes, il y a des "sociétés de noblesse » aussi gaies et aussi fastueuses que dans les grandes. Pendant la belle saison, ce sont les plaisirs habituels de la vie de château. Les parlementaires, qui constituent souvent la fraction la plus aisée de la noblesse provinciale, se font remarquer par le luxe de leurs réceptions. La mode est surtout aux repas plantureux; au château de Thorigny, en Dauphiné, chez les Lavalette, on consomme, en trois mois, près de 4000 livres de victuailles.

Toutefois, bien des nobles aisés ne quittent jamais leurs terres, s'adonnant surtout à la chasse. Dans la seconde moitié du XVIII ${ }^{\mathrm{e}}$ siècle, certains gentilshommes, gagnés par la mode, s'occupent de la culture. Tel, le marquis de Turbilly, dans son domaine de Volandry, en Anjou : il défriche des landes, dessèche des marais, construit des chemins, mérite de devenir président de la Société d'agriculture de Paris. Tel encore, le duc de la Rochefoucauld-Liancourt, qui s'applique à répandre les nouveaux procédés agricoles, ou, en Bretagne, le célèbre La Chalotais et le président de la Bourdonnaye-Montluc. Mais, il faut bien le dire, ces gentilshommes agriculteurs sont bien peu nombreux ; 
presque toujours, les propriétaires nobles ne s'occupent ni de la culture, ni de la gestion de leurs terres, qu'ils confient à leurs intendants. Leur seule occupation, c'est, pendant leur jeunesse, de servir comme officiers dans l'armée royale.

La noblesse pauvre. - Cependant, la noblesse pauvre est plus nombreuse, semble-t-il, que la noblesse aisée. Elle vit misérablement dans des manoirs qui tombent en ruine. On nous cite un gentilhomme breton, le comte de Sensy, qui, avec un revenu de 1200 livres, doit nourrir sept enfants. En 1774, un certain Colas de la Baronnais demande un secours au Roi : avec un revenu de 2000 livres, il doit élever dix-sept enfants. M. P. de Vaissière, dans son livre sur les Gentilshommes campagnards de l'ancienne France, nous cite beaucoup d'exemples analogues. Il remarque très justement que la misère des gentilshommes campagnards est grande surtout dans les pays de culture pauvre, où prédomine le métayage : les propriétaires nobles subissent le contrecoup des mauvaises récoltes et ils sont à peine plus à l'aise que leurs métayers. L'un d'eux, M. de Couladère, qui vit sur sa terre, près de Montauban, demande, en 1710, un secours au contrôleur général. La récolte a manqué ; on n’aura pas de blé pour se nourrir et pour faire les semailles, et il ajoute :

« Notre boulanger ne veut plus nous fournir du pain, voyant que nous n'avons point de récoltes ; car celle qu'on pourra faire des millets ne suffira pas pour vivre une année et faire subsister nos métayers..., et je m’estimerai heureux d'avoir de ce pain, quoique je n'aie pas accoutumé d'en manger. »

Puis ne faut-il pas pourvoir à l'éducation des garçons, à l'établissement des filles ? Les nobles ruinés ne mettent leur espoir que dans la générosité du roi.

Il n’est pas étonnant que bien des nobles soient réduits à la condition des paysans ou bien sollicitent quelque petit emploi dans les fermes et les gabelles. Il en est même qui deviennent porteurs de chaises, muletiers. Dès 1713, le maréchal d'Harcourt, parlant de la Normandie, écrivait au secrétaire d’État de la guerre :

« Je vois la pauvre noblesse de ce pays-ci en si pitoyable état que des gentils- 
hommes deviennent paysans pour n'avoir pas le moyen d'être élevés, ni d'apprendre seulement à lire et à écrire ; que cette pauvreté les oblige à se marier avec une paysanne, pourvu qu'elle ait un arpent de terre à labourer. »

En 1789, à l'assemblée provinciale du Poitou, se sont présentés sept gentilshommes, vêtus en paysans, et dont on a dû payer la dépense à l'auberge ; ils ont raconté que leurs filles s'occupaient de la basse-cour et gardaient les moutons dans les champs.

On comprend, en 1789, l'hostilité que la petite noblesse pauvre manifeste aux nobles de cour, qui recueillent toutes les faveurs, les sinécures lucratives, les charges militaires. On trouve comme l'écho de leurs plaintes dans ces lignes que Brissot, en 1790, publiait dans le Patriote français :

"S'il est un ordre de citoyens qui soit victime du despotisme et de l'aristocratie des grands et des riches..., c'est la noblesse pauvre, cette nombreuse classe de gentilshommes cultivateurs, bornée par un préjugé gothique à un seul état... Le tableau des vexations de tout genre auxquelles elle a été exposée, dans l'état militaire, est un des plus révoltants qu'on puisse voir. »

Cette situation de la petite noblesse préoccupe assez vivement l'opinion au cours du siècle. Certains écrivains - et notamment l'abbé Coyer, dans sa Noblesse commerçante - préconisent, pour la noblesse, l'activité industrielle et commerciale; mais des gentilshommes pauvres pouvaient-ils s'y adonner? En fait, si bon nombre de nobles participent, comme concessionnaires ou actionnaires, à des campagnes minières, ce sont surtout de grands seigneurs comme les Croy, les Conti, les Charost, les Solages, les Chaulnes.

La noblesse et les paysans. - Si bien des gentilshommes sont obligés de mener une vie si simple qu'ils ne se distinguent guère des paysans, faut-il croire qu'ils considèrent ces derniers comme des égaux ? En aucune façon. Les relations entre les seigneurs et leurs paysans n'ont nullement ce caractère idyllique que $\mathrm{M}^{\text {me }}$ de la Rochejaquelein nous décrit dans ses Mémoires ; même dans le Bocage vendéen, n’y a-t-il eu jamais qu'un accord parfait entre ces deux classes ? Il est permis d'en douter. Les gentilshommes pauvres, qui possèdent 
des droits seigneuriaux, ne sont-ils pas incités à les exercer de la façon la plus rigoureuse ? Il faut bien vivre. La noblesse de cour, absente de ses domaines, et dont le train de vie exige tant d'argent, se montre-telle plus douce ? Au cours du XVIII ${ }^{\mathrm{e}}$ siècle, la hausse des prix, le croissant besoin d'argent ont certainement eu pour effet d'aggraver l'exploitation seigneuriale : on l'a vu plus haut. C'est l'époque de la réfection des terriers, l'époque où se multiplient les afféagements de terres incultes, qui lèsent si manifestement les intérêts, les besoins de la masse des paysans. Non que les gentilshommes soient naturellement des tyranneaux; mais ce ne sont point des saints, ce ne sont point, pour la plupart, des philanthropes, et ils considèrent que les paysans sont d'une autre essence qu'eux-mêmes. En fait, les graves troubles agraires, qui se sont produits à l'époque de la Révolution, la façon dont les paysans se sont élevés contre le régime seigneurial prouvent bien que la noblesse, en général, n’exerçait nullement cette autorité bienfaisante et paternelle qu'on se plaît parfois à nous dépeindre.

La noblesse et les idées nouvelles. - Est-il vrai, comme on l'a dit parfois, qu'aux approches de la Révolution, une bonne partie de la noblesse ait été gagnée aux idées nouvelles de liberté et d'égalité, à ce qu'on appelle les idées philosophiques ? Sans doute, dans la haute noblesse de Paris, un certain nombre de gentilshommes, qui fréquentent les écrivains et les penseurs de l'époque, qui les rencontrent dans les salons, ont été gagnés à des sentiments d’humanité et de justice. On cite souvent ce passage bien significatif du comte de Ségur :

« Riants frondeurs des modes anciennes, de l'orgueil féodal de nos pères et de leurs graves étiquettes, tout ce qui était antique nous paraissait gênant et ridicule... Nous nous sentions disposés à suivre avec enthousiasme les doctrines philosophiques que professaient des littérateurs spirituels et hardis. Voltaire entraînait nos esprits, Rousseau touchait nos cœurs ; nous sentions un secret plaisir à les voir attaquer le vieil échafaudage, qui nous semblait gothique et ridicule... Nous goûtions tout à la fois les avantages du patriciat et les douceurs d'une philosophie plébéienne. »

Mais les idées philosophiques n'ont fait des adeptes que dans une infime minorité de la classe noble. Les gentilshommes, dans leur en- 
semble, songent avant tout à conserver intacts les privilèges de toutes sortes dont ils jouissent. Les membres des Parlements ont bien exprimé, à maintes reprises, dans leurs remontrances, les idées et les sentiments de la classe à laquelle ils appartiennent. S'ils combattent ce qu'ils appellent le despotisme, la tyrannie des agents de la royauté, les impôts nouveaux, c'est qu'ils se sentent atteints dans leurs privilèges. Ils en veulent surtout, vers la fin de l'ancien régime, aux ministres éclairés, à Necker, et plus encore à Turgot, qui s'efforcent de réaliser des réformes administratives et sociales tendant à diminuer les inégalités. La noblesse déteste les intendants, qui sont les agents les plus actifs et puissants d'un gouvernement dont elle redoute les tendances. Si elle invoque la liberté, c'est qu'elle craint les progrès d'une égalité dangereuse pour ses privilèges.

Voilà pourquoi la noblesse réclame des États Généraux, dans lesquels elle espère faire triompher sa cause, et une Constitution qui garantira, pense-t-elle, ses privilèges. On comprend alors que, suivant le mot de Mounier, tous les députés de la noblesse aient été « d'accord sur ce point qu'ils n’avaient pas de constitution et que les États Généraux devaient leur en procurer une ».

La noblesse et l'opinion publique. - L'opinion publique, d'ailleurs, ne crut en aucune façon à ce libéralisme de la noblesse. De plus en plus vivement, comme le montre M. Henri Carré dans son précieux ouvrage sur La noblesse de France au XVIII ${ }^{\mathrm{e}}$ siècle, elle se prononçait contre les nobles. D’ailleurs, leur discrédit, quoi que pense le savant historien, n'a pas surtout pour cause la décadence morale d'une partie de ses membres, trop adonnés au jeu et aux femmes, les scandales provoqués par les escroqueries et les violences de tel ou tel gentilhomme ; mais ils apparaissent de plus en plus comme des parasites, ruineux pour le Trésor royal, comme des privilégiés qui lèsent les intérêts de la nation tout entière.

Bien longtemps avant la Révolution, le marquis d'Argenson, dans ses Pensées pour la réformation de l'État, déclarait que « la race des grands seigneurs était complètement à détruire » :

« J'entends par grands seigneurs, ajoutait-il, des gens qui ont des dignités, des 
biens, des titres, des charges, des fonctions, qui, sans mérite, sans être à peine des hommes, n'en sont pas moins grands, et qui, par cette raison, ne valent nécessairement jamais rien... Entendez ces gens-là et même tout le monde : on vous dira que c'est le soutien de l'État, qu'il faut conserver ces beaux noms de Montmorency, La Trémoille, etc. Je vois que l'on conserve une race de bons chiens de chasse, quand ils sont bons, mais, quand ils dérogent, on les noie. »

En réalité, contre la noblesse se dressent unanimement toutes les classes sociales que l'on englobe sous le nom de tiers état. Les paysans se plaignent surtout du régime seigneurial et de ses abus les plus flagrants. La bourgeoisie, de son côté, s'élève surtout contre les exemptions d'impôts dont jouissent les nobles, contre leurs privilèges en matière judiciaire ; elle prétend être admise, comme eux, sur un pied d'égalité, à toutes les fonctions de l'État. Par ses capacités naturelles et par son instruction, n’est-elle pas tout naturellement désignée pour administrer la chose publique ? Ne connaît-elle pas mieux que les gentilshommes la législation ? Puis, son amour-propre a souffert de maintes humiliations. Qu'on abolisse donc le droit d'armoiries, tous les titres et toutes les "décorations »; qu'on ferme les maisons entretenues pour donner 1' "éducation " aux enfants de la noblesse pauvre. Que les lois civiles et pénales ne distinguent plus entre nobles et roturiers. Si vifs étaient les sentiments antinobiliaires qui animaient les députés du Tiers aux États Généraux, que l'ambassadeur des ÉtatsUnis, Gouverneur Morris, pouvait écrire en 1789 : «le courant contre la noblesse est si fort que j'appréhende sa destruction ».

Les nobles n'ont pas conscience de leurs intérêts collectifs. Cependant, ce n'est pas l'hostilité de tout le tiers état qui constitue le plus grand danger pour les nobles. Ce qu'il y a de plus grave, c'est qu'ils ne se sentent pas solidaires les uns des autres. La petite noblesse provinciale déteste plus la noblesse de cour que le tiers état lui-même. Cet ordre privilégié se subdivise en un grand nombre de catégories distinctes, que séparent des intérêts opposés. Les nobles ne constituent pas une classe sociale, ayant conscience de ses intérêts collectifs. Ils forment un amas assez incohérent de privilégiés, qui songent avant tout à leurs intérêts de famille, à leurs intérêts personnels. Même lorsqu'ils disposent d'une portion de l'autorité publique, ils ne savent pas en user comme il conviendrait. La Bretagne, à cet égard, nous présen- 
te un cas tout à fait significatif. Aux États de cette province, c'est l'ordre de la noblesse qui joue un rôle prépondérant. Il songe à défendre ses intérêts contre les entreprises du gouvernement royal. S'il conjuguait ses efforts avec le Parlement, exclusivement composé de gentilshommes, il se rendrait bien redoutable. Mais l'entente n'a eu lieu que très rarement. Le Parlement, de son côté, ne songe qu'à ses privilèges particuliers ; il est animé surtout de l'esprit de corps, et souvent il se trouve en conflit avec les États. Ainsi, les agents du pouvoir royal profitent de cet état de choses pour triompher séparément de deux adversaires, qui, réunis, pourraient bien souvent les mettre en échec. Rien de plus instructif, à cet égard, que la thèse de $\mathrm{M}$. Rebillon sur les États de Bretagne au XVIII ${ }^{\mathrm{e}}$ siècle.

Ce qui fait la supériorité des adversaires de la noblesse, des membres des diverses classes qui composent le tiers état, c'est qu'ils sentent qu'ils ont contre les privilégiés des intérêts communs à défendre. C'est en ce sens que le Tiers représente vraiment le peuple français, la nation française. Voilà pourquoi la noblesse, malgré ses antiques privilèges, sa richesse, l'appui de la Cour, succombera fatalement dans la lutte qui commence à s’engager en 1789.

$\underline{\text { Table des matières }}$

\section{Ouvrages à consulter}

Outre les ouvrages, cités aux chapitres précédents, de Loutchisky, Lefebvre, E. Lavisse, Soulgé, H. Sée, etc. :

CARRÉ Henri, La Noblesse de France et l'opinion publique au XVIII siècle, Paris, Champion, 1920.

Boiteau, État de la France en 1789, 2éd., Paris, 1889.

RoupNEL G., La Ville et la campagne au XVII ${ }^{\mathrm{e}}$ siècle : étude sur les populations du pays dijonnais, 1922.

De VAISSIERE P., Gentilshommes campagnards de l'ancienne France, Paris, 1903, et Lettres d'aristocrates, Paris, 1907.

FERDINAND-DREYFus, Un Gentilhomme d'autrefois, La RochefoucauldLiancourt.

De Loménie, Les Mirabeau, Paris, 1879, 2 vol.

SÉE H., Les Classes rurales en Bretagne du XVI $\mathrm{e}^{\mathrm{e}}$ siècle à la Révolution, 1906. 
- Esquisse d'une histoire du régime agraire en Europe aux $\mathrm{XVIII}^{\mathrm{e}}$ et $\mathrm{XIX}^{\mathrm{e}}$ siècles, 1921.

MiReuR, Le Tiers État à Draguignan (Bull, de la Société des études scientifiques et archéologiques de Draguignan, t. 27, an. 1908-1909).

DE RiBBE Ch., La Société provençale à la fin du moyen âge, Paris, 1902.

Du Halgouet Hervé, Droits honorifiques et prééminences dans les Églises de Bretagne (Mém. de la Société d'histoire de Bretagne, année 1923).

BOURDE DE LA ROGERIE H., Étude sur la réformation de la noblesse en Bretagne (1688-1721) (même publication, année 1922).

Les droits féodaux, Instructions, Recueil de textes (Coll. Doc. civil de la Révolution), 1924.

Carré Henri et De Monsabert R.-P., Correspondance de $M^{m e}$ de Médel, Poitiers, 1931 , in- $8^{\circ}$.

LÉVY-BRuHL Henri, La Noblesse de France et le commerce à la fin de l'Ancien Régime (Revue d'histoire moderne, 1933).

PAGÈs Georges, La Vénalité des offices dans l'ancienne France (Revue Historique, mai-juin 1932).

Consulter les monographies de L. LACROCQ sur le Haut-Quercy, de G. HUBRECHT sur Sedan, de G. RAMIÈRE DE FonTENIER sur le Lauraguais, de P. LEMERCIER sur les justices seigneuriales dans la région parisienne, de Raoul BRIQUET sur la Provence. 


\section{Chapitre 5}

\section{NOBLESSE PARLEMENTAIRE ET NOBLESSE ADMINISTRATIVE.}

Un trait qui caractérise bien la société du XVIII siècle, c'est l'existence d'une noblesse parlementaire et d'une noblesse administrative : phénomène qui présente, dans une certaine mesure, quelque analogie avec le Tchin russe. Dans l'ancienne France, comme en Russie, la fonction anoblissait ; mais, chez nous, le passage des magistrats et fonctionnaires dans les rangs de la noblesse s'opérait par une lente ascension.

Origines de la noblesse parlementaire. - $\mathrm{Au} \mathrm{XVII}^{\mathrm{e}}$ siècle, les magistrats des Cours souveraines, des Parlements, occupaient encore une situation intermédiaire entre la bourgeoisie et la noblesse. Au $\mathrm{XVIII}^{\mathrm{e}}$ siècle, il y a fusion complète entre la noblesse d'épée et la noblesse de robe, surtout dans les Parlements de Rennes, Rouen et Grenoble, qui ont décidé de ne plus recevoir comme membres que des nobles à quatre quartiers. C'est la vénalité des offices de judicature qui a permis aux magistrats de s'élever ainsi à une situation privilégiée ; M. G. Pagès l'a montré avec beaucoup de force.

M. Roupnel, dans l'ouvrage que nous avons déjà cité, nous montre, par quelques exemples significatifs, comment les familles parlementaires se constituent de grands domaines nobles, qui consacrent leur haute situation sociale. La famille Bouhier, en Bourgogne, de 1631 à 1730 , acquiert de nombreux domaines dans la région voisine de la capitale bourguignonne, accapare des biens communaux, remet en vigueur les anciens droits seigneuriaux de la seigneurie de Lantenay, de sorte qu'au XVIII ${ }^{\mathrm{e}}$ siècle, ses propriétés constituent « un des beaux en- 
sembles domaniaux de la province ». Les Minot de Mairetet, descendants d'un marchand du XVI ${ }^{\mathrm{e}}$ siècle, après une lente ascension vers la noblesse, acquièrent peu à peu un grand domaine et constituent, au $\mathrm{XVIII}^{\mathrm{e}}$ siècle, une puissante famille parlementaire de Dijon.

Grandes familles parlementaires. - On s'explique comment les grandes familles parlementaires peuvent parfois éclipser la noblesse d'épée ; tels, les d'Ormesson, les Joly de Fleury, les Lepelletier, les Mole, les d'Aguesseau, les Séguier, les Pasquier, les Malesherbes. La plupart sont puissamment riches: le premier président d'Aligre a 700000 livres de revenus. Comme les offices se déprécient de plus en plus au XVIII ${ }^{\mathrm{e}}$ siècle, les riches bourgeois ne les recherchent plus, et la noblesse parlementaire devient de plus en plus une caste fermée.

Elle s'allie avec la noblesse d'épée, bien qu'elle s'en distingue souvent encore par les mœurs et les usages. Elle est, sinon plus austère, du moins plus gourmée ; son luxe, souvent plus coûteux, semble plus sobre. Elle se ressent encore de ses origines bourgeoises.

Valeur personnelle des parlementaires. - Que vaut ce personnel des Parlements? Il est difficile de porter sur lui un jugement d'ensemble. Souvent, les membres des cours exercent leurs fonctions à un âge où ils ne possèdent ni l'instruction, ni la pratique nécessaires. Dans les Universités, ils ont souvent acquis à prix d'argent un diplôme qui ne prouve, en aucune façon, qu'ils aient étudié le droit ; l'enquête faite par la corporation n'a aucune valeur réelle. En somme, beaucoup de parlementaires sont ignorants ou incapables ; mais, dans les cours de justice, il y a toujours un certain nombre d'hommes de mérite, voire de personnages d'une grande valeur, comme La Chalotais. On peut citer des érudits, comme Bouhier, des littérateurs distingués, comme le président Hénault, le président de Brosses, un chimiste de premier ordre, comme Guyton de Morveau.

Esprit conservateur des parlementaires. - Quoi qu'il en soit, les membres des Parlements prétendent s'en tenir aux pratiques anciennes. Ils ne veulent pas entendre parler de la diminution des frais 
de justice, de l'abolition des épices, de l'unification des coutumes. Ils ne veulent rien changer à l'ancienne procédure criminelle, si inique, qui entraîne tant d'erreurs judiciaires, au système barbare de la torture, et ce fut seulement à la veille de la Révolution qu'on abolit la question préalable et la question préliminaire (1780-1788).

Les parlementaires protestaient bien contre les lettres de cachet, qu'ils considéraient comme une atteinte à leurs prérogatives judiciaires. Mais ils réprouvaient la liberté de la presse ; ils condamnaient et faisaient brûler une foule d'ouvrages, comme irrespectueux des vérités religieuses ou des institutions existantes. Ils combattirent la déclaration qui accordait l'état civil aux protestants.

Enfin, les Parlements se firent les défenseurs de tous les privilèges sociaux et se dressèrent contre toutes les réformes qui s'efforçaient de les atténuer. Turgot n'eut pas de pires adversaires, quand il voulut supprimer la corvée en nature ou abolir les jurandes ; ils condamnèrent, on le sait, le livre de Boncerf, qui dénonçait l'injustice des droits seigneuriaux, et l'on peut même penser que leur lutte contre le pouvoir royal avait sa source dans leur esprit conservateur ; le « despotisme royal » les gêna surtout quand des ministres réformateurs tentèrent d'améliorer les institutions existantes.

On comprend alors l'hostilité que manifestent aux Parlements les « philosophes » et tous les esprits libres; on s'explique les invectives de Diderot et de Voltaire :

« Intolérant, bigot, stupide, dit le premier, conservant ses usages gothiques et vandales..., ardent à se mêler de tout, de religion, de gouvernement, de police, de finance, d'art et de sciences, et toujours brouillant tout d'après son ignorance, son intérêt et ses préjugés. »

Voltaire se distingue encore plus par sa haine contre les Parlements. Il déplore leur rappel, en 1774 : « il était digne de notre nation de singes de regarder nos assassins comme nos protecteurs; nous sommes des mouches qui prenons le parti des araignées ».

Cependant, parmi les membres des Parlements, il y a des esprits libres et généreux, comme du Paty, des libéraux, comme Robert de Saint-Vincent, même des radicaux, la «faction américaine », qui 
comprend Adrien Duport et Hérault de Séchelles. Ce sont ces hommes qui ont contribué au prestige du Parlement ; c'est grâce à eux qu'on a pu le considérer comme le défenseur de la liberté.

Le rôle social des Parlements. - Les Parlements représentaient le passé plutôt que l'avenir, mais on ne peut contester qu'ils aient joué un grand rôle social au XVIII ${ }^{\mathrm{e}}$ siècle. Dans les villes qui servent de résidence aux cours, leurs membres tiennent le premier rang par leur richesse et leur influence. Tout un monde d'hommes de loi, d'avocats, de procureurs gravite autour d'eux. Des villes comme Rennes, Dijon, Aix conservent encore leurs somptueux hôtels. Dans la campagne environnante, les plus beaux châteaux leur appartiennent ; ce sont de puissants seigneurs et propriétaires fonciers, en Bretagne, que les Caradeuc, les Châteaugiron, les Talhouët, que les Ornacieux et les Bérulle, en Dauphiné. Les villes parlementaires nous présentent l'un des aspects intéressants de l'ancienne France.

La noblesse administrative. Les intendants. Les Conseillers d'État. - Les hauts fonctionnaires, les membres du Conseil d'État, les intendants forment aussi une véritable caste. En ce qui concerne les intendants, nous n'avons pas à insister ici sur l'importance et l'étendue de leurs fonctions, qui se sont encore accrues au XVIII ${ }^{\mathrm{e}}$ siècle, et qu'ils remplissent souvent avec zèle et intelligence. Mais il faut dire que leur rôle social est considérable. Il forment souvent de véritables dynasties, comme les Amelot, les La Galaisière, les La Bourdonnaye de Blossac, les Feydeau, et ils tiennent de près au monde parlementaire, auquel souvent ils ont appartenu. Ils ont des traitements élevés, variant de 20000 à 40000 livres. Beaucoup, comme Montyon, comme les Blossac, ont une grande fortune personnelle. Cette situation sociale contribue à accroître leur indépendance administrative ; ils ne suivent pas aveuglément les ordres des ministres ; ils font souvent preuve d'initiative, comme Turgot dans le Limousin. De plus en plus, vers la fin de l'ancien régime, ils s'occupent - et parfois avec bonheur - des questions économiques. S'ils sont impopulaires, c'est qu'ils se montrent hostiles aux tentatives de self government, notam- 
ment à l'institution des assemblées provinciales ; c'est qu'on voit en eux les principaux agents du « despotisme ».

Les intendants tiennent étroitement au Conseil d'État, où ils ont débuté comme maîtres des requêtes, et dont ils sont les commissaires départis. Le Conseil d'État forme comme le centre de la noblesse administrative ; c'est dans cette assemblée que se recrutent la plupart des hauts fonctionnaires, des auxiliaires des ministres, souvent même les ministres.

Table des matières

\section{Ouvrages à consulter}

Outre les ouvrages cités au chapitre IV :

Flammermont, Remontrances du Parlement de Paris au XVIII ${ }^{\mathrm{e}}$ siècle, 3 vol., 1888-1898.

FloQUet, Histoire du Parlement de Normandie, Rouen, 1840-1849, 7 vol.

SAULNIER, Le Parlement de Bretagne, 1908, 2 vol.

LE MoY A., Le Parlement de Bretagne et le pouvoir royal au XVIII siècle, 1909.

CARrÉ Henri, La Fin des Parlements, 1913.

De LA Cuisine, Le Parlement de Bourgogne, Dijon, 1864, 3 vol.

ARDASCHEFF, Les Intendants en France sous le règne de Louis XVI, trad. fr., 1909.

DuMAS F., La Généralité de Tours au XVIII ${ }^{\mathrm{e}}$ siècle, 1894.

LHÉRITIER Michel, Tourny, 1920.

SEE Henri, L'Évolution de la pensée politique en France au XVIII siècle, Paris, 1925.

DELBEKE Francis, L'Action politique et sociale des avocats au XVIII siècle et leur part dans la préparation de la Révolution française, Louvain et Paris, 1927, in-8 ${ }^{\circ}$.

BÉZARD Yvonne, Une Famille bourguignonne au XVIII siècle, Paris, 1930, in- $8^{\circ}$. (Les Loppin de Gémeaux, de la Chambre des Comptes et du Parlement de Dijon). Cf. Lettres du Président de Brosses à Ch. Loppin de Gémeaux (17571771), Paris, 1929 , in- $8^{\circ}$.

SÉE H., Le Livre de raison d'un parlementaire breton au XVIII siècle (Annales d'histoire économique et sociale, 1931).

RÉBILLON Armand, Les États de Bretagne de 1661 à 1789. Paris et Rennes, 1932. 
Henri Sée

La France économique et sociale au XVIII ${ }^{\mathrm{e}}$ siècle 


\section{Chapitre 6}

\section{LA PETITE INDUSTRIE. LES MÉTIERS ET LES CORPORATIONS.}

Prédominance de la petite industrie. - Au XVIII ${ }^{\mathrm{e}}$ siècle, malgré les transformations économiques qui annoncent l'avènement de la grande industrie (que l'on exposera plus loin), c'est le régime de la petite industrie, des petites entreprises, qui reste prédominant. Cela est vrai, non seulement de tous les métiers qui ont pour objet de pourvoir aux besoins de l'alimentation, du vêtement, de la construction, etc., mais aussi des métiers de l'industrie textile, qui, plus tard, constitueront le domaine de la grande industrie. On le verra, les établissements « concentrés », même à la fin de l'ancien régime, restent l'exception. En Poitou, écrit en 1747 un inspecteur des manufactures, " on compte cinq cents fabricants, mais la plupart travaillent par eux-mêmes, de sorte qu'il n'y a pas plus de cinquante maîtres qui fassent travailler uniquement à façon " ; trente ans plus tard, on constatera, dans cette province, à peu près la même organisation du travail.

Partout, en France, les tanneries, les verreries, les papeteries, à part quelques grands établissements, les teintureries et blanchisseries sont de petites exploitations, qui n'occupent que quelques ouvriers. Dans la plupart des villes, les petits artisans travaillant seuls ou n'employant qu'un seul compagnon sont en majorité. A Bordeaux, les compagnons ne sont que quatre fois plus nombreux que les maîtres. A Paris, en 1791, si quelques fabriques d'étoffes emploient plusieurs centaines d'ouvriers, la moyenne n'est cependant que de seize ouvriers par patron. A fortiori, dans les villes de second ou de troisième ordre, comme Rennes, les grands établissements industriels sont très rares. 
Les corporations. Métiers libres et jurandes. - C'est donc le régime des métiers que nous avons d'abord à considérer. On distingue les métiers libres et les jurandes.

Malgré les efforts du pouvoir royal, en dépit de l'édit de 1673, qui renouvelait les édits de 1581 et de 1597, les métiers libres n’ont pas tous été transformés en jurandes ; ils subsistent encore fort nombreux, plus nombreux, au total, que les autres. Même lorsqu'ils aspirent à cette transformation, ils se heurtent à l'opposition, soit des jurandes existantes, soit des autorités municipales, qui invoquent l'intérêt public.

La transformation du métier libre en jurande a pour effet : de déterminer les règles de l'apprentissage; de rendre le chef-d'œuvre obligatoire ; de fixer les rapports entre les maîtres ; de créer des jurés. Les métiers libres, d'ailleurs, ont aussi des règlements, mais qui sont moins stricts que les statuts et dont l'application est contrôlée, non par les jurés du métier, mais par l’autorité municipale ou seigneuriale.

L'apprentissage. - Dans les métiers libres, la durée de l'apprentissage n'est pas fixée, le nombre des apprentis n'est pas limité. Dans les métiers jurés, au contraire, le contrat d'apprentissage est obligatoire et la durée en est déterminée par les statuts, variant, en général, de quatre à huit ans. On fixe les droits et les devoirs respectifs des maîtres et des apprentis. L'apprenti doit donner une pension pour son entretien, et il s'engage à ne pas quitter son maître. Le maître, de son côté, doit lui enseigner son métier "sans lui rien cacher », le nourrir et loger convenablement, le traiter avec douceur. Le nombre des apprentis est limité par les statuts, le plus souvent à un ou deux ; ont veut éviter ainsi qu'aucun maître ne puisse avoir d'avantage sur ses confrères, et les compagnons tiennent aussi à cette règle, car ils craignent la concurrence des apprentis.

On voit bien clairement qu'au XVIII ${ }^{\mathrm{e}}$ siècle, pas plus qu'aux époques antérieures, les apprentis ne sont pleinement assurés de jouir des garanties que prétendaient leur assurer les statuts corporatifs et les contrats d'apprentissage. Souvent, ils sont soumis à un travail excessif, on les emploie comme domestiques, ils ont à endurer les brutalités 
des maîtres et des compagnons, si bien que les autorités publiques se préoccupent de les protéger.

Les compagnons. - Pour devenir compagnon, deux conditions sont nécessaires : il faut avoir été apprenti et il faut donner un droit d'entrée. Les maîtres veulent se réserver l'embauchage de leurs ouvriers ; ils craignent que les compagnons ne s'en chargent eux-mêmes, comme c'est le cas dans les métiers du tour de France.

Le compagnon est lié au maître par un contrat de louage, souvent verbal, auquel il doit, en toute circonstance, rester fidèle. La discipline est souvent très dure : l'ouvrier doit achever l'ouvrage qu'il a commencé et ne pas quitter son maître sans lui avoir donné congé quinze jours à l'avance.

En somme, il existe, en quelque sorte, un monopole collectif des maîtres sur la main-d'œuvre ; il est défendu aux maîtres de débaucher les compagnons d'un confrère. Il est défendu aussi aux ouvriers de travailler pour leur compte, en chambre : les chambrelans sont comme traqués par les communautés de métiers ; il en subsiste toujours cependant.

Au XVIII siècle, plus encore qu'aux époques antérieures, il est impossible à la plupart des compagnons de sortir de leur condition : c'est surtout la conséquence de l’organisation légale des métiers.

L'accès à la maîtrise. - L'accès à la maîtrise devient, en effet, de plus en plus difficile. Le chef-d'œuvre, absolument obligatoire, est souvent très compliqué, très long à achever, par conséquent fort onéreux, en dépit des règles fixées par les ordonnances royales, sans compter qu'il faut faire des présents aux maîtres chargés de le juger.

Puis, l'aspirant à la maîtrise doit payer des vacations aux maîtres jurés, donner à la corporation une redevance, souvent fort élevée, et qui s'accroît encore au XVIII ${ }^{\mathrm{e}}$ siècle : chez les apothicaires de Paris, elle s'élève à 1000 l., chez les limonadiers-distillateurs, à 800. De leur côté, les pouvoirs municipaux, seigneuriaux, royaux exigent aussi des droits de maîtrise de plus en plus élevés. Enfin, il faut compter avec 
les exactions et les abus des jurés, qui parfois se font donner par les candidats des sommes indues.

Considérons, d'autre part, que les fils et gendres des maîtres sont souvent dispensés complètement du chef-d'œuvre, ou n'ont à faire qu'un demi chef-d'œuvre : que les droits auxquels ils sont soumis sont réduits presque à rien. Aussi la maîtrise est-elle devenue presque entièrement un monopole familial.

L'administration de la communauté. Les jurés. - Les corporations se réunissent à certaines époques déterminées, forment des assemblées électorales, tous les ans, et des assemblées d'affaires, environ tous les mois ; seulement, ces assemblées n’ont pas une grande indépendance, car ce sont les pouvoirs publics qui déterminent leur ordre du jour.

Toutefois, l'administration de la corporation se trouve entre les mains des jurés, au nombre de quatre ou de deux, élus pour deux ans par les maîtres. Leurs attributions sont très complexes : ils ont la police du métier, le contrôle de la fabrication, examinant la qualité des produits, vérifiant leur poids, inspectant les mesures et les instruments, marquant les objets qui leur paraissent loyalement fabriqués ; ils ont aussi la gestion des intérêts matériels, des finances de la communauté. Ils se montrent très actifs, mais commettent souvent des abus.

Les confréries. - A côté de la corporation, on trouve la confrérie, qui souvent d'ailleurs se confond avec elle, mais dont le caractère est uniquement religieux et charitable. La confrérie a une chapelle ou un autel, où elle fait dire des messes, le jour de la fête patronale et aux grandes fêtes de l'année ; elle fait célébrer les obsèques de ses membres. La confrérie a aussi pour fonction de donner des secours aux confrères tombés dans la misère, aux veuves et aux orphelins, parfois même aux compagnons. Mais elle s'intéresse beaucoup moins à ces derniers. Les compagnons forment donc souvent des confréries séparées, des associations, des compagnonnages, qui leur permettent de 
s'entraider et de lutter contre les maîtres ; on le verra plus loin, d'une façon plus précise.

Le véritable rôle des communautés de métiers. - Elles ont surtout pour but de maintenir le monopole collectif des maîtres du même métier. Elles s'efforcent aussi de diminuer entre eux les effets de la concurrence, leur défendant d'avoir plus d'une boutique, s'opposant aux accaparements, se préoccupant d'assurer à tous la matière première dont ils ont besoin. Chacun des métiers forme un corps fermé en lutte avec les autres corporations ; chacun s'efforce de maintenir ses privilèges et son monopole, de se défendre contre les empiétements d'une corporation voisine ou d'empiéter sur une autre. Aussi partout voit-on des procès souvent interminables éclater entre cordonniers et savetiers, tailleurs et fripiers. Les merciers sont sans cesse en conflit avec toutes sortes de corporations, précisément parce qu'ils prétendent vendre toutes sortes de marchandises. Les marchands drapiers font de constants efforts pour se défendre contre la concurrence des merciers, grossiers, tailleurs et joailliers, qui ne se font pas scrupule de vendre des draps à leurs clients ; on le voit bien nettement à Nantes, pendant tout le cours du XVIII ${ }^{\mathrm{e}}$ siècle. Les corporations luttent aussi contre les étrangers, contre les forains ; à Rennes, la communauté des marchands prétend les obliger à ne vendre qu'en gros. Et aux forains on assimile les marchands juifs, dont on redoute la concurrence.

D’ailleurs, en ce qui concerne les marchands, à côté de ceux qui sont organisés en jurande, on trouve de nombreux petits marchands qui échappent au régime corporatif, et aussi de gros négociants qui parviennent plus facilement à maintenir leur indépendance, surtout dans les grandes places de commerce. Ces négociants se trouvent souvent en conflit avec des corporations d'artisans, par exemple, à Nantes, avec les cloutiers, qui prétendent interdire l'importation des clous étrangers ; les négociants assurent que ces derniers, d'accord avec les maîtres de forges, se livrent à des pratiques condamnables.

Hiérarchie légale des métiers. - On trouve souvent, parmi les métiers, une hiérarchie légale, qui procède presque toujours d'une hiérarchie économique, car certains métiers mènent plus aisément à 
l'aisance et même à la fortune. C'est ainsi qu'une ordonnance municipale de Dijon, de janvier 1727, répartit les métiers en quatre classes.

Première classe : les imprimeurs, libraires, chirurgiens, apothicaires, merciers, drapiers, orfèvres, quincailliers, cartiers, boutonniers.

Deuxième classe : les métiers de l'alimentation (boulangers, bouchers, pâtissiers, charcutiers, cuisiniers, marchands de vin), les métiers de la sellerie et des peaux, les cordonniers, les tapissiers.

Troisième classe : les métiers du métal et de l’ameublement.

Quatrième classe : les ouvriers du bâtiment, les savetiers, les ouvriers travaillant à façon (drapiers, ouvriers agricoles, etc.).

A Paris, au-dessus des autres communautés, se sont élevés les Six Corps (drapiers, épiciers, merciers, pelletiers, bonnetiers, orfèvres), qui exercent une prépondérance de plus en plus grande sur les autres métiers.

Conséquences économiques du régime des jurandes. - Sans doute, la surveillance et la réglementation ont eu parfois pour effet d'empêcher les malfaçons, d'obtenir des produits de bonne qualité. Mais, d'autre part, des fraudes et des négligences nombreuses se produisent, qui sont nuisibles au public, et que la concurrence pourrait entraver. L'organisation des métiers favorise aussi l'esprit de routine, l'hostilité contre toute innovation.

Si l'esprit de corps engendre parfois la dignité morale, accentue le sentiment de la responsabilité, par contre, l'organisation corporative produit de futiles querelles de préséance, le mépris des métiers les uns pour les autres : du tanneur pour le corroyeur, du sergetier pour le cardeur, de l'apothicaire pour l'épicier, etc.. L'organisation est démocratique en un sens, puisqu'elle tend à établir l'égalité entre les maîtres, l'égalité dans la médiocrité, mais elle a, d'autre part, un caractère aristocratique, puisqu'elle tend à transformer les communautés en corps fermés, inaccessibles aux compagnons. La communauté de métier n'est, en aucune façon, l'association familiale où maîtres et compagnons sont censés vivre côte à côte en parfaite harmonie ; elle ne défend que les intérêts des maîtres, et c'est un grossier contresens que de 
vouloir assimiler les corporations de l'ancien régime aux modernes syndicats. Enfin, l'organisation du travail que représentent les jurandes est de moins en moins d'accord avec les besoins économiques de l'époque.

Accentuation de l'organisation corporative. - Tous les caractères que nous venons de décrire s'accentuent de plus en plus au cours du XVIII ${ }^{\mathrm{e}}$ siècle. La royauté y contribue, lorsqu'elle s'efforce encore une fois de soumettre tous les métiers au régime des jurandes, par son arrêt du 23 août 1767, qui renouvelle l'édit de 1673. Elle favorise aussi la réforme, la révision des statuts, que demandent les communautés, afin de rendre plus étroites la réglementation, plus strict leur monopole, afin d'empêcher la concurrence ; elle y a intérêt, car elle touche un droit pour chacune de ces réformations. Puis, l'autorité royale exerce sur les communautés une tutelle plus étroite encore, surtout en matière financière.

L'esprit routinier des corporations ne fait que s'exagérer. Elles sont hostiles à toute innovation. En 1736, les boutonniers prétendent s'opposer à la fabrication des boutons au métier. En 1756, le roi avait autorisé Bedel à appliquer aux étoffes de coton un genre de teinture bleue, dont il était l'inventeur ; il monta son industrie, mais, en 1763, les grands teinturiers lui intentent un procès. Un chapelier de Paris, Leprevost, fabrique des chapeaux mêlés de soie ; ses confrères ne cessent de le persécuter ; en 1760, les jurés saisissent un grand nombre de ses chapeaux et il lui faut quatre années pour obtenir l'autorisation de continuer son commerce. Ainsi, à un moment où les besoins de la production s'accroissaient, les communautés de métiers constituaient une entrave à tout progrès industriel.

Ruine financière des corporations. - Les corporations sont en butte à des difficultés financières de plus en plus graves. La cause essentielle nous en apparaît clairement : ce sont les exigences croissantes de la fiscalité royale, exigences qui se manifestent surtout à la suite des guerres engagées par Louis XV. 
Voici que, comme sous le règne de Louis XIV, on édicte des créations d'offices, en vue de rachats lucratifs. En 1745, on établit des inspecteurs et contrôleurs des jurés, dont on autorise le rachat. Mais, en fait, on ne put l'opérer que très difficilement ; les corporations rennaises, par exemple, ne pouvaient trouver les 194000 livres exigées, car elles étaient déjà ruinées par les rachats du commencement du siècle ; dans le Roussillon, l'intendant déclare qu'il est impossible de recouvrer les sommes qu'imposerait le rachat, "quand même on dépouillerait les gens de métiers de tous les meubles ou effets qu'ils peuvent avoir dans leur maison ».

Le pouvoir royal crée aussi des lettres de maîtrise, bien moins nombreuses, il est vrai, qu'au XVII ${ }^{\mathrm{e}}$ siècle. En 1757, le roi avait promis de n'en plus délivrer ; mais, en 1767, comme il avait besoin d'argent, il créait 12 maîtrises par métier à Paris ; 8, dans les villes ayant une cour supérieure ; 4, dans celles dotées d'un présidial ; 2, dans les autres. Les communautés sont maintenant tellement endettées que souvent elles ne rachètent plus les nouvelles maîtrises. Enfin, il faut noter encore les dons, plus ou moins volontaires, comme les 514000 livres offertes par les Six Corps de Paris, en 1759, au lendemain de la défaite de Rosbach.

Les communautés de métiers sont toujours obérées par leurs dettes anciennes, par les procès qu'elles doivent soutenir, par leurs frais d'administration. Les emprunts accroissent les dépenses annuelles, et il faut sans cesse en contracter de nouveaux pour payer les intérêts des anciens. Il arrive un moment où les corporations ne peuvent se tirer d'affaire qu'en ayant recours à des égails, à des contributions sur leurs membres, à l'augmentation des droits de réception, etc... La ruine des communautés rejaillit donc sur leurs membres, dont la situation économique devient de plus en plus difficile, comme on peut s'en rendre compte dans le Roussillon, à Rennes, ailleurs encore. Le gouvernement se préoccupe donc, surtout après 1750 , de la liquidation des dettes des communautés, et c'est cette question qui provoque précisément les premiers projets de réformes.

Les projets de réformes. - De nombreux mémoires, surtout après 1750 , réclament la restriction des monopoles corporatifs ou 
même un complet régime de liberté. Le secrétaire d'État Bertin, en 1761, demande qu'on réduise le nombre des corporations en en fondant plusieurs en une seule.

Profitant de l'arrivée de Turgot au pouvoir, les économistes engagent une active campagne. Ils font paraître, en 1775, un mémoire de Bigot de Sainte-Croix, Essai sur la liberté du commerce et de l'industrie, qui expose fortement tous les défauts du régime corporatif et qui demande la complète liberté du commerce et de l'industrie ; les Six Corps, pour y répondre, font rédiger par $\mathrm{M}^{\mathrm{e}}$ Delacroix un long mémoire, qui veut démontrer que la conservation des anciens privilèges est une garantie pour le public.

La réforme de Turgot. - L'édit de 1776 procédait de tout le mouvement d'idées antérieur. Dans le préambule, Turgot s'appliquait à démontrer les effets désastreux du régime corporatif sur l'industrie, les ouvriers, les consommateurs. Au droit royal il opposait le droit naturel et proclamait qu'on ne pouvait vendre le droit au travail, car ce droit était "la propriété de tout homme », et cette propriété "la première, la plus sacrée et la plus imprescriptible de toutes ». En conséquence, « il sera libre à toute personne, de quelque condition et qualité qu'elle soit », d'exercer toute espèce de commerce et même d'en « réunir plusieurs ». Les procès, ainsi que les malfaçons, seront jugés par les officiers de police. Il est défendu aux maîtres et aux ouvriers « de former aucune association ni assemblée entre eux, sous quelque prétexte que ce puisse être » ; toute confrérie est également supprimée.

Mais l'édit, qui se heurta d'ailleurs à une très vive opposition, n'a pas été appliqué ; Turgot l'a entraîné dans sa chute. Cependant, on ne rétablit pas intégralement l'ancien régime, comme le montre le nouvel édit d'août 1776, qui est une sorte de compromis : certaines professions seront libres ; d'autres seront organisées en communautés, mais on réunira ensemble plusieurs communautés similaires. L'édit d'août ne concernait que Paris ; on essaya cependant d'en étendre les dispositions à la province, mais cela ne se fit que très lentement et péniblement ; dans la Flandre française, en Artois, en Bretagne, l'ancienne organisation fut maintenue. 
En somme, malgré certaines améliorations dans le régime, la question des corporations de métiers se posait toujours aussi fortement lorsqu'éclata la Révolution. En 1789, beaucoup de cahiers se prononcent pour leur suppression; c'est qu'ils reflètent les sentiments de la haute bourgeoisie, des professions libérales et des négociants; au contraire, les maîtres des métiers en demandent le maintien ; ainsi se marque l'opposition des classes, dont on verra plus loin le caractère. La Constituante ne fera que reprendre la mesure radicale de Turgot.

Table des matières

\section{Ouvrages à consulter}

Outre l'ouvrage de RouPNEL, déjà cité au chapitre IV :

ACLOCQUe Geneviève, Les Corporations, l'industrie et le commerce à Chartres du $\mathrm{XI}^{\mathrm{e}}$ siècle à la Révolution, Paris, 1917.

BoIssonnade P., Étude sur l'organisation du travail en Poitou, 1899, 2 vol.in-8.

Bourgeors Alfred, Les Métiers de Blois (Mém. de la Soc. des lettres et sciences de Loir-et-Cher, 1891-1897), 2 vol. in-8.

FOURNIER Joseph, Cahiers de doléances de la sénéchaussée de Marseille, 1908 (Coll. des Doc. écon. de la Révolution).

HAUSER Henri, Travailleurs et marchands de l'ancienne France, Paris, 1920. Notes sur l'organisation du travail en Bourgogne au $\mathrm{XVI}^{\mathrm{e}}$ et au $\mathrm{XVII}^{\mathrm{e}}$ siècles (Revue bourguignonne de l'Enseignement supérieur, 1904).

PIED, Les Anciens Corps de métiers de Nantes, Nantes, 1903.

ReBillon A., Les Anciennes Corporations ouvrières et marchandes de Rennes, Rennes, 1902 (extr. des Annales de Bretagne).

Recueil des règlements généraux et particuliers concernant les manufactures du royaume, 1730-1750, $7 \mathrm{vol}$.

VIDAL et DURU, Histoire de la corporation des marchands merciers, Paris, 1912.

LEVASSEUR Émile, Histoire des classes ouvrières et de l'industrie en France avant 1789, $2^{\mathrm{e}}$ éd., 1901.

SÉE Henri, L'Évolution commerciale et industrielle de la France sous l'ancien régime, Paris, 1925. 


\section{Chapitre 7}

\section{L'ÉVOLUTION COMMERCIALE AU XVIII ${ }^{\mathrm{E}}$ SIÈCLE.}

Les progrès du commerce ont devancé et déterminé les progrès de l'industrie. Or, on observe, au XVIII ${ }^{\mathrm{e}}$ siècle, un développement remarquable du commerce, intérieur et surtout extérieur.

Les voies de communication. - Les diverses régions de la France tendent à sortir de leur isolement ; on sent le besoin de relations plus actives, de communications moins rudimentaires.

Le réseau des routes se développe sensiblement, surtout dans la seconde moitié du siècle. Deux créations très importantes contribuent à ces progrès : la fondation de l'école des ingénieurs des ponts et chaussées, en 1747, et l'organisation du corps des ingénieurs (entre 1750 et 1754). Le budget des Ponts et Chaussées s'accroît sensiblement aussi, s'élevant, vers la fin de l'ancien régime, à 7 millions de livres : il ne sert d'ailleurs qu'aux travaux d'art et au traitement du personnel, car les travaux de construction et d'entretien des routes se font au moyen de la corvée des grands chemins. En 1788, on comptait 12000 lieues de routes construites et 12000 lieues de routes tracées ou en construction. Les grandes routes, les routes royales, larges de 12 à 20 mètres, rayonnent, en général, de Paris vers les extrémités du royaume, conséquence naturelle de la centralisation. Le tracé du réseau routier ressemble par sa configuration au réseau de nos chemins de fer: $\mathrm{Pa}$ ris-Strasbourg, Paris-Lyon-Marseille, Paris-Brest, Paris-Toulouse, Paris-Lille, voilà les routes essentielles. D’Est en Ouest, elles sont beaucoup moins nombreuses. Il est visible qu'en exécutant ce réseau routier, on s'est préoccupé encore plus des intérêts stratégiques que des intérêts commerciaux; en Bretagne, c’est au début de la guerre de 
Sept ans que le duc d'Aiguillon, obéissant à des préoccupations militaires, pousse activement la construction des grands chemins, ce qui mécontente fort les États de la province.

N'oublions pas, d'ailleurs, que ces routes étaient souvent en assez mauvais état ; l'empierrement, auquel devait pourvoir le travail de la corvée, était très défectueux ; cependant, vers la fin de l'ancien régime, on voit se réaliser de notables améliorations, dont témoignent des voyageurs comme Arthur Young. Mais partout en France les chemins de traverse étaient impraticables.

La navigation intérieure était encore plus importante pour le commerce que les routes. C'est surtout après 1770 que l'État se préoccupa activement de la navigation, la considéra comme un service public, reprit les projets abandonnés après Colbert. Et encore s'agit-il moins de la navigabilité des rivières, plutôt en régression, gênée par les moulins et les péages, que de la construction de canaux. C'est surtout dans le Nord que le travail fit le plus de progrès (tout un réseau fut achevé) ; on ne fit que commencer les travaux du canal du Centre, du canal de Bourgogne, du canal du Rhône au Rhin. Un mémoire des « entrepreneurs de la voiture du sel pour la grande gabelle », de 1785, déclarait, non sans exagération, qu'à cause de tous les obstacles qui entravaient la navigation, la " voiture » des marchandises par voie d'eau était encore plus coûteuse que par voie de terre.

Les moyens de transport. - Malgré des progrès réels, ils apparaissent encore comme très imparfaits. Ce sont les messageries, affermées à des traitants jusqu'en 1775, qui sont chargées du transport des voyageurs. Les voitures publiques sont encore peu confortables, surtout les fourgons et les carrosses ; les diligences sont mieux aménagées ; quant aux chaises de poste, elles sont plus rapides, mais fort chères. Sur les rivières, les coches d'eau n'ont, en général, que trois départs par mois et leurs voyages sont interminables (il faut 18 à 20 jours pour aller de Paris à Rouen). Sur les routes, les diligences ne font que deux lieues par heure, les carrosses, huit à dix lieues par jour. Turgot établit partout, il est vrai, des diligences. Mais les départs restent toujours rares (un ou deux par semaine, en Bretagne). Puis, les 
lignes transversales sont peu nombreuses. Les prix sont très élevés (13 sous et 7 sous par lieue dans les diligences).

Considérons maintenant la durée des voyages. Dans les soixante premières années du XVIII ${ }^{\mathrm{e}}$ siècle, elle est encore assez longue. Il y a, à cet égard, un progrès assez notable à la fin de l'ancien régime. Il est dû, en partie, aux efforts de Turgot, qui essaya d'améliorer le service des diligences et messageries, en le détachant du bail des postes et en le concédant, en régie, à un directeur concessionnaire. La réforme, il est vrai, fut éphémère ; éphémère aussi la vogue des nouvelles voitures, appelées turgotines. Cependant, à partir de 1776, les voyages par diligences deviennent plus rapides : de Paris à Lyon, on ne met guère plus que 5 jours (on en mettait 10 au XVII $^{\mathrm{e}}$ siècle); à Bordeaux, 6 ; à Lille, 3 (au XVII $\left.{ }^{\mathrm{e}}, 4\right)$; à Marseille, 11. Les chaises de poste sont plus rapides, mais pour en user il faut être vraiment riche.

On comprend que le service de la poste soit très défectueux, surtout d'une ville de province à une autre. Il y a, en effet, très peu de lignes transversales : de Lyon à Bordeaux, les lettres passent par Paris et ne parviennent qu'au bout de huit jours ; de Rennes à Granville, il en faut sept.

Les transports des marchandises, excepté pour les paquets de moins de 50 livres, se font par le roulage, réservé à des entrepreneurs particuliers. Il est très lent et fort coûteux, puisque les transports doublent souvent les prix des marchandises. Par eau, les prix sont deux ou trois fois moins élevés que par terre, mais on a à redouter les fraudes et même les vols des bateliers, et la navigation est entravée par les droits de péages, les moulins, etc.. Cependant les relations, au cours du siècle, deviennent plus actives ; la preuve, c'est que le bail des postes, de 1222000 livres, en 1676, s'éleva à 8800000 livres, en 1777. La difficulté des transports sur les routes ou sur les rivières nous fait comprendre que l'on ait, plus que de nos jours, recours au cabotage, dans toutes les provinces maritimes. Un armateur de Saint-Malo, Magon de la Balue, déclare, dans une de ses lettres, que, de cette ville, le transport des marchandises par mer pour Nantes est beaucoup moins coûteux que pour Rennes par voie de terre. Les ports étaient beaucoup plus nombreux qu'aujourd'hui, et c'étaient souvent des «barques » de 50 à 100 tonneaux qui transportaient les marchandises de Bretagne à Bordeaux ou à Bayonne, du Havre à Granville. 
Notons encore que, pour la première fois, en 1783, furent créés des paquebots royaux entre la métropole et les Antilles ; réservés aux passagers, aux lettres, aux objets précieux, ils partaient une fois par mois pour les "îles d'Amérique », soit du Havre, soit de Bordeaux, huit fois par an du Havre, pour les États-Unis, quatre fois pour Bourbon et l’̂̂le-de-France. C’était là une grande innovation.

On peut donc conclure qu'au XVIII ${ }^{\mathrm{e}}$ siècle, il y eut un sérieux progrès des voies de communication et des transports. Mais, à considérer la révolution qui s'opérera à ce point de vue au siècle suivant, on voit qu'en trente ans (de 1840 à 1870), la transformation sera infiniment plus grande que celle qui s'est accomplie au cours des trois siècles précédents.

Décadence des foires. Progrès du crédit. - Un indice très significatif de l'évolution commerciale, c'est la décadence des grandes foires, non seulement de celles de Paris (Saint-Germain, Lendit), mais des foires de Lyon. Cependant, bien que moins internationales qu'autrefois, celles de Beaucaire font toujours un gros chiffre d'affaires, et celles de Caen et de Guibray sont encore actives.

En ce qui concerne le crédit privé, il ne semble pas qu’il y ait eu de grandes transformations. La ruine du système de Law fit que l'on renonça à la création d'une grande banque, semblable aux banques de Londres ou d'Amsterdam. Les banques de Lyon n'avaient plus la même importance qu'autrefois. Marseille, malgré l'activité de son commerce, ne possédait pas de banques importantes et devait y suppléer en ayant recours à des courtiers de commerce. Mais, à Paris, les banques paraissent avoir augmenté en nombre et en importance, sans compter qu'un peu partout les gens de finances se livrent à des opérations bancaires. Vers la fin de l'ancien régime, on sentit la nécessité de créer des institutions de crédit, comme la Caisse d'escompte, fondée par Turgot, en 1776, au capital de 15 millions de livres, et qui fut ensuite porté à 100 millions. Mais la France, en ce qui concerne le crédit, était beaucoup moins bien outillée que la Hollande et l’Angleterre. 
Les tendances libérales de la politique commerciale. Les traités de commerce. - Le commerce de la France a été favorisé par l'activité des administrateurs qui constituaient le Conseil du commer$c e$ et surtout par les tendances libérales, qui, dans la seconde moitié du XVIII ${ }^{\mathrm{e}}$ siècle, se manifestèrent dans la politique commerciale. Ce fut, en grande partie, l'œuvre d'économistes comme Vincent de Gournay (intendant du commerce de 1750 à 1758), et de ses disciples, comme les Trudaine, l'œuvre aussi de l'école physiocratique, fondée par Quesnay, qui combat la thèse mercantiliste et prétend qu'il y a entre les diverses nations une véritable solidarité économique. Turgot et Condillac se préoccupent, plus encore que les disciples de Quesnay, de la liberté du commerce.

Les idées nouvelles se manifestent d'abord surtout dans la question des grains, dont le commerce était très étroitement réglementé. En 1763, l'autorité royale autorisait le libre transport des grains d'une province à l'autre et, en 1764, la libre exportation hors du royaume. Si une réaction se manifesta en 1770, Turgot, en 1774, établit la liberté du commerce des grains, et, après la réaction partielle qui suivit sa chute, la déclaration du 17 juin 1787 établissait la libre circulation à l'intérieur du royaume et l'exportation à l'étranger.

Il y a aussi tendance à la suppression des droits de douane excessifs et prohibitifs, et on commence à vouloir conclure des traités de commerce avec les puissances étrangères. On ne put réussir à négocier avec l'Espagne, mais, en 1778, en même temps qu'un traité d'alliance, un traité de commerce était signé avec les États-Unis naissants, sur le pied de la « nation la plus favorisée ».

Plus important encore fut le traité de commerce conclu avec l'Angleterre en 1786. Il mettait fin à la guerre commerciale, qui n'avait jamais cessé depuis plus d'un siècle, car le traité de commerce d’Utrecht, de 1713, n’avait jamais été exécuté ; seule, une active contrebande apportait quelque remède à ce régime prohibitif. Le traité de 1786 renouvelait presque toutes les stipulations de 1713, déclarait que les vins de France ne paieraient pas de droits plus élevés que les vins de Portugal, les batistes et linons, pas plus que les toiles de Hollande, frappait les tissus de coton et la plupart des autres étoffes d'un droit de $12 \%$ ad valorem, mais ne stipulait rien pour les soieries, ce qui causait un grand dommage à l'industrie française. Le traité, d'une 
façon générale, était beaucoup plus avantageux pour l'Angleterre que pour la France, étant donné la supériorité de l'industrie anglaise, servie par les progrès du machinisme. L'accord de 1786 détermina en France une crise industrielle très grave, qui affecta surtout les cotonnades, la faïence, la quincaillerie et le cuir. Il n'est donc pas étonnant qu'à l'époque de la Révolution, une réaction très vive se soit manifestée contre la politique libérale de la fin de l’ancien régime.

Le commerce avec les pays d'Europe. - On constate un réel progrès dans les relations commerciales de la France avec la plupart des pays de l'Europe.

En ce qui concerne l'Espagne, on remarque, il est vrai, que dans la seconde moitié du XVIII ${ }^{\mathrm{e}}$ siècle, malgré le rapprochement politique de 1761 , il s'est produit une décadence relative du commerce. Une ordonnance du roi d'Espagne ferma même, en 1779, le marché espagnol à certains de nos produits ; néanmoins, le commerce des toiles constituait encore un article important de nos relations avec l'Espagne, et les exportations s’élevaient, en 1789, à 66 millions. Avec la Hollande non plus, les transactions n'ont plus la même importance qu'au XVII ${ }^{\mathrm{e}}$ siècle. Avec l'Angleterre, le traité de 1786 accrut, dans une très notable proportion, le chiffre de nos transactions. Avec l'Italie, le commerce français n’a cessé de se développer, et aussi avec les villes hanséatiques, la Russie, les pays Scandinaves. L'Allemagne reçoit de la France beaucoup de produits manufacturés.

Le commerce du Levant. - Il joue toujours un rôle considérable ; il n’est pas tombé en décadence, comme on l'a parfois déclaré ; seulement, il n'a plus la même importance relative qu'au XVII ${ }^{\mathrm{e}}$ siècle, précisément par suite des progrès du commerce avec les Antilles. Marseille, port franc, conserve le monopole des transactions avec le Levant. A la France appartient toujours le premier rang dans ce commerce ; elle est, en effet, favorisée par ses relations amicales avec la Turquie. Tandis que le commerce de la Hollande, de l'Angleterre, de Venise décline, la France, à la veille de la Révolution, importe 37 millions de marchandises venant du Levant, y exporte 28 millions, consacre à ce trafic 500 ou 600 bâtiments. Elle a de plus en plus besoin de 
la soie et surtout du coton pour ses manufactures, des huiles et des peaux pour les savonneries et les tanneries marseillaises. Cependant, l'exportation des draps du Languedoc, fort importante jusque vers 1773, diminue dans les dernières années de l’ancien régime.

Le grand commerce maritime et colonial. La Compagnie des Indes. - On n'a pas renoncé au système des compagnies de commerce privilégiées. Mais Law les avait toutes fondues dans la Compagnie des Indes, qui, après la chute du système, fut reconstituée en 1725. C'est la Compagnie des Indes qui contribue à l'extension du domaine colonial de la France. Elle met en valeur la Louisiane, à l'époque de Law ; plus tard, elle étend les possessions françaises dans l'Inde et son agent Dupleix y crée un véritable empire, qui fut définitivement perdu en 1763, au traité de Paris. Dépossédée de la plus grande partie de son domaine, la Compagnie se transforme en une simple société commerciale. En 1769, on lui enlève son privilège et le commerce de l'Extrême-Orient devient libre jusqu'à l'établissement, en 1785, d'une nouvelle Compagnie des Indes; mais celle-ci, société par actions, fondée par des financiers, n'eut en aucune façon l'importance de l'ancienne, et les négociants, habitués maintenant à la liberté, ne tardèrent pas à en demander la suppression.

Le commerce avec les Antilles. - C'est avec les Antilles, surtout dans la seconde moitié du XVIII ${ }^{\mathrm{e}}$ siècle, que se fait le commerce colonial le plus important. Ces colonies se sont beaucoup développées au XVIII ${ }^{\mathrm{e}}$ siècle : les plantations de cannes à sucre, de café, d'indigo, de coton font la richesse de la Guadeloupe, de la Martinique et surtout de Saint-Domingue, qui possède deux villes importantes (le Cap français et Port-au-Prince), avec une population s'élevant à 400000 habitants, dont 42000 colons. A la veille de la Révolution, les «îles d'Amérique » envoyaient en France pour 185 millions de marchandises (sucre et café, 134 millions ; coton, 26 millions ; indigo, 11 millions ; cacao et gingembre, 10 millions), et importaient pour 78 millions de marchandises de la métropole, surtout des objets manufacturés (42 millions), des comestibles, des vins et eaux-de-vie. 
Un commerce subsidiaire très important, c'était la traite des nègres, qui enrichit de nombreux armateurs du Havre et surtout de Bordeaux et de Nantes. En 1789, la question de l'affranchissement des esclaves ayant été posée par les partisans des idées nouvelles, ce fut pour les armateurs, comme pour les colons, une cause de graves inquiétudes. En 1789, la Chambre de commerce de Bordeaux, dans ses instructions à ses députés extraordinaires du commerce, déclare : " La France a besoin de ses colonies pour soutenir son commerce, et par conséquent d'esclaves pour faire fleurir l'agriculture dans cette partie du monde, jusqu’à ce qu'on ait trouvé un autre moyen d'y suppléer ».

Une autre question très grave se posait à la fin de l'ancien régime, c'était de savoir si l'on maintiendrait ou non les règles du pacte colonial, la législation restrictive en vertu de laquelle, en France comme à l'étranger, la métropole se réservait le monopole du commerce colonial. Les colons ne pouvaient transporter leurs produits à l'étranger, ni en recevoir directement les marchandises de pays étrangers ou de colonies dépendant d'autres puissances. Mais, comme les Antilles françaises ne pouvaient se passer du bois, des farines, du poisson des colonies anglaises de l'Amérique, - surtout après la perte du Canada et de la Louisiane - , comme, d'autre part, les colonies anglaises avaient besoin du café, du sucre et des mélasses de nos " îles d'Amérique », il se faisait une active contrebande, qu'il était impossible de réprimer. Choiseul, après 1763, dut autoriser les Anglais à importer de la morue aux Antilles, moyennant 8 l. par quintal ; puis, l'arrêt du 30 août 1784 donna accès aux navires étrangers dans quelques ports de nos îles. C'était là une grave innovation, conforme aux tendances libérales de la politique commerciale qui tendait à s'implanter, et qui mécontenta fort les gros négociants et armateurs de la métropole.

La question du pacte colonial, au moment où s'ouvre la Révolution, est encore aggravée par la campagne que les philanthropes, les Amis des Noirs, engagent pour l'émancipation des esclaves noirs, campagne qui inquiète, tout à la fois, les négociants de la métropole et les colons.

D’ailleurs, ce n'est pas seulement en France que le commerce colonial donne lieu aux plus grandes difficultés. Dès le XVII siècle, Anglais, Hollandais et Français avaient essayé d’ouvrir à leur trafic les colonies espagnoles de l'Amérique, et leurs expéditions interlopes y 
parvenaient en partie. Les colons espagnols étaient de plus en plus gênés par les pratiques absurdes de leur métropole, et ce sera la grande cause de leur émancipation au début du XIX ${ }^{\mathrm{e}}$ siècle. Les colons anglais de l'Amérique du Nord veulent aussi se débarrasser des entraves de la législation commerciale, qu'a inaugurée l'Acte de navigation ; c'est en grande partie pour s'en affranchir qu'ils font la révolution qui donne naissance aux États-Unis. L'expansion économique du XVIII ${ }^{\mathrm{e}}$ siècle ne s'accommodait plus des restrictions de l'ancienne politique mercantiliste. On voit toute la portée d'un mouvement qui met en jeu les plus graves intérêts, mouvement vraiment international, et qui retentit profondément sur la politique française, à la fin du XVIII ${ }^{\mathrm{e}}$ siècle.

Les ports français au XVIII ${ }^{\mathrm{e}}$ siècle. - On comprend que les places de commerce les plus florissantes soient les ports, et, en particulier, les ports de l'Atlantique. C'est ainsi que la prospérité de Bordeaux ne fait que s'accroître au cours du XVIII ${ }^{\mathrm{e}}$ siècle, grâce surtout au commerce avec les Antilles. Tandis qu'en 1724 le commerce maritime de Bordeaux se chiffre par 40 millions, à la veille de la Révolution, il s’élève à 250 millions ; 310 navires sont expédiés aux Antilles et en rapportent pour 130 millions de marchandises ; la traite des noirs y est également florissante. Toute une industrie est née du commerce colonial : ce sont surtout des distilleries et des raffineries. De grandes fortunes s'y édifient, comme celles de Bonnafé et de Gradis. Nantes s'est beaucoup développé aussi au XVIII ${ }^{\mathrm{e}}$ siècle, et pour les mêmes raisons : 150 vaisseaux en partent chaque année pour les "îles d’Amérique "; le commerce colonial, la traite négrière enrichissent les négociants, les armateurs et toute une industrie s'y développe : des raffineries et des manufactures d'indiennes. Le commerce d'Amérique avait fait aussi la prospérité de la Rochelle ; mais, dans la seconde moitié du siècle, cette place décroît sensiblement, moins encore par suite de la perte du Canada et de la Louisiane que de l'insuffisance du port, qui n'est plus assez profond pour des bateaux d'un plus fort tonnage. Saint-Malo, bien que conservant son important commerce de toiles avec l'Espagne, décline visiblement au cours du XVIII ${ }^{\mathrm{e}}$ siècle, sans doute parce que le port n'a pas de moyens de communication aisés avec le reste du royaume. Par contre, Le Havre fait de grands progrès après la guerre de Sept ans et participe de plus en plus au grand commerce maritime et colonial. 
Sur la Méditerranée, on ne compte qu'un grand port, Marseille, mais dont le développement s'accentue de plus en plus au cours du siècle. Marseille ne se restreint plus au commerce avec les régions de la Méditerranée : elle participe de plus en plus au commerce mondial, et elle serait plus florissante encore si les communications alpines ne restaient fort malaisées.

Grand épanouissement du commerce au XVIII ${ }^{\mathrm{e}}$ siècle. - Quel a été, dans son ensemble, le développement du commerce extérieur de la France au XVIII ${ }^{\mathrm{e}}$ siècle ? On peut s'en rendre compte d'une façon relativement précise, grâce aux tableaux d'importations et d'exportations, dressés par les agents des douanes, et qui deviennent beaucoup plus explicites dans la seconde moitié du siècle ; c'est grâce à eux qu'Arnould a pu écrire son livre si instructif De la balance du commerce (1788).

Au début du règne de Louis $\mathrm{XV}$, les importations sont évaluées à 93 millions et les exportations, à 122. Vers le milieu du siècle, on constate déjà un sensible progrès : le commerce extérieur s'élève à plus de 600 millions. La guerre de Sept ans détermine une crise très grave, mais, après la paix de 1763, les chiffres se relèvent rapidement :

Dans la période

$1764-1776$

$1777-1783$

$1784-1788$

725 millions de 1 .

683

1061

En 1787, les importations sont évaluées par Arnould à 611 millions, et les exportations, à 542. Le traité de commerce de 1786 va encore contribuer à accentuer la supériorité des importations.

Chaptal, dans son Industrie française, de 1819, estime, pour 1789, les importations à 634365000 fr., et les exportations, à 438477000 . Mais il remarque que dans les importations sont comptés 250 millions de marchandises provenant des colonies françaises, de sorte qu'en réalité les exportations excédaient les importations. La France importe surtout des objets manufacturés, des matières premières pour l'industrie textile, des bois, des denrées coloniales. Ses exportations portent surtout sur les denrées agricoles (notamment les vins et les 
eaux-de-vie), les soieries, le tabac, les produits coloniaux. Chaptal remarque que le commerce avec les Antilles avait une importance de premier ordre : «les productions des colonies entraient dans toutes nos expéditions pour des sommes plus ou moins considérables, et elles formaient même la presque totalité de celles qui étaient destinées pour le Nord ».

De toutes les données précédentes, on peut conclure, semble-t-il, que, de 1716 à 1789, le commerce extérieur de la France a quadruplé, et l'on peut constater encore que les chiffres donnés pour 1825 sont à peine supérieurs à ceux qui nous sont fournis pour 1788 .

Le progrès des transactions commerciales va exercer une influence certaine sur le développement industriel ; c’est là un phénomène économique qui se manifeste en France comme en Angleterre. Les capitaux accumulés par le grand commerce maritime et colonial vont commencer à s'employer dans les entreprises industrielles, et ainsi pourra-t-on voir les premiers symptômes d'une révolution économique qui, en France du moins, ne s’achèvera qu'au siècle suivant.

\section{Table des matières}

\section{Ouvrages à consulter}

AfAnAssieV, Le Commerce des céréales en France au XVIII ${ }^{\mathrm{e}}$ siècle, trad. fr., Paris, 1894.

ARNOUld, De la Balance du commerce, 1788.

BARREY Ph., Le Commerce maritime du Havre (dans les Mémoires et documents pour servir à l'histoire de l'industrie et du commerce de J. Hayem, t. V et VI).

CHAPTAL, L'Industrie française, 1819, 2 vol.

DuMAS F., Étude sur le traité de commerce de 1786 entre la France et l'Angleterre, Toulouse, 1904.

Gerbaux et SchmidT, Procès-verbaux des comités d'agriculture et de commerce de la Constituante, de la Législative et de la Convention, 1906-1910, 4 vol. in$8^{\circ}$.

LETACONNOUX, Les Subsistances et le commerce des grains en Bretagne au XVIII siècle, Rennes, 1909.

LEVASSEUR E., Histoire du commerce de la France, 1911. 
MAlvezin, Histoire du commerce de Bordeaux, 3 vol. in-8 1892.

MARTIN Germain et BEZANÇON, Histoire du crédit en France sous le règne de Louis XIV, Paris, 1913.

MAssON Paul, Histoire du commerce français dans le Levant au XVIII ${ }^{\mathrm{e}}$ siècle, Paris, 1912.

SÉE H., L'Évolution commerciale et industrielle de la France sous l'ancien régime, Paris, Giard, 1925. - Le commerce de Saint-Malo au XVIII ${ }^{\mathrm{e}}$ siècle (Mém. et doc. sur l'histoire du commerce et de l'industrie, publiés par J. Hayem, $9^{\mathrm{e}}$ série, 1925). 


\section{Chapitre 8}

\section{L'ÉVOLUTION INDUSTRIELLE AU XVIII ${ }^{\mathrm{e}}$ SIÈCLE.}

Dans la première moitié du XVIII siècle, on voit se développer les manufactures, organisées comme elles l'étaient à l'époque de Colbert. Comme au siècle précédent, elles dépendent étroitement du pouvoir royal, qui exerce sur elles une tutelle de plus en plus active.

Progrès de l'administration industrielle. - Aussi n'est-il pas étonnant que l'administration industrielle se soit perfectionnée. Le Conseil du commerce ne cesse de jouer un rôle très actif jusqu'à la fin de l'ancien régime, comme en témoignent ses procès-verbaux, qui ont été publiés par Bonnassieux et Lelong ; il s’efforce de résoudre « toutes les difficultés concernant le commerce de terre et de mer, les fabriques et manufactures ». Il a à sa tête, depuis 1730, un directeur du commerce, personnage considérable ; cette fonction a été tenue pendant assez longtemps par les hommes éminents qu'ont été les Trudaine, père et fils.

Les députés du commerce, élus en théorie par les négociants ou les Chambres de commerce, ne jouent qu'un rôle assez passif ; ils rédigent parfois cependant des mémoires intéressants. Plus importante nous apparaît l'institution des Chambres de commerce, qui va en se développant au cours du siècle ; mais elles s'occupent plus encore de commerce que d'industrie.

Les inspecteurs des manufactures, créés par Colbert, se maintiennent jusqu'à la Révolution, et l'on établit même quelques inspecteurs généraux. Ils semblent s'être, en général, acquittés avec conscience de leurs fonctions difficiles et délicates ; quelques-uns d'entre eux, surtout dans la seconde moitié du XVIII ${ }^{\mathrm{e}}$ siècle, sont des hommes de gran- 
de valeur : tels, Desmarets, Hellot, Dupont de Nemours, Roland de la Platière. Quant aux intendants, ils ont de plus en plus à s'occuper des questions industrielles. Non seulement l'administration leur demande souvent de faire des enquêtes sur l'état du " commerce ", mais ils prennent fréquemment l'initiative d'encourager telle ou telle fabrication, surtout les industries nouvelles ; depuis 1744, les mines, les forges, les verreries, les papeteries sont plus spécialement soumises à leur contrôle ; leur droit de juridiction en matière industrielle s'étend de plus en plus.

Les manufactures et leurs monopoles. - Les manufactures dépendent toujours très étroitement de l'administration royale, dont elles sont, à bien des égards, les créations.

En dehors des manufactures d'État, comme les Gobelins, la Savonnerie et Sèvres, dont le roi est le patron, on compte un bien plus grand nombre de manufactures royales, pour l'établissement desquelles il faut une autorisation du gouvernement. Les manufactures royales sont encouragées par des subventions, des prêts sans intérêts, des primes directes ou indirectes. Elles reçoivent aussi, en bien des cas, l'aide pécuniaire des États provinciaux ou des municipalités urbaines.

Les manufactures, qui s'occupent surtout de l'industrie textile, reçoivent le monopole de telle ou telle fabrication dans un rayon plus ou moins étendu. Ainsi, les Van Robais, d'Abbeville, dans un rayon de dix lieues, possèdent, pendant plus d'un siècle, le monopole de la fabrication des draps fins de Hollande. Bien qu'on commence à se rendre compte des inconvénients des monopoles, on crée encore beaucoup de manufactures royales pendant toute la première moitié du XVIII ${ }^{\mathrm{e}}$ siècle.

La réglementation. - La réglementation, qui était l'un des caractères essentiels de l'ancienne organisation industrielle, s'est maintenue. Elle se développe même jusque vers 1750 . Sans cesse on édicte de nouveaux règlements, " parce que les précautions prises par les premiers règlements n'étaient pas suffisantes », ou, comme le dit une circulaire d’Orry, en 1740, pour parer « à la négligence et à la mau- 
vaise foi des fabricants et des marchands ». Plus minutieusement encore qu'à l'époque de Colbert, les règlements déterminent la qualité et la nature des matières premières que l'on doit employer, la nature de l'outillage, les procédés de fabrication, les diverses qualités des objets fabriqués. En 1735, l'autorité royale réglemente l'industrie de la verrerie, en 1739, celle de la papeterie.

L'administration s'efforce aussi de rendre la réglementation plus efficace par un contrôle plus rigoureux ; on accroît le nombre des bureaux de fabrique et on facilite leurs procédés de contrôle.

La réglementation était une cause de vexations perpétuelles, une gêne de tous les instants pour l'industrie ; elle était une entrave aux inventions. Pour prendre un exemple, de 1719 à 1731, il fallut batailler pour obtenir le droit d'employer le plomb laminé, qui constituait un très grand progrès sur le plomb coulé, dont se servait exclusivement la communauté des plombiers, et dont l'usage était imposé par les statuts et règlements. Les besoins de la production ne pouvaient plus se concilier avec les règles si étroites de l'ancienne organisation du travail.

Les progrès de l'industrie dans la première moitié du $\mathrm{XVIII}^{\mathrm{e}}$ siècle. - Cependant, on constate de sérieux progrès industriels entre 1715 et 1750, surtout à partir de 1730. Ainsi, la fabrication de la soie, des étoffes d'or et d'argent se répand à Paris et dans le Midi ; en Languedoc, l'industrie drapière semble assez florissante ; dans l'Est et en Normandie, l'industrie cotonnière s'est beaucoup développée ; fabrication nouvelle, en France comme en Angleterre, elle échappe plus que les autres industries à la réglementation. Puis, ce sont de nouvelles manufactures de fer-blanc, et, en Dauphiné, de nouvelles aciéries ; en Dauphiné et surtout en Angoumois, de nouvelles papeteries. Les mines de houille, jusqu'alors peu et mal exploitées, sont mises en valeur avec plus de méthode, dans le Nord et dans le bassin de SaintÉtienne ; les mines d'Anzin et de Carmaux deviennent actives, et l'arrêt de 1744 va donner un nouvel essor à l'industrie houillère. On s'efforce d'autant plus de la développer que l'on se préoccupe vivement du déboisement, dont on rend surtout responsables les forges et usines. 
Les nouvelles doctrines économiques. - Les transformations industrielles furent certainement hâtées par les idées nouvelles qui se font jour vers le milieu du XVIII ${ }^{\mathrm{e}}$ siècle. La cause de la liberté commerciale et industrielle fut soutenue, tout d'abord, par Vincent de Gournay, qu'avait instruit l'observation des faits, et qui voyait dans le régime corporatif, la réglementation, les privilèges et les monopoles, autant d'obstacles à la production et à la consommation. Il faut donc affranchir de toute entrave la production industrielle. Gournay se livre à une propagande très active pour l'abolition des corporations, pour la suppression de la réglementation. Intendant du commerce, il parvient, tout au moins, à atténuer dans la pratique la rigueur des règlements et le régime des monopoles ; grâce à son influence, le Bureau du commerce n'accorde plus de privilège exclusif. Il sut gagner à ses idées toute une pléiade de jeunes administrateurs, comme les Trudaine et Turgot. L’influence de Quesnay et de ses disciples fut considérable aussi ; après 1760, la doctrine physiocratique fait une active propagande, qui tend à ruiner les anciennes conceptions mercantilistes.

Affaiblissement du régime réglementaire. - En fait, le régime réglementaire s'est bien relâché dans la seconde moitié du XVIII ${ }^{\mathrm{e}}$ siècle. Un fait caractéristique, ce fut l'abolition de la prohibition des toiles peintes et teintes, qui était restée en vigueur pendant toute la première partie du siècle. Vers 1750, un mouvement se dessine vers la liberté ; puis un retour offensif de la prohibition, vers 1755, provoque la grande " querelle des toiles peintes », où entrent en lice, d'une part, des hommes comme Forbonnais, partisan de la tradition, et de l'autre des partisans de la liberté comme Gournay et Morellet, auxquels répondent encore les « Observations sommaires des fabricants de Lyon, Rouen, Tours et des Six Corps ». Enfin, l'édit de 1759, promulgué par le contrôleur général Silhouette, autorise l'entrée et la fabrication des toiles peintes. Ce fut le point de départ d'une grande prospérité pour l'industrie nouvelle de l'impression sur étoffes, pour les manufactures d'indiennes.

Dès lors, si la réglementation subsiste toujours légalement, dans la pratique, on ne l'applique plus qu'assez mollement. Il y a là une ten- 
dance qui se manifeste partout; en Languedoc même, en ce qui concerne l'industrie drapière, le gouvernement recommande aux inspecteurs de ne veiller à l'observation des règlements qu'avec beaucoup de circonspection, de se préoccuper uniquement « de la bonne foi dans la fabrication ». Dans ses lettres patentes du 5 mai 1779, Necker reconnaît qu'il est impossible d'appliquer à la lettre les anciens règlements ; les étoffes fabriquées conformément à ces règlements porteront une marque spéciale, les autres, seulement une «marque de grâce ", et on indiquera aussi le caractère du teint (grand ou petit). De nouvelles lettres, du 4 juin 1780, suppriment, pour toute l'industrie lainière, certaines dispositions relatives à la qualité, à la longueur et à la largeur des pièces. Elles expliquent aussi le caractère de la réforme: "Nous avons eu dessein d'encourager le talent et l'esprit d'invention, en affranchissant de toute espèce d'examen et de visite les étoffes qu'on voudrait fabriquer librement, mais en exigeant seulement qu'elles eussent une marque distincte des étoffes fabriquées librement, afin que la confiance publique ne pût jamais être trompée. " La chute de Necker marqua, à ce point de vue, une réaction ; mais, en fait, à la veille de la Révolution, beaucoup de marchandises sont vendues sans aucune marque ; les malfaçons ne sont plus punies d'amende, ni de confiscation. Dans la pratique, l'ancienne réglementation avait perdu toute efficacité.

Extension de l'industrie rurale. - L'un des traits caractéristiques de l'évolution industrielle du XVIII ${ }^{\mathrm{e}}$ siècle, c'est l'extension de l'industrie rurale ; elle marque fortement, en effet, l'emprise du capitalisme commercial sur la fabrication.

L'édit de 1762, qui donne aux habitants des campagnes le droit de fabriquer toute espèce d'étoffes sans faire partie de corporations de métiers, n'a pas l'importance qu'on lui a souvent attribuée ; sans doute, il a facilité les progrès de l'industrie rurale, mais il confirme surtout un état de fait.

On distingue nettement deux types d'industrie rurale. Le premier s'applique aux régions dont les ressources agricoles sont insuffisantes et où la vie urbaine est peu active, comme la Bretagne et le BasMaine. Dans ces contrées, l'industrie campagnarde de la toile ne fait 
nullement concurrence aux métiers urbains, peu nombreux. Les marchands se livrent exclusivement à des transactions commerciales, ne dirigent pas la production, ne distribuent pas la matière première, que le paysan récolte sur place ; tout au plus s'occupent-ils de faire opérer le blanchiment et le finissage des toiles ; c'est tout à fait par exception qu'ils deviennent entrepreneurs de manufactures. En Bretagne et dans le Bas-Maine, l'industrie rurale ne donnera pas naissance à l'industrie capitaliste ; quand elle tombera en décadence à la fin du XVIII ${ }^{\mathrm{e}}$ siècle et au XIX ${ }^{\mathrm{e}}$, ces provinces deviendront presque exclusivement agricoles.

Au contraire, dans des pays comme la Flandre, la Picardie, la Haute-Normandie, où l'agriculture est prospère, où l'industrie urbaine a essaimé dans les campagnes environnantes, où l'industrie rurale s'est développée surtout parce que nombre de paysans sont dépourvus de propriété, l'artisan rural dépend souvent de véritables manufacturiers, qui lui font des commandes et donnent des directions à son travail. En tout cas, les négociants distribuent aux travailleurs de la campagne la matière première, leur fournissent même les métiers. Ce sont eux qui soutiennent la fabrication rurale au point de ruiner les métiers urbains, comme s'en plaignent les maîtres et compagnons de Troyes ; ce sont eux qui, à la fin de l'ancien régime, dans la bonneterie et dans la filature du coton, introduisent les métiers mécaniques, ce qui rend plus désastreuse encore pour l'industrie urbaine la concurrence des campagnes. Il suffira que les métiers soient concentrés dans des usines pour que naisse la grande industrie, pour que le négociant-entrepreneur se transforme en patron industriel.

L'emprise du capitalisme commercial sur l'industrie. - Dans les métiers urbains de l'industrie textile, on voit souvent s'exercer la même emprise du capitalisme commercial, qui a pour effet de faire tomber les artisans, autrefois indépendants, au rang de salariés. L'exemple le plus frappant nous est fourni par l'industrie lyonnaise de la soie. Déjà au XVII ${ }^{\mathrm{e}}$ siècle, la distinction s'était faite entre maîtres marchands et maîtres ouvriers, comme le montre le règlement de 1667. Le règlement de 1744 consacre la dépendance économique des maîtres ouvriers, qui deviennent les salariés des marchands. Leur dépendance est d'autant plus grande que le marchand fournit la matière première, ainsi que les dessins, et leur avance souvent les sommes né- 
cessaires pour l'achat de l'outillage. Enfin, le prix de la façon est fixé par le marchand ; le salaire n'est établi que quand l'ouvrage est terminé.

Dans l'industrie drapière, on perçoit une évolution analogue, mais moins générale. L'emprise du capitalisme commercial sur le travail s'explique surtout par des raisons techniques, par la multiplicité des opérations auxquelles donne lieu la fabrication. La laine doit être lavée et dégraissée. On la soumet au battage, au cardage ou au peignage, puis on la remet aux fileurs ou fileuses. Après le filage, c'est le dévidage, le bobinage et l'ourdissage. Ensuite, la pièce passe à la teinture et, s'il s'agit d'une laine cardée, au feutrage. Enfin, ce sont les derniers apprêts : le lainage, le tondage et le ratissage. On s'explique ainsi l'intervention du marchand, qui se charge de diriger tout le processus de la fabrication, et cette intervention devient encore plus nécessaire lorsque l'industrie se répand dans les campagnes. Cette concentration commerciale, qui, à la fin du XVIII ${ }^{\mathrm{e}}$ siècle, est complète dans les plus grands centres (Sedan, Reims, Louviers, Elbeuf), ne se manifeste pas partout. Parfois, comme à Amiens, le travail est réparti entre plusieurs entrepreneurs successifs, indépendants les uns des autres ; dans le Midi, les petits fabricants sont encore nombreux.

Les origines de la concentration industrielle. - Là où la concentration commerciale est parfaite, elle entraîne parfois la concentration industrielle. C'est qu'en effet les marchandsentrepreneurs ont intérêt à grouper les ouvriers sous le même toit pour surveiller leur travail et éviter les frais de transport. Tel est le cas d'un certain nombre de manufactures drapières du Midi, comme celles de la Trivalle, près Carcassonne, de Villeneuve, près Clermont ; à Montauban, un manufacturier fait construire un bâtiment qui lui coûte 125000 livres. A Reims, près de la moitié des métiers sont groupés dans de grandes manufactures. A Louviers, la concentration est plus forte encore : quinze entrepreneurs groupent des milliers d'ouvriers ; l'un d'eux fait construire, pour 200000 livres, une énorme manufacture abritant cinq ateliers.

Dans l'impression sur toile, la concentration industrielle s'opère de bonne heure sur une vaste échelle, bien avant l'introduction du ma- 
chinisme. On se l'explique si l'on considère que, comme le dit Ch. Ballot, « les condition techniques de la fabrication nécessitaient l'immobilisation d'importants capitaux, la réunion des ouvriers en ateliers et la division du travail entre eux ». Il faut des terrains étendus pour le blanchiment des toiles, de vastes bâtiments pour les ateliers, de grandes pièces pour le séchage. L'outillage est compliqué et coûteux, et l'on a besoin de stocks importants de matières premières. En outre, la diversité des manipulations exige la division du travail entre de nombreuses catégories d'ouvriers spécialisés, et qui doivent travailler dans le même établissement. Rien d'étonnant que, vers la fin de l'ancien régime, cette industrie comprenne plus d'une centaine de manufactures, produisant pour plus de 12 millions de livres de toiles peintes, la plupart appartiennent à des compagnies d'associés et surtout à des sociétés par actions, fort riches : la société d'Oberkampf, à Jouy, en 1789, a un capital social de près de 9 millions.

Les progrès du machinisme. - Toutefois, la concentration ouvrière et industrielle, condition nécessaire de la grande industrie capitaliste, ne pouvait devenir un phénomène vraiment général que grâce au triomphe du machinisme. Or, au XVIII ${ }^{\mathrm{e}}$ siècle, le machinisme, en France, ne s'introduit que dans quelques industries.

C'est d'abord dans le moulinage de la soie, où on le voit apparaître dès la première moitié du siècle, puis se développer grâce aux inventions de Vaucanson ; aussi cette industrie donne-t-elle lieu à la fondation de grands établissements, comme ceux des Jubié à la Sône.

Mais c'est dans l'industrie cotonnière, - fabrication nouvelle que le machinisme se développe de la façon la plus intense. Comme les inventions techniques ont vu le jour en Angleterre, où l'invention de la navette volante, de John Kay, a suscité tant de perfectionnements, nous devons emprunter à nos voisins ouvriers et machines, la spinning jenny (inventée en 1765), le water-frame, d'Arkwright, qui date de 1767, la mule-jenny, de Crompton. La spinning jenny, étant un petit métier à bras, ne nuit nullement à l'industrie rurale et dispersée ; au contraire, les mule-jennys favorisent la concentration.

Déjà Holker, avant 1760, avait préconisé l'introduction de machines anglaises. Mais ensuite c'est surtout Milne — un autre Anglais — 
qui joue un grand rôle en fabriquant, à la Muette, des métiers employés dans son pays. C'est surtout à partir de 1775-1780 que l'on introduit en France les inventions d'Arkwright et de Cartwright. D’importantes manufactures concentrées sont créées dans la filature du coton, comme celles de Lecler, à Brives, de Martin et Flesselles, à Amiens, du duc d'Orléans — ce grand homme d'affaires — à Orléans et à Montargis.

Il est vrai que la France n'emploie encore que 900 jennys, tandis qu'il en existe 20000 en Angleterre. Ce n'est donc qu'un début. N'empêche qu'en 1789 on voit se dessiner les progrès du machinisme, qui se développera surtout au siècle suivant. Le mémoire de Tribert, inspecteur des manufactures de l'Orléanais, note, en 1790, les progrès du machinisme dans la filature du coton, ce qui va faire disparaître le filage au rouet :

« Depuis environ deux ans, dit-il, on fait mouvoir à Orléans un nombre assez considérable de ces machines nouvellement construites en France sur le modèle de celles employées en Angleterre (machines d'Arkwright et mule-jennys). On vient de construire un vaste monument pour les contenir. Le directeur forme le projet de faire mouvoir, jour et nuit, au moyen d'une pompe à feu, 6000 bobines, qui permettront de filer 1000 livres pesant de coton en 24 heures. Les produits s'élèveront l'an prochain à 900000 livres. »

\section{Et Tribert ajoute :}

« Au moyen de ces machines, dont le nombre commence à beaucoup s'accroître en France, on doit bientôt s'attendre à voir extrêmement diminuer le prix des cotons filés, mais aussi les bénéfices à faire sur cette nouvelle espèce de filature diminueront en proportion, de sorte qu'il sera de l'intérêt des entrepreneurs de faire ouvrager leurs cotons filés. »

C’est dire qu'on devra aussi perfectionner la technique du tissage.

Dans quelques papeteries, notamment à Annonay, on substitue l'industrie mécanique au travail à la main. Mais la plupart de ces établissements sont dotés d'un outillage sommaire et n'emploient que quelques ouvriers. 
Dans l'industrie métallurgique, on commence à remplacer la fonte au bois par la fonte au coke, comme on le fait déjà à Montcenis sur une grande échelle, et, en 1787, est fondée la Société par actions du Creusot, qui, comprenant 4000 actions de 2500 l. chacune, dispose d'un capital suffisant pour employer des machines à vapeur, des marteaux-pilons, un outillage perfectionné et coûteux.

Un mémoire de juin 1787 contient à cet égard des données bien significatives :

« On peut couler dans les quatre hauts fourneaux dix millions de fonte par an, à raison de 2500000 livres par fourneau ; ainsi, le département de la marine pourrait, dans le cas où ses besoins l'exigeraient, tirer de Montcenis 2000 pièces de canon dans une année... Les machines à feu, qui font mouvoir les soufflets, les marteaux et les foreries de Montcenis suppléent aux cours d'eau dont se servent les autres forges du royaume... Les chemins de fer que l'on a faits à Montcenis, à l'imitation de ceux d'Angleterre où des particuliers en ont de 5 à 6 lieues de longueur, paraissent au premier coup d'œil, comme les machines à feu, très dispendieux; mais, lorsqu'on voit sur ces chemins un seul cheval traîner le poids de cinq chevaux, on cesse de s'alarmer sur le sort d'une pareille mise hors. »

A la fonderie d'Indret, créée en 1777, on dépense en 1778, 307000 l., en 1779, 577 000, en 1780, 830 000. Mais Le Creusot et Indret sont des établissements tout à fait exceptionnels. Presque tous les établissements sidérurgiques sont encore de très modestes exploitations à outillage rudimentaire et n'employant que huit ou dix ouvriers. Les forges sont éparpillées sur tout le territoire, tout au moins dans les régions forestières, car elles n'usent encore que de charbon de bois.

Les mines de houille, grandes exploitations capitalistes. - Ce sont les mines de houille qui annoncent le plus fortement le triomphe futur de la grande industrie capitaliste. A la suite de l'arrêt de 1744, établissant qu'aucune mine ne pourrait être exploitée qu'en vertu d'une concession royale, de grandes compagnies accaparent toute l'exploitation houillère aux dépens des propriétaires ou des anciens entrepreneurs. Seules, en effet, elles sont capables d'accomplir les perfectionnements techniques nécessaires : les sondages, l'ouverture 
des galeries et des puits, l'aérage, l'épuisement de l'eau ; seules, elles peuvent employer des "pompes à feu ", c'est-à-dire des machines à vapeur. C'est que ces compagnies - Alais, Carmaux, Anzin surtout — sociétés par actions, menées par des hommes d'affaires énergiques et intelligents, soutenues aussi par quelques gentilshommes entreprenants, comme le prince de Croy et le chevalier de Solages, ont l'aspect de grandes entreprises capitalistes. La Compagnie d'Anzin, en 1789, compte 4000 ouvriers et 600 chevaux; elle emploie 12 machines à vapeur ; l'extraction du charbon produit 3750000 quintaux ; ses bénéfices s’élèvent à 1200000 l., bien que le prix du charbon ait sensiblement diminué. Ainsi, exploitation scientifique, concentration de nombreux ouvriers, emploi de capitaux considérables : voilà déjà tous les caractères de la grande industrie capitaliste qui se manifestent dans l’industrie houillère avant la fin de l'ancien régime.

La petite industrie, toujours prédominante. - Cependant, en 1789, le machinisme et la concentration industrielle n'en sont encore qu'à leur début. Le régime prédominant, dans toute la France, c'est celui des petites entreprises, n'occupant que quelques ouvriers. Voici, par exemple, la généralité d'Orléans, que nous décrit l’inspecteur Tribert, en 1790. On trouve bien à Orléans une grande filature de coton et il s'en monte une autre à Montargis. Mais la fabrication des bas s’opère dans 55 ateliers, employant 2287 ouvriers, dispersés dans la ville et sa banlieue ; la bonneterie au tricot est une industrie rurale qui emploie en Beauce 12000 personnes ; les étoffes de laine et les teintures sont aux mains de fabricants peu aisés ; la ganterie est fabriquée par 21 maîtres, qui font travailler 900 ouvriers.

Sans doute, en France, à la veille de la Révolution, le capitalisme commercial commence à exercer une grande action sur l'industrie. Mais l'évolution y est plus tardive et plus lente qu'en Angleterre ; on ne perçoit encore que les symptômes d'une révolution industrielle, qui ne s'achèvera qu'un demi-siècle plus tard. 


\section{Ouvrages à consulter}

Outre les ouvrages cités aux chapitres VI et VII :

BALloT Ch., L'Introduction du machinisme dans l'industrie française, publié par Cl. Gével (Comité des travaux historiques, section d'histoire moderne et contemporaine, fasc. IX, 1923).

BonnassieuX et LeLONG, Inventaire analytique des procès-verbaux du Conseil de Commerce, Paris, 1900, in- $4^{\circ}$.

BOURDAIS F. et DuRAND R., L'Industrie et le commerce de la toile en Bretagne au XVIII siècle (Comité des Travaux historiques, 1922, fasc. VII).

BouRGIN Hubert et Georges, L'Industrie sidérurgique en France à la veille de la Révolution, 1920 (Coll. des Doc. économiques de la Révolution).

DePITRE E., La Toile peinte en France aux XVII ${ }^{\mathrm{e}}$ et XVIII ${ }^{\mathrm{e}}$ siècles, Paris, 1912.

Dutil Léon, L'État économique du Languedoc à la fin de l'ancien régime, Paris, 1911.

GODART Justin, L'Ouvrier en soie de Lyon, 1901.

HAYEM Julien, Mémoires et documents pour servir à l'histoire du commerce et de l'industrie en France, 8 séries, Paris, 1911-1924.

Histoire documentaire de l'industrie à Mulhouse, publ. de la Soc. industrielle de Mulhouse, 2 vol., 1901.

LEVAINVILLE, L'Industrie du fer en France, 1922 (Coll. Armand Colin).

LEVASSEUR E., Histoire des classes ouvrières et de l'industrie en France avant 1789, $2^{\mathrm{e}}$ éd., 1901, 2 vol. in- $8^{\circ}$.

LÉvY Robert, Histoire économique de l'industrie cotonnière en Alsace, Paris, 1912.

MANTOUX Paul, La Révolution industrielle au XVIII ${ }^{\mathrm{e}}$ siècle, Paris, 1905.

MARTIN Germain, La Grande Industrie sous le règne de Louis XV, Paris, 1900.

- L'Industrie et le commerce dans le Velay aux $\mathrm{XVII}^{\mathrm{e}}$ et XVIII ${ }^{\mathrm{e}}$ siècles, Le Puy, 1900.

PARISET E., Histoire de la fabrique lyonnaise, Lyon, 1901.

Clerget Pierre, L'Industrie de la soie en France, 1925 (Coll. Armand Colin).

RoufF Marcel, Les Mines de charbon en France au XVIII siècle, Paris, 1922.

SÉE H., Quelques Aperçus sur les métiers urbains en Bretagne au XVIII ${ }^{\mathrm{e}}$ siècle (Revue d'histoire économique, 1926).

- Le Commerce des toiles du Bas-Maine pendant la première moitié du XVIII siècle (Mémoires et documents, publiés par J. Hayem, 10e série, 1926).

BACQUiÉ F., Les Inspecteurs des manufactures sous l'Ancien Régime, 1669-1792 (Mémoires et documents, publiés par J. Hayem, $11^{\mathrm{e}}$ série, 1927). 


\section{Chapitre 9}

\section{LES CLASSES OUVRIÈRES ET MARCHANDES.}

Il importe maintenant d'examiner les répercussions sociales des phénomènes économiques que nous venons d'exposer. Dans la population industrielle et commerçante, les différenciations s'accentuent au cours du XVIII ${ }^{\mathrm{e}}$ siècle, conséquence même de l'expansion économique.

\section{Les artisans.}

Leur mode de vie. - Toujours fort médiocre, il semble qu'il devienne encore moins satisfaisant au XVIII ${ }^{\mathrm{e}}$ siècle. Dans la plupart des villes de province, beaucoup de maîtres, sur lesquels rejaillit la ruine financière de leurs corporations, sont gênés, ont du mal à vivre, se trouvent dans un état voisin de la misère, comme le constate le rapport de l'intendant de Bretagne, de 1755.

Au XVIII ${ }^{\mathrm{e}}$ siècle, comme au XVII ${ }^{\mathrm{e}}$ leur vie est bien étroite. Leur habitation est peu confortable. A Angers, nous disent les Souvenirs d'un nonagénaire, " les artisans étaient pour la plupart très étroitement logés ; outre leur boutique ou atelier, ils n'occupaient souvent qu'une grande chambre à coucher pour la famille, puis une autre pièce pour les compagnons que l'on était dans l'usage de nourrir et de loger ». Les boutiques les mieux achalandées ont un aspect assez misérable : cependant, à la fin du XVIII ${ }^{\mathrm{e}}$ siècle apparaissent, dans les grandes villes au moins, quelques magasins vitrés.

L'alimentation est grossière, souvent insuffisante. A Châtellerault, la femme d'un coutelier décrit ainsi la nourriture : « du pain et de la soupe plusieurs fois par jour, parce que la viande est trop chère : sou- 
pe aux herbes, soupe aux carottes, soupe à l'oignon avec l'huile ; on boit de l'eau à la maison, mais, le lundi, le maître va boire du vin au cabaret avec ses compagnons ».

Leur condition n'est pas uniforme. - D'ailleurs, la condition des artisans varie assez sensiblement suivant le métier qu'ils professent. Les seuls qui soient vraiment aisés, ce sont ceux qui pourvoient à l'alimentation, surtout les aubergistes, pâtissiers, confiseurs, parfois les boulangers, plus rarement les bouchers, dont le métier n'est souvent que peu lucratif. Les métiers de l'habillement sont bien moins avantageux : ils contiennent beaucoup d'artisans, peu fortunés, qui se font concurrence : tel est le cas des tailleurs et des cordonniers. Dans le bâtiment, la plupart des maîtres sont assez peu aisés, bien que, parmi les maçons et les charpentiers, on trouve déjà des entrepreneurs, qui disposent de capitaux plus importants. Dans les industries urbaines du fer, on n'aperçoit encore aucune trace d'une semblable transformation ; les métiers de taillandiers et de tourneurs sont encore assez misérables. Parmi les teinturiers et les artisans du cuir, on observe une grande diversité de conditions.

Artisans perdant leur indépendance économique. - Si une petite minorité d'artisans tend à s'élever à une classe supérieure, bien plus nombreux sont ceux qui perdent de plus en plus leur indépendance économique et tendent à devenir des salariés. Tel est le cas de beaucoup d'artisans de l'industrie drapière, de plus en plus soumis à la domination économique des marchands drapiers. Tel est le cas surtout des maîtres ouvriers de la soie à Lyon, comme l'a montré d'une façon si précise M. Justin Godart. Le règlement de 1744, aggravant celui de 1667, rend plus stricte la "lettre de crédit » où sont inscrits les travaux que le maître ouvrier s'engage à livrer au marchand, de sorte qu'il ne peut que très difficilement quitter le négociant pour lequel il travaille, et qui fixe, sans le consulter, les prix de façon. Ainsi, une aristocratie de marchands tient sous sa dépendance une plèbe d'ouvriers. C'était là le résultat d'une évolution fatale ; les marchands, disposant de capitaux souvent considérables, devaient, à mesure que 
la production et le marché s'étendaient, faire la loi aux ouvriers, qui n'avaient pas d'avances.

En fait, les prix de façon, que les marchands imposent aux ouvriers, sont insuffisants pour assurer à ces derniers une vie convenable. Beaucoup d'entre eux sont réduits à la misère et réclament en vain un tarif équitable. Leur budget est toujours en déficit, même lorsque l'industrie est prospère. La journée de travail est excessive : " toujours, déclare l'abbé Bertholon, l'ouvrier fabricant devance l'aurore et prolonge ses travaux bien avant dans la nuit, pour pouvoir, par la longueur du temps, compenser la modicité des salaires insuffisants. Aussi des révoltes éclatent-elles assez fréquemment ; on les réprime durement, et elles n'ont pas pour effet d'améliorer le sort de ces malheureux ouvriers ».

\section{Les marchands, les négociants, les directeurs de manufactures.}

Diversité des conditions. - Parmi les corporations marchandes, il en est dont certains membres, par leur situation de fortune, confinent à la haute bourgeoisie ; ce sont surtout les corporations des apothicaires, des imprimeurs et libraires, des orfèvres, des merciers, des marchands de drap et de soie. Mais, dans d'autres corporations, on constate des conditions bien diverses ; tel est le cas des épiciers. Puis il y a beaucoup de petits marchands : tels, les fripiers et surtout les revendeuses, regrattières, etc...

Dans la bourgeoisie commerçante, la place la plus haute est tenue par les négociants en gros, qui échappent à l'organisation corporative. On a déjà vu le rôle qu'ils jouent, comment, dans l'industrie textile surtout, ils commencent à imposer leur domination économique aux artisans. Ils ouvrent directement la voie à la classe des grands patrons industriels. Dans les ports comme Nantes, Bordeaux, Marseille, ce sont les armateurs qui constituent le principal contingent de la classe des négociants et jouent un rôle prépondérant. D’ailleurs, ils ne se bornent pas à l'armement; ils font le plus souvent le commerce de commission et entreprennent l'assurance maritime. 
C'est dans la même classe qu'il faut ranger les directeurs de manufactures, qui nous apparaissent parfois comme de grands capitalistes, ainsi que les concessionnaires de mines, tels les Mathieu, les Tubeuf, gros entrepreneurs qui se trouvent à la tête de puissantes sociétés capitalistes.

Les négociants possèdent déjà une situation prépondérante dans les rangs du tiers état ; c’est ainsi que, dans les assemblées électorales de 1789, bien que peu nombreux, ils éclipsent souvent les maîtres des corporations et sont souvent les seuls, avec les hommes de loi et les bourgeois vivant noblement, à rédiger les cahiers du tiers. L'opposition se marque entre négociants et artisans, tandis que les maîtres des métiers et les compagnons ont souvent les mêmes intérêts.

Le mode de vie de la bourgeoisie commerçante. - Comme il y a de grandes différences de situation entre les simples marchands et les négociants, leur genre de vie diffère aussi profondément. Les marchands, même aisés, vivent très simplement ; ils n’ont pas de salon ; ils mangent dans leur cuisine. Au contraire, les négociants ont un train de vie souvent plus luxueux que les nobles. Les armateurs de Nantes, ceux de Bordeaux et de Saint-Malo se font construire de splendides demeures, et ils connaissent tous les raffinements du luxe. Dans la seconde moitié du siècle, on constate encore un nouveau progrès du luxe et du confort ; dans une petite ville comme Laval, les négociants en toile se font élever de nouvelles habitations ou modifient tout l'aménagement des anciennes ; ils ne se contentent plus d'une " pièce à feu ", ils ne vivent plus dans leur cuisine, ils veulent déjà se donner un bien-être tout moderne.

\section{Les compagnons.}

Les diverses catégories. - Il faut distinguer, parmi eux, les ouvriers des corps de métiers et ceux des manufactures. Ceux-ci sont plus mobiles et parfois on n'exige d'eux aucun apprentissage régulier. Il leur est plus facile aussi de franchir les divers échelons de la hiérarchie. Mais, d'autre part, ils sont soumis à la discipline plus sévère des 
règlements d'ateliers. Il leur est difficile aussi de quitter la manufacture : il leur faut un " congé par écrit »; c'est déjà l'obligation du livret. A ceux qui passent à l'étranger et que l'on considère comme des déserteurs on inflige des peines fort sévères. Les ouvriers des corps de métiers sont traités d'une façon plus paternelle ; les maîtres souvent voient en eux des hommes appartenant à la même classe.

Condition de vie. - Le niveau de vie de l'ouvrier ne diffère pas profondément du standard of life du maître, seulement, il lui est encore inférieur. Il habite, en général, une mansarde peu confortable et son mobilier rudimentaire a une valeur qui ne dépasse guère une centaine de livres. Par son habillement il se distingue aussi, beaucoup plus qu'aujourd'hui, des autres classes de la société. Quand le compagnon est logé et nourri par le maître, son genre de vie est très variable suivant les métiers et les maîtres ; les papetiers ont su obtenir une nourriture confortable.

A quel point est dure la condition du compagnon, c'est ce que montrent surtout la durée de la journée de travail et les salaires.

En règle générale, la journée commence de bonne heure et finit tard. A Versailles, dans nombre d'ateliers, on besogne de 4 heures du matin à 8 heures du soir ; à Paris, dans la plupart des métiers, on travaille seize heures, et les relieurs et imprimeurs, dont la journée ne dépasse pas quatorze heures, sont considérés comme des privilégiés. Il est vrai que le travail était moins intense que de nos jours et que les journées de chômage, imposées par les fêtes, étaient nombreuses ; mais les journées de travail n’en étaient pas moins pénibles.

Quant aux salaires, ils sont évidemment très variables, suivant les métiers et suivant les localités. Les plus favorisés des compagnons, des ouvriers qualifiés des villes, peuvent gagner 40 sous ; mais, dans l'industrie textile notamment, la moyenne ne dépasse pas 20 ou 25 sous ; en Bretagne, un tisserand ne reçoit guère plus de 10 à 12 sous, une fileuse, 5 à 6 sous ; dans les mines mêmes, les manœuvres gagnent souvent moins de 15 sous, les ouvriers qualifiés, de 20 à 25 sous. Dans les villes, il existe une grande quantité de manœuvres, exerçant de petits métiers, et qui ne parviennent pas à gagner leur vie. Les salaires se sont élevés, il est vrai, sous le règne de Louis XVI, 
mais, à cette époque aussi, s'est produite une hausse des prix qui dépasse de beaucoup la hausse des salaires, de sorte que la condition des ouvriers s’est plutôt aggravée.

Ce qui prouve, en tout cas, combien la condition des ouvriers était précaire, c'est qu'à chaque époque de crise, un grand nombre d'ouvriers sont réduits positivement à la mendicité ; cette misère apparaît d'une façon frappante lors de la crise de 1787-1789, qui a singulièrement contribué à provoquer la Révolution.

L'organisation ouvrière. Les compagnonnages. - Si les ouvriers n’ont pu améliorer sensiblement leur condition, c'est qu'il n'existe pas d'organisation ouvrière vraiment forte.

Il est vrai que les compagnons, exclus des confréries des maîtres, forment des confréries particulières, qu'on ne peut arriver à dissoudre. Ils forment aussi des associations générales, des compagnonnages, presque exclusivement restreints aux métiers du tour de France. Les compagnons du devoir ou dévorants et les compagnons du devoir de liberté ou gavots ne ressemblent, d'ailleurs, que fort peu aux modernes syndicats ; ce sont des associations secrètes, où un rituel, affectant des formes mystérieuses, joue un grand rôle. Cependant, les compagnonnages constituent des organes de défense et de résistance vis-àvis des maîtres ; ils établissent des secours mutuels, jouent un grand rôle dans l'embauchage des ouvriers, au grand déplaisir des maîtres, que souvent ils parviennent à mettre à l'index en prévenant leurs camarades par des sortes de circulaires. Ils ont donc rendu de sérieux services aux ouvriers des métiers du tour de France. Mais la rivalité des deux compagnonnages, qui se manifeste souvent par des rixes sanglantes, les a empêchés de jouer un rôle pleinement efficace. Cette concurrence déplorable prouve précisément à quel point les ouvriers ont encore peu la conscience de leurs intérêts collectifs.

Les ouvriers de certains métiers, cependant, se distinguent par la puissance de leur organisation ; tels, les papetiers qui, grâce à elle, obtiennent des conditions de vie meilleure; tels aussi les chapeliers, qui s'entendent même avec les ouvriers belges, comme l'a montré M. des Marez. Il semble qu'il existe déjà, dans certains centres au 
moins, des sociétés de secours mutuels qui servent de couvert à de véritables sociétés de résistance.

Les grèves. - Les coalitions temporaires deviennent plus fréquentes au XVIII ${ }^{\mathrm{e}}$ siècle qu'aux époques antérieures. Mais ce sont surtout des explosions de colère violentes, qui s'éteignent rapidement. Certaines grèves, comme la grève des imprimeurs de Paris, en 1724, sont provoquées par le désir d'empêcher l'entrée dans les ateliers d'ouvriers étrangers ou non qualifiés, qui font baisser le prix de la main-d'œuvre. D’autres, comme la grève des relieurs de Paris (1776), ont pour objet la réduction de la journée de travail. Mais c'est surtout la question des salaires qui détermine les mouvements ouvriers. En 1724-1725, au moment où, pour abaisser les prix, on veut réduire les salaires, on signale un mouvement général dans les métiers parisiens, mais qu'on est parvenu assez rapidement à étouffer. A Paris, sous le règne de Louis XVI, il y eut un mouvement gréviste assez étendu : même les gagne-deniers, jusqu'alors sans organisation, ont formé une coalition. A Marseille, en 1787, éclate une grève très inquiétante d'ouvriers chapeliers.

Mais les grèves sont, en général, condamnées à des échecs, parce qu'elles sont presque toujours localisées à une corporation ou à une ville. D'autre part, les maîtres se coalisent contre les compagnons, s'entendent pour empêcher la hausse des salaires et intimider ceux de leurs confrères qui seraient disposés à céder aux réclamations ouvrières.

L'attitude des pouvoirs publics. - Considérons encore qu'au $\mathrm{XVIII}^{\mathrm{e}}$ siècle, les pouvoirs municipaux et l'autorité royale se montrent particulièrement hostiles aux revendications ouvrières. On réprime durement les grèves des tondeurs de Sedan et celles des compagnons parisiens, à l'époque de Louis XVI.

L'État, au moment même où il tend à relâcher les règlements de fabrication, s’applique plus activement à renforcer la réglementation du personnel. Il se préoccupe surtout de lier l'ouvrier au patron. Rien ne le montre mieux que les lettres patentes de janvier 1749, qui défen- 
dent aux ouvriers, sous peine de 100 livres d'amende, de quitter leurs maîtres sans un congé écrit, qui interdisent aussi aux compagnons de s'assembler, de " faire confrérie », de " cabaler, pour se placer les uns les autres chez des maîtres ou pour en sortir, ou d'empêcher, de quelque manière que ce soit, lesdits maîtres de choisir eux-mêmes leurs ouvriers, soit français, soit étrangers ". Ainsi on veut soumettre étroitement l'ouvrier au patron ; c'est qu'on songe uniquement à favoriser la fabrication, à accroître la production.

L'édit de Turgot, de 1776, supprime toute association de compagnons, comme toute corporation de maîtres, et le ministre réformateur conserve toutes les mesures policières en usage contre les associations ouvrières. Enfin, le règlement de police du 12 septembre 1781 accentue encore les prescriptions antérieures, interdit aux ouvriers de former des confréries, de tenir des assemblées, de cabaler pour augmenter leurs salaires ; ils ne pourront quitter leur patron qu'après l'avoir prévenu à l'avance et terminé l'ouvrage en train ; ils ne pourront être reçus chez aucun maître s'ils ne lui présentent un congé écrit de leur ancien patron. L'obligation du livret est bien devenue générale. A tout instant, Parlements, intendants, officiers de police rendent des arrêtés contre des coalitions, des assemblées, condamnent des ouvriers comme « cabaleurs ». On montre une grande défiance même à l'égard des mutualités, qui se contentent, comme la Société des faïenciers de Nevers, d'assurer à leurs membres des secours en cas de maladie et d'assister les vieillards. On supprime brutalement la société de secours fondée par les chapeliers de Marseille en 1772. On craint sans doute, - et ce n'est peut-être pas sans raison - , que ces associations ne servent de masques à des organisations plus militantes.

Il n'y a pas encore de question ouvrière. - Une preuve encore que les ouvriers ne comptent guère dans la société de l'ancien régime, c'est qu'ils ne participent que bien faiblement à la consultation nationale à laquelle donna lieu la convocation des États Généraux de 1789. Tandis que les paysans eurent la faculté d'exprimer leurs doléances dans d'innombrables cahiers de paroisses, les compagnons n'ont pas pu, pour ainsi dire, faire entendre leur voix. Seuls, les maîtres des métiers ont pris une part active aux assemblées électorales. Aussi ne possédons-nous que quelques cahiers des compagnons de Troyes et de 
Marseille, et leurs revendications se confondent, en général, avec celles des maîtres ; c'est le cas, tout au moins, pour les ouvriers de Troyes, qui, comme leurs patrons, s'élèvent contre les pratiques des négociants, protestent contre l'introduction des machines et l'extension de l'industrie rurale. Très visiblement, en 1789, les ouvriers ne se rendent guère compte encore de leurs intérêts collectifs de classe. Ils n'ont pas une idée nette des réformes qu'il conviendrait d'apporter à la législation ouvrière, et, lorsque la loi Le Chapelier, de 1791, interdit toute coalition ouvrière, elle semble n'avoir pas indigné outre mesure les compagnons parisiens, qui s'agitent surtout, on pourrait dire presque exclusivement, pour des questions de salaires.

Ainsi, la question ouvrière ne se pose nullement comme elle se posera plus tard. On ne perçoit pas encore nettement la lutte entre le capital et le travail ; on l'entrevoit peut-être d'une façon confuse ; elle n'apparaîtra en pleine lumière que lorsque les formules théoriques en seront données. Et on se l'explique aisément si l'on considère que les ouvriers sont encore relativement peu nombreux, que la petite industrie est toujours prédominante, que le machinisme fait à peine son apparition et que la concentration industrielle n'en est encore qu'à ses débuts. La question sociale qui se pose en 1789, c'est la question paysanne, et c'est elle que les assemblées révolutionnaires, sous le coup des troubles agraires, devront résoudre.

Est-ce à dire que la classe ouvrière n'ait joué aucun rôle pendant la crise révolutionnaire ? Artisans et compagnons formeront l'élément actif des journées révolutionnaires et tiendront une place importante dans les sociétés populaires. Mais la question sociale qui soulève les masses populaires, ce n'est pas celle de l'organisation du travail, mais bien celle des subsistances. Le chômage, la misère, la crainte de la disette, voilà ce qui émeut surtout le prolétariat des villes. Pour que la question ouvrière se pose vraiment, il faudra une profonde transformation économique, le développement de la grande industrie, le triomphe du machinisme ; c'est surtout grâce à ces phénomènes économiques que la classe ouvrière prendra nettement conscience de ses intérêts collectifs. 


\section{Ouvrages à consulter}

Outre les ouvrages cités aux chapitres VI et VII :

BLOcH Camille, Études d'histoire économique de la France (1760-1789), Paris, 1900.

BABEAu A., Les Artisans et les domestiques d'autrefois, Paris, 1886.

BOURDE DE LA ROGERIE, Notes sur les papeteries des environs de Morlaix (Bulletin historique et philologique, 1911).

Des Marez G., Le Compagnonnage des chapeliers bruxellois, Bruxelles, 1909.

FOURNIER J., Cahiers de doléances de la sénéchaussée de Marseille, Marseille, 1908.

HAUSER H., Les Compagnonnages d'arts et métiers de Dijon aux XVII ${ }^{\mathrm{e}}$ et XVIII ${ }^{\mathrm{e}}$ siècles (Revue bourguignonne d'Enseignement supérieur, 1907).

HAYEM Julien, La Répression des grèves au XVIII ${ }^{\mathrm{e}}$ siècle (Mém. et doc. sur l'histoire de l'industrie et du commerce, t. I).

MARTIN Germain, Les Associations ouvrières au XVIII siècle, Paris, 1900.

RICHARD J.-M., La Vie privée dans une province de l'Ouest, Laval aux $\mathrm{XVII}^{\mathrm{e}}$ et XVIII ${ }^{\mathrm{e}}$ siècles, Paris, 1922.

RoufF M., Tubeuf, un grand industriel français au XVIII siècle, Paris, 1922.

TARLÉ E., La Classe ouvrière en France pendant la Révolution, en russe (analysé par Karéiev, Révol. franc, 1912, t. 62).

Vernier J.-J., Cahiers de doléances du bailliage de Troyes, 1909 (Coll. des Doc. écon. de la Révolution). 


\section{Chapitre 10}

\section{LES GENS DE FINANCE.}

La classe des gens de finance comprend deux grands groupes : $1^{\circ}$ les banquiers ; $2^{\circ}$ les officiers de finance qui, à un titre quelconque, gèrent les finances royales.

Les banquiers. - Les banquiers et gens d'affaires ne jouent encore qu'un rôle secondaire. La banque lyonnaise, si importante au XVI siècle, est bien déchue de son ancienne splendeur. A Paris, le nombre des banquiers s'accroît au cours du XVIII ${ }^{\mathrm{e}}$ siècle, surtout dans la seconde moitié du siècle, mais ils s'occupent plus encore des emprunts de l'État que d'affaires industrielles et commerciales. Le change est encore l'une de leurs principales fonctions ; ils reçoivent, en grande quantité, des piastres de l'Amérique espagnole, que fournit le commerce de Cadix, et les échangent contre des valeurs françaises. En province, les banquiers sont très peu nombreux ; une ville comme Angers n'en comptait aucun en 1789. A Rennes, il n'y en avait guère que deux ou trois, dont l'importance peut s'expliquer par le voisinage de la place de Saint-Malo et le commerce des toiles, qui donne lieu, en Bretagne, à un trafic fort actif. Il est vrai que les divers officiers de finance se livraient le plus souvent à des opérations de banque.

Il convient de signaler la part très considérable que prennent à la banque française des Genevois, comme Thélusson, Isaac Vernet, Saladin, Necker ; l'histoire de leur activité resterait encore à écrire.

Les banquiers de la cour ont une situation particulièrement importante. On peut citer parmi eux : Jean-Joseph de la Borde, un des plus puissants manieurs d'argent de l'époque, qui donna à chacune de ses deux filles un million de dot, et Magon de la Balue, de la famille des 
grands armateurs malouins, qui fut mêlé à toutes les grandes affaires et devint fermier général.

Parmi les gens d'affaires, il faut citer encore Samuel Bernard, qui profita surtout des embarras du Trésor, à la fin du règne de Louis XIV ; peu délicat dans ses tractations, ayant fait, en 1709, une faillite de 30 millions, il était cependant, au début du règne de Louis $X V$, le plus puissant des hommes de finance. Seuls, les Crozat pouvaient rivaliser avec lui. Les Pâris, fils d'un cabaretier de Moirans (en Dauphiné), avaient fait leur fortune comme fournisseurs d'armée. Ce fut Pâris-Duverney qui fut chargé de la liquidation du système de Law. Éloignés des affaires pendant le ministère de Fleury (1726-1743), Pâris-Duverney et son frère, Pâris de Montmartel, restent, pendant le règne de Louis XV, les grands capitalistes que l'on trouve mêlés à toutes les affaires commerciales et industrielles exigeant de fortes mises de fonds.

Les officiers des finances. - Mais les officiers des finances royales tiennent une plus grande place encore que les hommes d'affaires. Ils sont très nombreux. Que l'on songe que chaque généralité compte deux receveurs généraux alternatifs, et chaque élection, un receveur particulier. Puis viennent les officiers des différentes administrations financières. Ainsi, dans une ville comme Rennes, vers le milieu du $\mathrm{XVIII}^{\mathrm{e}}$ siècle, outre le trésorier général des États, les rôles de la capitation nous révèlent l'existence d'un receveur des domaines, d'un receveur des octrois, d'un contrôleur des eaux et forêts, de deux receveurs des fouages, d'un receveur des saisies réelles, d'un agent des fermes, d'un trésorier des guerres, d'un directeur des vivres, d'un directeur de la Trésorerie, d'un directeur et d'un essayeur de la monnaie, d'un receveur du tabac, d'un directeur et d'un caissier général des devoirs, des employés du contrôle (directeur et ambulants). Tous ces officiers, qui ont des cotes élevées de capitation, jouissent d'une situation de fortune vraiment brillante. Et encore en Bretagne n'y a-t-il pas d'officiers de la gabelle.

Les fermiers généraux. - Au premier rang des gens de finance se placent les fermiers généraux. On comprendra leur importance si 
l'on considère que de la ferme générale dépend tout ce que nous appelons aujourd'hui impôts indirects : aides, contrôles, domaine, traites, gabelle, tabac. Tous les six ans, le bail de ces revenus était adjugé à un particulier pour une certaine somme ; celui-ci avait comme cautions des financiers, qu'on appelle improprement fermiers généraux, et qui étaient au nombre de 40. Ils versaient, chacun, un cautionnement, d'abord d'un million, puis de 1560000 livres à partir de 1768 ; ils touchaient les intérêts de ce cautionnement à 10 \% et, en outre, une indemnité fixe d'environ 30000 livres. L'accroissement progressif des baux de la ferme générale marque la hausse de ses revenus : en 1726, 80 millions ; en 1744, 92 ; en 1756, 110 ; en 1768, 132 ; en 1774, 152. Necker, en 1780, a ôté à la ferme générale les aides, qui furent données à une régie générale, et les domaines, qui furent confiés à une "administration générale ", ce qui n’empêcha pas le dernier bail, celui de 1786, d'atteindre la somme de 150 millions. Ce qui aggravait les abus que l'on reprochait à la ferme générale, c'étaient les croupes, c'est-à-dire les " parts d'intérêt » servies à des personnes qui avaient contribué à fournir les cautionnements des fermiers généraux ou qui simplement avaient, par leur influence, fait attribuer un poste de fermier général à tel ou tel financier. On ne saurait nier les abus auxquels donnait lieu la perception des impolis affermés, mais ces abus allaient en s'atténuant, vers la fin de l'ancien régime, et il ne faut pas croire sur parole des pamphlétaires, comme Darigrand, l'auteur de l'Anti-financier, de 1763, ni le marquis de Mirabeau.

On a beaucoup reproché à certains fermiers généraux leur basse extraction. On compte, il est vrai, parmi eux, surtout dans la première moitié du siècle, des hommes qui avaient débuté comme valets, tels que Teissier et La Bouexière. Mais la plupart avaient commencé leur carrière comme agents des finances; ce fut, par exemple, le cas de Bouret, receveur général à la Rochelle, puis trésorier général de la maison du roi ; on cite un de ses collègues qui a été receveur général de Tours. Grimod de la Reynière avait pour père un financier. Dupin était le fils d'un receveur de tailles et sa fortune avait pour origine son mariage avec une fille naturelle de Samuel Bernard. Lallemand de Retz, Live de Bellegarde, d'Arnoncourt, fermiers généraux en 1726, appartenaient à des familles aisées et considérées. Quelques-uns même, comme d'Arconville et d'Angray de Vallerand, étaient issus de la noblesse de robe. 
Ce qui est vrai, c'est que beaucoup d'entre eux jouissaient d'énormes fortunes; tels Bouret, auquel on attribuait un revenu de 1500000 livres, et Thoynard qui, en 1753, laissa 19 millions à son fils, lequel ne tarda pas à les dissiper. Les fermiers généraux devinrent célèbres aussi par leur faste. A Paris, ils se font construire de splendides hôtels, parmi lesquels on peut citer l'hôtel de Samuel Bernard, dont les curieux restes sont conservés au musée André ; à la campagne, ils ont de superbes résidences, sans compter les " petites maisons » ou "folies » des faubourgs. Dans les environs immédiats de Paris, à Passy, Auteuil, Vanves, Ivry, Puteaux, Neuilly, on admire les maisons de campagne des riches financiers. Ce sont eux qui commandent les plus riches ameublements, les œuvres d'art du goût le plus sûr ; c'est pour eux que travaillent les artisans et les artistes les plus habiles. Les mémoires et les correspondances du temps nous entretiennent aussi des folles dépenses auxquelles se livrent les financiers pour leurs maîtresses, comédiennes ou «filles d’opéra ».

Rôle social des financiers. - Les financiers ont certainement contribué à la splendeur de la vie parisienne au XVIII ${ }^{\mathrm{e}}$ siècle, qui a si vivement frappé J.-J. Rousseau, l'amateur des mœurs simples. Dans la Nouvelle-Héloïse, il montre que les arts ne travaillent que pour cette société de richards; les auteurs dramatiques eux-mêmes ne savent plus, comme Molière, faire parler les gens du peuple ; ils ne peignent que des gens qui « ont un carrosse, un suisse, un maître d’hôtel ».

Cependant, Rousseau a été l'ami, le commensal, l'hôte, à l'Ermitage, de $\mathbf{M}^{\text {me }}$ d'Epinay, dont la maison s'ouvrait hospitalière aux hommes de lettres. Voltaire, de son côté, a eu bien des relations avec les financiers et notamment avec La Poplinière. Faut-il rappeler que, dans son salon, à sa table, Helvétius réunissait tout ce que Paris comptait de littérateurs distingués et de penseurs illustres ?

Ces financiers, en effet, ont voulu faire figure de mécènes ; pour décorer leurs demeures, ils ont fait appel à des artistes, à des peintres, à des sculpteurs. Les fermiers généraux ont souscrit aux superbes éditions des Contes et des Fables de La Fontaine ; ce sont les éditions des fermiers généraux, si recherchées des bibliophiles. 
La nouvelle génération des fermiers généraux. - Toutefois, à partir de 1755, on constate un grand changement dans le personnel des fermiers généraux. Les hommes de plaisir ne constituent plus qu'une minorité, et les Turcarets mal dégrossis ont tout à fait disparu. Nombreux sont les titulaires de la ferme générale qui se distinguent par leur intelligence, leur probité et leur connaissance des affaires : tel, Jacques Delahante, fermier général depuis 1765 ; tel Paulze, le beaupère de Lavoisier. Lavoisier lui-même se fait remarquer de bonne heure par ses connaissances en matière économique; il consacre une bonne partie de sa fortune à des recherches de chimie ; il se montre toujours généreux et désintéressé ; il doit illustrer la science française. Quant à Benjamin de la Borde, sa gloire est moindre ; mais, musicien, artiste et littérateur, c'est un homme vraiment distingué. Il semble, en un mot, qu'on puisse souscrire au jugement de Mollien, lorsqu'il déclare :

«La très grande majorité des fermiers de 1780, par la culture de l'esprit et l'aménité des mœurs, tenait honorablement sa place dans les premiers rangs de la société française et plusieurs, par la direction qu'ils avaient donnée à leurs études, auraient été très disposés à mieux servir l'État, même avec moins de profit, si les ministres, connaissant mieux leur siècle, avaient su mieux discerner les sources de la fortune publique, y mieux puiser et la diriger plus habilement vers son véritable but. »

Il n'en est pas moins vrai que la dureté des impôts que percevait la ferme générale avait pour conséquence de rendre impopulaires ses titulaires ; on s'explique ainsi que les cahiers de 1789 s'accordent à demander «l'abolition entière des fermes générales, qui ne contribuent qu'à enrichir une vingtaine d'hommes ", tout en ruinant le peuple, et l'on comprend, sans en approuver la rigueur impitoyable, le procès et la condamnation de 1793.

$\underline{\text { Table des matières }}$

\section{Ouvrages à consulter}

THIRION, Vie privée des financiers au XVIII ${ }^{\mathrm{e}}$ siècle, Paris, 1895.

DelaHANTE, Une Famille de finance au XVIII ${ }^{\mathrm{e}}$ siècle, 1881.

GRIMAUX, Lavoisier, 1888. 
MARION M., Dictionnaire des institutions de la France aux XVII ${ }^{\mathrm{e}}$ et XVIII ${ }^{\mathrm{e}}$ siècles, Paris, 1923, art. croupes, ferme générale, receveurs généraux.

BIGo Robert, Les Bases historiques de la finance moderne, Paris, 1933, in-16.

HARsin Paul, Euvres complètes de John Law, Paris, 1934, 3 vol. in-8 ${ }^{\circ}$, et nombreux travaux sur le Système. - Les doctrines monétaires et financières de la France $d u \mathrm{XVI}^{\mathrm{e}}$ au XVIII ${ }^{\mathrm{e}}$ siècle, Paris, 1928, in-8 ${ }^{\circ}$.

Bouchary Jean, Les Manieurs d'argent à Paris à la fin du XVIII ${ }^{\mathrm{e}}$ siècle, Paris, 1939, in-8 $8^{\circ}$ 


\section{Chapitre 11}

\section{HAUTE ET MOYENNE BOURGEOISIE.}

II est toute une catégorie du tiers état dont l'existence dépend moins strictement du régime économique ; ce sont les hommes de loi, les médecins, et aussi les bourgeois qui sont réputés « vivre noblement », c'est-à-dire qui vivent de leurs rentes.

Les professions libérales. - Avocats, procureurs, notaires, agents seigneuriaux, tous ces hommes de loi appartiennent à la même classe sociale. Au premier rang, surtout dans les villes parlementaires, comme Rennes ou Dijon, figurent les avocats et les procureurs. A Rennes, les procureurs au Parlement, au nombre de plus de 80, ont souvent une situation de fortune fort importante. Les avocats, plus nombreux encore, sont dans l'ensemble moins aisés, mais un certain nombre d'entre eux, jouissant d'une grande notoriété, occupent dans la ville une place de premier rang ; ainsi s'explique le rôle qu'ont joué, en 1789, des hommes comme Le Chapelier, Lanjuinais, Glezen, etc.. Les procureurs des sièges présidiaux et surtout les notaires ont une condition fort inférieure aux avocats. Les offices de notaires, dans les grandes villes, ne valent guère que 16000 l. et, dans les campagnes, 3000. Quant aux juges des sièges royaux (des bailliages et sénéchaussées), ou des sièges seigneuriaux, ils sont, dans toutes les régions de la France, en très grand nombre ; mais, bien que beaucoup d'entre eux aient le titre d'avocats, ils forment une classe bien moins fortunée que les avocats et procureurs des villes parlementaires.

En général, les membres des autres professions libérales ont une situation bien inférieure à celle des hommes de loi. Les médecins cependant, dans les villes importantes, semblent jouir d'une large aisan- 
ce, et quelques-uns d'entre eux ont, surtout à la fin de l'ancien régime, une situation morale considérable : tel, un Bagot, à Saint-Brieuc, qui, maire de la ville, devint plus tard député à l'assemblée législative ; tels, des médecins très réputés à Paris, comme Vicq d'Azyr, Guillotin, les Tronchin. Les chirurgiens sont en bien plus grand nombre ; pendant longtemps, confondus avec les gens de métiers, ils sont, dans la seconde moitié du XVIII ${ }^{\mathrm{e}}$ siècle, considérés comme exerçant une profession libérale ; c'est qu'en effet on les astreint maintenant à de sérieuses études.

Les professeurs sont beaucoup moins nombreux et jouissent de beaucoup moins de prestige que de nos jours. D'ailleurs, professeurs de droit et de médecine sont, avant tout, des avocats ou des médecins. Les facultés des lettres ou des arts correspondent à ce que nous appellerions l'enseignement secondaire ; une exception est cependant à faire pour le Collège de France. Les collèges sont presque entièrement entre les mains des ecclésiastiques, surtout jusqu'au moment de l'expulsion des Jésuites (1762). Aussi, dans la plupart des villes, ne trouve-t-on que quelques rares maîtres de latin ou de mathématiques, généralement peu fortunés. Les maîtres et maîtresses d'école, très souvent nombreux, ont une condition très humble et ne peuvent être considérés comme appartenant à la bourgeoisie. On peut en dire autant des maîtres de musique, de danse et d'armes.

Bourgeois vivant noblement. - Dans les villes, et surtout dans les villes importantes, on trouve d'assez nombreux bourgeois qui vivent de leurs rentes, ou, comme l'on dit, qui "vivent noblement », sans exercer aucun métier. Ces rentiers ont des conditions de fortune fort diverses : les uns sont fort riches ; d'autres n'ont qu'une modeste aisance ; d'autres enfin ne possèdent que de très maigres ressources. C'est qu'ils sont loin d'avoir tous la même origine : les uns sont des marchands enrichis et retraités (c'est là une des grandes sources de la bourgeoisie) ; d'autres, d'anciens hommes de loi ; d'autres encore, des propriétaires fonciers ; il y a aussi un grand nombre de vieilles demoiselles, des veuves. Besnard, dans ses Souvenirs, déclare qu'on se retire volontiers des affaires, quand on a amassé de 3000 à 4000 l. de rente. 
Cette classe de rentiers, de bourgeois « vivant noblement » est bien l'un des traits caractéristiques de la société française du XVIII ${ }^{\mathrm{e}}$ siècle. Les familles riches tendent au repos, répugnent à l'effort. En Angleterre, cette tendance n'existe guère : les fils de riches bourgeois et de gentlemen n’hésitent pas à travailler, à se livrer au négoce. Le contraste est intéressant à signaler, surtout à une époque où le droit d'aînesse existait en France, comme en Angleterre.

Les anoblis et le patriciat urbain. - Dans toutes les villes, on constate l'existence d'une sorte de patriciat urbain. Il comprend un certain nombre de familles qui détiennent, d'une façon héréditaire, les charges municipales; leurs membres sont souvent anoblis, car ces charges confèrent la noblesse. A eux viennent se joindre des personnes anoblies par les charges de judicature. Aussi, presque partout, voit-on une rivalité, en quelque sorte permanente, entre ces familles, qui forment la haute bourgeoisie, et la moyenne et petite bourgeoisie (avocats, médecins, marchands, artisans, etc.). Au moment de la convocation des États Généraux, il s'élève, dans la plupart des villes, des luttes fort vives entre ces deux éléments de la bourgeoisie, et l'on comprend que l'ordre du tiers ait voulu exclure du droit de le représenter à l'assemblée ceux que l'on désigne sous la qualification d'anoblis.

Notons encore que les bourgeois les plus aisés possèdent souvent, à la campagne, des propriétés foncières, plus ou moins considérables, des fermes et des maisons de plaisance. Le cas est fréquent, surtout dans les environs des villes, et les propriétaires bourgeois ajoutent souvent à leurs patronymes le nom de leurs terres : ils sont "sieurs de »; mais la particule, comme l'on sait, n'est nullement un indice de noblesse.

Le train de vie. - La haute bourgeoisie ne constitue, d'ailleurs, qu'une très petite minorité. La classe bourgeoise, dans son ensemble, a un train de vie fort simple, comme en peut s'en rendre compte par les inventaires après décès et par un certain nombre de mémoires. 
Les Souvenirs d'un nonagénaire, écrits par un Angevin, FrançoisYves Besnard, nous montrent avec une grande précision le mode d'existence des hommes de loi et agents seigneuriaux des petites villes. Besnard nous décrit la maison de sa bisaïeule, veuve d'un notaire. Au rez-de-chaussée, se trouve une grande pièce servant à la fois de cuisine, de "salon à manger » et de chambre à coucher, avec deux lits ; à côté, une autre pièce moins grande, sans cheminée, contient un seul lit, deux armoires, quelques chaises ; pour les réceptions, il y a un grand salon, avec une armoire et des fauteuils, et qui contient aussi un lit. Au premier, une chambre à deux lits et un grenier.

Même en de grandes villes, comme Angers, dans la plupart des maisons bourgeoises, on ne voit ni tapisseries, ni riche mobilier ; les vastes cheminées ne contiennent aucun ornement : ni vases de cristal, ni porcelaine, ni pendules. L'argenterie comporte rarement plus de douze couverts et quelques gobelets. On se sert d'assiettes et de plats de terre cuite ou de faïence grossière. Il n'y a qu'une seule servante. Partout, il est vrai, on possède d'abondantes provisions de linge, souvent assez grossier, mais solide ; la toile est fabriquée par des artisans de campagne.

« Toutes les familles bourgeoises mangent dans leur cuisine. » On fait quatre repas par jour : un premier déjeuner à 7 ou 8 heures du matin ; le dîner, à 11 heures ou midi, comprend une soupe ou un bouilli ; à quatre heures, le goûter ; le soir, un souper, avec un rôti et de la salade. Il est vrai que, lorsque l'on a des invités, la table est abondamment servie : on a des pâtés, plusieurs rôtis, des salades, peu de légumes.

Peu de luxe aussi dans les vêtements : la garde-robe comprend des vêtements d'été et des vêtements d'hiver ; quant aux habits et robes de noces ou de gala, ils se transmettent, comme aujourd'hui chez les paysans bas-bretons, d'une génération à l'autre. «Les fontanges ou rubans de couleurs vives " et les falbalas, nous disent les Souvenirs d'un nonagénaire, ne sont portés que par les femmes de la noblesse ou de la haute bourgeoisie ; on ne les voit jamais chez les femmes de notaires, de chirurgiens ou de « marchands en boutiques ».

D’ailleurs, les dots des filles dépassent rarement 6000 livres; « celles de 10000 à 15000 francs supposaient de vastes propriétés ou 
de grandes richesses commerciales ", même dans une ville comme Angers. C'est seulement dans la haute bourgeoisie (négociants, gens de finance, hommes de loi fortunés) que le mode d'existence se transforme dans la seconde moitié du XVIII ${ }^{\mathrm{e}}$ siècle. C'est ainsi que, dans des villes comme Rennes ou Laval, on construit de nouvelles habitations ou l'on aménage d'une façon plus confortable les anciennes ; on prend l'habitude d'avoir des salons et des salles à manger ; on commence à faire du feu dans plusieurs pièces. Mais, à Paris même, Besnard le remarque aussi —, la moyenne et la petite bourgeoisie vivent fort simplement ; le luxe est réservé à la noblesse, aux financiers, aux gros négociants.

La culture intellectuelle. - Certains membres de la classe bourgeoise (c'est, en particulier, le cas des hommes de loi) ont une très forte culture. On peut s'en rendre compte en étudiant les inventaires de bibliothèques privées qui nous ont été conservés. L'ancien fonds de la bibliothèque municipale de Rennes a été, en grande partie, constitué par la bibliothèque des avocats de Rennes : elle contient les meilleurs ouvrages qui aient paru au XVIII ${ }^{\mathrm{e}}$ siècle, et notamment la plupart des écrits «philosophiques ». Les ouvrages juridiques, émanant d'avocats, sont souvent remarquables, témoignent d'une connaissance approfondie de toutes les questions administratives, et plus d'un se distingue par un grand talent d'exposition.

Arthur Young, voyageant en France peu de temps avant la Révolution, est frappé de la distinction d'esprit de dames qui appartiennent à la bourgeoisie ; il est séduit notamment par une $\mathrm{M}^{\text {me }}$ Picardet, de Dijon, qui est « un trésor pour M. Guyton de Morveau (le célèbre chimiste), car elle est capable et désireuse de converser avec lui sur des sujets de chimie, aussi bien que sur d'autres, soit agréables, soit instructifs ». Les $\mathrm{M}^{\mathrm{me}}$ Roland n'étaient pas très rares dans la société bourgeoise du XVIII ${ }^{\mathrm{e}}$ siècle.

Sentiments révolutionnaires de la bourgeoisie. - La bourgeoisie, - la haute bourgeoisie surtout — , semble relativement privilégiée, car elle est, en général, exempte de la taille et un assez grand nombre de fonctions lui sont accessibles. Cependant, elle est exclue de 
beaucoup de charges, et notamment de l'armée, depuis l'édit de 1781 ; elle ne peut participer aux grandes fonctions administratives, qu'elle se sent plus apte à remplir que les membres de la noblesse. Elle est souvent blessée dans son orgueil ou dans son amour-propre. Tous ces griefs de la bourgeoisie ont été fortement exposés par un gentilhomme, le marquis de Bouillé, dans ses Mémoires :

« Les bourgeois avaient reçu en général une éducation qui leur devenait plus nécessaire qu'aux gentilhommes dont les uns, par leur naissance et leur richesse, obtenaient les premières places de l'État sans mérite et sans talents, tandis que les autres étaient destinés à languir dans les emplois subalternes de l'armée. Ainsi, à Paris et dans les grandes villes, la bourgeoisie était supérieure en richesses, en talent et en mérite personnel. Elle avait dans les villes de province la même supériorité sur la noblesse des campagnes ; elle sentait cette supériorité ; cependant, elle était partout humiliée, elle se voyait exclue, par les règlement militaires, des emplois dans l'armée ; elle l'était, en quelque manière, du haut clergé, par le choix des évêques parmi la haute noblesse, et des grands vicaires en général parmi les nobles... La haute magistrature la rejetait également, et la plupart des cours souveraines n'admettaient que des nobles dans leur compagnie. Même pour être reçu maître des requêtes, on exigeait dans les derniers temps des preuves de noblesse. »

On comprend donc qu'en 1789, — et on le voit bien par les cahiers des États Généraux - , ce soit tout le tiers état qui se soit levé pour demander l'abolition des privilèges de l'aristocratie, l'admission de tous à tous les emplois et, dans les campagnes, l'anéantissement du régime seigneurial, que les paysans ont forcé la bourgeoisie à inscrire sur son programme. Sans doute, ni la bourgeoisie ni les populations rurales ne forment des classes bien définies : il y a, parmi elles, bien des catégories distinctes, dont les intérêts s’opposent souvent. Cependant, tandis que les deux premiers ordres s'efforcent de sauvegarder un ensemble de privilèges particuliers, sans se sentir vraiment solidaires les uns des autres, les non privilégiés, au contraire, se rendent compte qu'ils ont tous, contre les privilégiés, les mêmes revendications à soutenir, les mêmes abus à combattre ; et c'est pourquoi, faisant bloc contre les premiers ordres, ils sentent qu'ils représentent vraiment la nation.

On a pu soutenir - et avec raison - que beaucoup de nobles étaient issus du tiers état, qu'il y avait eu, surtout grâce à la vénalité 
des charges, une lente accession des classes populaires vers la noblesse, et que la haute bourgeoisie confinait à la noblesse. Tout cela importait peu à la bourgeoisie du XVIII siècle, d'autant plus que les classes sociales étaient de plus en plus des castes fermées. Puis, ce n'était qu'une infime minorité du tiers état qui s'élevait à la noblesse. Les observations de Mireur sont surtout intéressantes pour qui veut se rendre compte des sources de la noblesse.

Les éléments les plus actifs du tiers état ont été les hommes de loi, mus non seulement par leurs intérêts de classe, mais par les idées nouvelles, qui excitaient leur enthousiasme ; sans doute, la classe des négociants, industriels, hommes d'affaires, entreprenante, novatrice, ennemie de la réglementation et des privilèges juridiques qui entravaient son activité, contribue à saper l'ancien régime. Mais, en 17881789, ce sont les hommes de loi qui jouent le grand rôle, qui mènent la campagne du tiers état, rédigent la plupart des cahiers de doléances.

Table des matières

\section{Ouvrages à consulter}

LAVISSE E., Histoire de France, t. IX.

Port Célestin, Les Souvenirs d'un nonagénaire, Mémoires de François-Yves Besnard, Angers, 1880, 2 vol. in- $8^{\circ}$.

Monin, État de Paris en 1789 (Coll. des Documents relatifs à l'histoire de la ville de Paris), Paris, 1889.

Young Arthur, Voyages en France, trad. Henri Sée, Paris, 1931.

BABEAu, La Ville sous l'Ancien Régime, Paris, 1884.

BUSSIÈRE, La Révolution en Périgord, t. I : la bourgeoisie périgourdine au XVIII siècle, 1877.

SÉE H., La Vie économique et les classes sociales en France au XVIII ${ }^{\mathrm{e}}$ siècle, Paris, 1924.

MIREUR, Le Tiers État à Draguignan.

Sur une ville de France, voir :

EVRARD Fernand, Versailles, ville du Roi, 1770-1789 (Documents économiques de la Révolution), Paris, 1935, in-8 ${ }^{\circ}$. 


\section{Chapitre 12}

\section{LA MISÈRE ET L’ASSISTANCE.}

Les historiens qui ont parlé de la société française au XVIII ${ }^{\mathrm{e}}$ siècle ont souvent décrit avec complaisance tout le décor brillant de cette civilisation raffinée, grâce à laquelle les privilégiés avaient connu « la douceur de vivre ». Mais il y a à la médaille un revers qu'on laisse volontiers dans l'ombre : c'est la misère, qui atteint si durement une bonne partie de la population des campagnes et des villes. Or, on ne peut avoir une idée précise de la vie économique et sociale d'une époque, si l'on ne considère pas cet élément essentiel de la question.

La misère dans les campagnes. - Contrairement à ce qui se passe de nos jours, c'est, au XVIII ${ }^{\mathrm{e}}$ siècle, dans les campagnes que la misère est le plus intense. Pour le comprendre, il suffit de se rappeler ce que nous avons dit de la propriété paysanne et de l'agriculture.

Partout, on trouve des paysans aisés, des laboureurs, mais ils ne constituent qu'une infime minorité de la population rurale. La plupart des paysans n'ont qu'une quantité de terre insuffisante pour les faire vivre et sont même dénués de toute propriété ; ce fait, qui se manifeste clairement en Bretagne, apparaît plus frappant encore dans les provinces du Nord, surtout en Artois, en Picardie, en Flandre. Ces journaliers n'ont pour vivre que le travail de leurs bras. Leurs salaires sont généralement très faibles : ils ne dépassent pas 8 à 10 sous par jour en Bretagne et, même dans les provinces les plus riches, ils sont toujours inférieurs à 20 ou même 15 sous. S'il y a eu une hausse sur les salaires à la fin du XVIII ${ }^{\mathrm{e}}$ siècle, elle a été bien moins considérable que la hausse des prix. 
En temps normal, les travailleurs agricoles peuvent tout juste suffire à leurs besoins rudimentaires. Mais vienne une de ces crises si fréquentes encore au XVIII ${ }^{\mathrm{e}}$ siècle, une série de mauvaises récoltes, les voilà condamnés au chômage, précisément au moment où les vivres renchérissent dans d'énormes proportions. C'est pour des milliers de familles la misère, l'obligation de demander l'aumône. Les paysans aisés, loin de les secourir, ne songent qu’à "renchérir leurs grains ", comme le remarque un curé breton en 1775 .

La misère dans les villes. - Dans les villes, on constate souvent aussi l'existence de nombreux pauvres. Dans une ville comme Rennes, un sixième de la population est trop dénué de ressources pour être astreint à la capitation, et, parmi ceux qui doivent l'acquitter, il y a de nombreux manœuvres et petits marchands dont la condition est bien précaire. D'ailleurs, les compagnons de métiers eux-mêmes n’ont que de très faibles salaires, qui ne dépassent guère 12 ou 15 sous par jour. Une crise industrielle ou une hausse des denrées suffit pour les réduire à la misère. A Vitré, à partir de 1760, la dépression économique qui atteint la fabrication des toiles réduit les trois quarts des habitants à la plus noire détresse ; ils meurent de faim dans leurs taudis, comme le montre la lettre d'un subdélégué, en 1762. Dans les grands centres industriels, dans la Normandie orientale, en Picardie, en Flandre, en Champagne, la crise industrielle qui a été déterminée par le traité de commerce avec l'Angleterre, de 1786, produit une misère extrême parmi la population ouvrière. Puis, beaucoup de pauvres, qui ne peuvent plus subsister dans les campagnes, viennent se réfugier dans les villes, où ils espèrent trouver du travail ou du moins des aumônes plus larges qu'aux champs.

Néanmoins, on peut se convaincre que la misère, au XVIII ${ }^{\mathrm{e}}$ siècle, est plus fréquente et plus intense dans les campagnes que dans les villes. Les épidémies y sévissent plus souvent et y sont plus meurtrières.

Ce sont surtout les pauvres des campagnes qui constituent ces bandes de mendiants et de vagabonds que l'on voit parcourir les routes en tous sens, pillant les villages, détroussant les voyageurs, terrorisant les habitants des fermes et des hameaux isolés, si nombreux dans l'Ouest. Ce fléau ne fait que s'aggraver à la fin de l'ancien régime, et les ca- 
hiers de 1789 s'accordent tous à demander qu'on prenne des mesures propres à les en délivrer.

Impuissance de la charité. - Contre la misère, la charité privée se montre absolument impuissante. Les propriétaires nobles, en général, ne s'acquittent que très mollement de leurs devoirs de charité, et les décimateurs ecclésiastiques eux-mêmes ne consacrent que bien peu d'argent au soulagement des pauvres : c'est ce que déclarent non seulement les cahiers de paroisses, mais les subdélégués des intendants et les curés eux-mêmes.

Dans les campagnes, au moyen âge, on constatait l'existence d'un assez grand nombre d'hôpitaux et d'aumôneries ; mais la plupart ont disparu au XVI ${ }^{\mathrm{e}}$ siècle. Quant aux fondations charitables des paroisses rurales, destinées à soulager les pauvres, elles sont peu nombreuses et médiocrement dotées.

Dans les villes, l'assistance, en général, laisse aussi fort à désirer ; M. Chaudron nous dit bien qu'à Troyes elle était parfaitement organisée, mais son argumentation ne nous semble pas convaincante. La plupart des villes, il est vrai, possèdent des Hôtels-Dieu, et ces hôpitaux jouissent de biens-fonds, de rentes mobilières, de dons volontaires, plus ou moins abondants, mais qui ne suffisent pas pour l'hospitalisation des malades, comme le prouvent les enquêtes faites par l'autorité royale, au cours du XVIII ${ }^{\mathrm{e}}$ siècle, et, si leurs secours ont quelque efficacité, c'est surtout grâce aux services que leur rendent certaines communautés religieuses de femmes qui les desservent. L'Hôtel-Dieu de Rennes ne contient que 120 lits pour une population de 30000 habitants et il n'a pas de salle spéciale pour les femmes en couches. Les hôpitaux de Paris sont organisés de la façon la plus déplorable ; les malades sont entassés pêle-mêle dans des locaux malsains ; on en couche plusieurs dans le même lit; la nourriture et les soins médicaux sont également insuffisants ; c'est ce que montre notamment l'enquête que fit faire Necker.

Dans bien des villes, on créa, il est vrai, des marmites des pauvres, destinées surtout à secourir les pauvres honteux, et tenues par des sœurs de charité ; c'est l'origine de nos bureaux de bienfaisance. Mais cette charité, telle que l'exercent, par exemple, les compagnies parois- 
siales et le Grand bureau des pauvres de Paris, ne s'adresse pas aux gens les plus misérables ; elle se propose surtout de secourir les bourgeois tombés dans la misère, les " pauvres honteux ", et encore à la condition qu'ils remplissent strictement leurs devoirs religieux. C'est que, comme le dit à merveille M. Léon Cahen, « la charité des Compagnies a son origine dans une pensée de dévotion religieuse, non dans un sentiment de révolte contre la misère humaine ; leurs membres poursuivent une œuvre, non de justice et d'apaisement social, mais d'édification personnelle ».

L'assistance de l'État. - Jusque vers 1760, le pouvoir royal ne s'occupe que faiblement de l'assistance. Il essaie, il est vrai, de combattre la mendicité, mais surtout pour des raisons de police, pour maintenir le bon ordre. C'est dans ce but que, dès le règne de Louis XIV, le gouvernement ordonne d'enfermer les mendiants et les vagabonds dans des hôpitaux généraux, où on les astreint au travail. On en installe dans la plupart des villes ; mais leurs ressources sont insuffisantes, toujours inférieures à leurs besoins, et ils ne peuvent recevoir qu'une faible partie des professionnels de la mendicité. Les hôpitaux généraux doivent souvent aussi recueillir les enfants abandonnés, mais ils s'acquittent fort mal de ce devoir.

Aussi est-on obligé de laisser les mendiants demander la charité ; on essaie seulement de réglementer leur profession, comme le montre un curieux document de 1763, relatif à la ville de Rennes :

« On a distribué à chaque pauvre des boîtes ou troncs de fer blanc, avec des numéros et armes de la ville ; on désigne à chacun des portes d'église ou des quartiers pour recevoir des charités dans leur boîte, avec défense de quêter dans les églises, dans les rues et dans les maisons. »

Dans la seconde moitié du XVIII ${ }^{\mathrm{e}}$ siècle, le gouvernement s'occupe plus activement de l'assistance. Il crée des dépôts de mendicité, où l'on doit enfermer les vagabonds valides. Mais ces établissements semblent n'avoir que médiocrement atteint le but pour lequel ils avaient été créés ; leurs ressources sont insuffisantes et leur organisation défectueuse. 
C'est avec Turgot et Necker que des conceptions nouvelles se manifestent; l'administration, consciente des devoirs que l'État doit remplir à cet égard, s'efforce de remplacer les mesures de coercition par des mesures d'assistance. Turgot, dès 1770 , lorsqu'il était encore intendant en Limousin, disait: "Le soulagement des hommes qui souffrent est le devoir de tous, et toutes les autorités se réuniront pour y concourir. » Et, un peu plus tard, Necker écrira dans son Administration des finances :

« C’est au gouvernement de faire, pour la classe nombreuse et déshéritée, tout ce que l'ordre et la justice lui permettent... L'administration saura découvrir les devoirs de la Société envers l'infortune... dans la distribution des impôts, dans l'établissement des travaux publics, dans toutes les dispositions propres à prévenir la misère et la mendicité qui marche à sa suite. »

Des idées analogues se font jour dans les assemblées provinciales, de 1787-1789.

Turgot, le premier, s'efforça sérieusement d'organiser l'assistance par le travail en instituant des ateliers de charité. Mais ces ateliers de charité, s'ils rendirent quelques services, notamment pour la confection des routes, ne parvinrent pas à supprimer la mendicité et le vagabondage et ne furent qu'un remède insuffisant à la misère. Dans certaines provinces, même, on ne put jamais les organiser, notamment en Bretagne, où le conflit entre les États et l'administration royale, qui essayaient de s'en rejeter réciproquement la charge, fit échouer toute tentative en ce sens. C'est dire que les États provinciaux n'ont guère contribué à l'œuvre d'assistance. C'est le gouvernement central qui se montra le plus soucieux de l'organiser véritablement, tout au moins dans les vingt dernières années de l'ancien régime. Une autre création, qui fut tentée à la fin de l'ancien régime, ce fut celle des bureaux d'aumônes ou de charité ; mais elle ne paraît pas non plus avoir donné de grands résultats :

« Dans plusieurs provinces, lisons-nous dans une lettre de l'intendant de Bretagne, en 1778, on a établi des bureaux d'aumônes et de charité, qui s'occupent de l'emploi des aumônes qu'ils obtiennent, soit en indiquant des travaux et fournissant des matières et des outils à ceux qui sont en état de travailler, soit en procurant des soulagements aux malades dans leur infirmité, soit en ne faisant que de simples prêts à ceux qui n'ont que des besoins mo- 
mentanés. »

Mais on ne s'adressait qu'à la charité privée, qui, dans les paroisses de campagne, s'était toujours montrée impuissante à secourir les pauvres. En vain les évêques joignirent-ils leurs efforts à ceux de l'autorité royale, invitant les recteurs à éveiller les sentiments charitables de leurs paroissiens. Les bureaux d'aumônes ne semblent pas avoir produit grands résultats, même dans les endroits où l'on put les instituer.

Les efforts les plus sérieux qui aient été tentés dans les vingt dernières années de l'ancien régime ont trait à l'assistance médicale. En temps d'épidémie, on distribue des médicaments dans les campagnes comme dans les villes, on commence à nommer des médecins des épidémies, et bon nombre d'entre eux furent des hommes de mérite, comme ce médecin de Saint-Brieuc, Bagot, l'auteur d'intéressantes Observations médecinales. Turgot a beaucoup contribué à améliorer l'assistance médicale, notamment en créant, en 1776, la Société royale de médecine, qui se composa de médecins éclairés, dégagés de la routine. La Société suscita des enquêtes dans toutes les provinces sur la santé publique, encouragea les progrès de la thérapeutique, l'inoculation, etc.. Cependant, l'assistance médicale, surtout dans les campagnes, laissa encore bien à désirer ; dans les villes mêmes, la population se refusait obstinément à se soumettre à l'inoculation; les épidémies de variole, de fièvre typhoïde, voire d'influenza, étaient encore bien meurtrières, plus encore dans les campagnes que dans les villes. On essaya aussi parfois d'augmenter le nombre des sagesfemmes instruites en favorisant la création de cours d'accouchement, comme ceux de $\mathrm{M}^{\text {me }}$ Delaunay, en 1775 et 1776 ; mais, en 1789 , les cahiers des paroisses se plaignent encore de l'impéritie des sagesfemmes, dont tant de femmes étaient victimes.

En réalité, la charité privée et aussi la charité que les établissements ecclésiastiques avaient le devoir de prendre en charge s'étaient montrées impuissantes à combattre la misère, même à l'atténuer en diminuant le nombre des pauvres. L'État n'avait pas mieux réussi à réprimer la mendicité et le vagabondage. Mais de nouvelles tendances se manifestaient à la veille de la Révolution, lorsque des ministres réformateurs essayèrent d'organiser l'assistance par le travail. La néces- 
sité de réformes profondes s'imposait, et c'est l'État qui devait en avoir l'initiative. C'est ce que comprirent les assemblées révolutionnaires, et tout d'abord la Constituante, lorsqu'elle institua son Comité de mendicité. Mais elles ne purent que tracer un vaste programme ; le temps et les ressources financières leur manquèrent pour le réaliser. Puis, ce qui était essentiel pour une lutte sérieuse contre la misère, c'étaient précisément de meilleures conditions de vie économique et sociale. Le régime de privilèges, qui marquait l'état social de l'ancienne France, avait pour conséquence directe l'aggravation de la misère. Si, au XIX ${ }^{\mathrm{e}}$ siècle, les progrès de la grande industrie doivent produire aussi bien des maux et bien des souffrances, surtout dans les villes, il n'en est pas moins vrai qu'en abolissant le régime seigneurial, en favorisant l'accès des paysans à la propriété, la Révolution française a eu pour effet d'améliorer la condition économique des populations rurales. Au XIX ${ }^{\mathrm{e}}$ siècle, la misère s'est singulièrement atténuée dans les campagnes ; la mendicité et le vagabondage, ces fléaux que dénonçaient les cahiers de 1789, ont presque entièrement disparu.

Table des matières

\section{Ouvrages à consulter}

Outre les ouvrages de Lefebvre, Sée, etc., cités aux chapitres I et II :

Bloch C., L'Assistance et l'État en France à la veille de la Révolution, Paris, 1909.

Boissonnade P., L'Assemblée provinciale du Poitou et la question de la mendicité (1789-1790), Paris, 1904.

VALRAN, Misère et charité en Provence au XVIII ${ }^{\mathrm{e}}$ siècle, 1899.

DupuY A., Les Épidémies en Bretagne au XVIII siècle (Annales de Bretagne, t. IIII).

CAHEN Léon, Le Grand Bureau des pauvres de Paris au milieu du XVIII ${ }^{\mathrm{e}}$ siècle, Paris, 1904.

LORÉDAN Jean, La Grande Misère et les voleurs au XVIII siècle, Paris, 1910, in$8^{\circ}$.

RAmBAud P., L'Assistance publique à Poitiers jusqu'à l'an V, 2 vol., 1914.

CHAUdRon Émile, L'Assistance publique à Troyes à la fin de l'ancien régime et pendant la Révolution, Paris, 1923.

Bloch C. et Tuetey, Procès-verbaux du Comité de mendicité de la Constituante (Coll. des Documents économiques de la Révolution). 
SÉE Henri, Recherches sur la misère, la mendicité et l'assistance en Bretagne à la fin de l'ancien régime (Mémoires de la Société d’histoire de Bretagne, année 1925). 


\section{Chapitre 13}

\section{LES VCEUX DES DIVERSES CLASSES SOCIALES EN 1789.}

Pour qui veut comprendre la divergence des intérêts économiques qui se manifeste, au XVIII ${ }^{\mathrm{e}}$ siècle, parmi les diverses classes de la société, pour qui veut se rendre compte des catégories sociales qui apparaissent dans chacun des ordres, il importe de parcourir les cahiers rédigés au moment de la convocation des États Généraux : cahiers généraux des bailliages ou sénéchaussées, cahiers des villes et des paroisses rurales, cahiers des communautés de métiers.

Accord des trois ordres. - Il est vrai que les trois ordres s'accordent dans leurs protestations contre l'absolutisme, ou, pour mieux dire, contre le despotisme de l'administration royale, tout en manifestant le plus grand respect pour le principe de la royauté et pour la personne du Roi. Tous les cahiers s'élèvent contre les lettres de cachet, les arrestations arbitraires, les tribunaux d'exception, la violation du secret de la correspondance. On ne veut plus de l'ancienne fiscalité, on demande la garantie de la dette publique ; on réclame aussi la réforme complète de la législation criminelle. Tiers état, noblesse et clergé placent également au premier rang de leurs vœux l'établissement de la Constitution, l'institution d’États Généraux périodiques, qui auraient le pouvoir de consentir les impôts, et aussi la suppression des intendants, ainsi que l'affermissement des libertés municipales et provinciales. Remarquons toutefois que les nobles et les membres des Parlements, lorsqu'ils attaquent l'absolutisme, songent surtout au despotisme éclairé, aux réformes égalitaires que des ministres réformateurs ont essayé d'instituer à la fin de l'ancien régime. 
Les dissentiments entre les ordres. - Mais, sur les autres questions, éclatent les dissentiments des trois ordres. Ainsi, le clergé se montre hostile à la liberté de la presse, dénonce la licence de la littérature, se prononce contre la tolérance religieuse et même contre l'octroi de l'état civil aux protestants. Il se trouve ainsi en opposition, non seulement avec le tiers état, mais aussi avec la noblesse qui, au XVIII ${ }^{\mathrm{e}}$ siècle, est en partie gagnée au libéralisme philosophique, et qui compte bien des lecteurs enthousiastes de Voltaire.

Le tiers état, de son côté, s’attaque aux privilèges des deux premiers ordres. Il demande unanimement la pleine égalité des droits, l'admission de tous à tous les emplois, le vote par tête aux États, l'abolition du régime seigneurial ou tout au moins le rachat des droits seigneuriaux, revendication que les paysans ont imposée à la bourgeoisie. Toutes les catégories du tiers, sentant qu'elles ont les mêmes revendications à soutenir, les mêmes abus à combattre, ont fait bloc, pour ainsi dire, contre les ordres privilégiés, et c'est ainsi que le troisième ordre représente vraiment la nation.

Dissentiments parmi les privilégiés. - Les privilégiés, au contraire, lorsqu'ils se défendent contre les réclamations du tiers état, c'est surtout un ensemble de privilèges particuliers qu'ils s'efforcent de sauvegarder sans se sentir vraiment solidaires les uns des autres. Ainsi, partout on voit des conflits éclater entre les nobles de cour, qui jouissent de toutes les faveurs de l'État, et la petite noblesse, qui est exclue des hauts grades de l'armée. La noblesse du Périgord, pour citer un exemple, déclare dans son cahier :

« Nos députés maintiendront avec toute la dignité de leur origine l'égalité essentielle de la noblesse, qui ne peut être distinguée en plusieurs classes. Nous nous honorons de considérer les princes du sang comme les premiers de notre ordre ; nous reconnaissons au Parlement les fonctions de la pairie ; mais nous n’en reconnaîtrons jamais la prééminence, encore moins les prétentions. Ainsi nos représentants s'opposeront soigneusement à toute préséance qui pourrait compromettre dans la chambre de notre ordre la dignité et l'égalité de la noblesse française. » 
La majorité de la noblesse demande l'abolition de la vénalité des grades militaires, le licenciement des corps privilégiés de l’armée.

Dans l'ordre du clergé, les curés se dressent souvent contre les évêques et les ordres religieux; non seulement ils demandent l'amélioration de leur sort, mais ils veulent une meilleure répartition des biens ecclésiastiques, qui seraient ainsi consacrés aux besoins du culte, au soulagement des pauvres ; ils ne sont pas loin de se rallier à l'idée d'une nationalisation de ces biens. Ils veulent aussi que la dîme soit rendue à sa " destination primitive ", au lieu de ne profiter qu'aux gros décimateurs. Enfin, ils réclament souvent le rétablissement des élections ecclésiastiques et des anciens conciles.

Les diverses classes du tiers état. - Considérons maintenant le tiers état. Les dissentiments entre paysans et bourgeois n'apparaissent guère dans les cahiers, surtout dans les cahiers généraux des bailliages et sénéchaussées, car la bourgeoisie, qui a rédigé ces cahiers, a eu l'habileté d'adopter les doléances des populations rurales contre les propriétaires privilégiés. Mais, dans les assemblées de paroisses, il arrive que les paysans, se refusant à accepter le cahier qui leur a été présenté par les bourgeois de la localité, tiennent une assemblée dissidente et rédigent un cahier distinct ; c'est ce qui se passa assez souvent dans la sénéchaussée de Rennes. Dans les assemblées de bailliages et de sénéchaussées, la bourgeoisie s’arrange de façon à faire élire des députés de sa classe, bien que les députés des paroisses rurales soient peu nombreux.

Entre les diverses classes de paysans, les divergences ne laissent pas de se manifester. Les paysans aisés, les laboureurs, d'une part, et la masse des paysans pauvres de l'autre, se heurtent surtout dans la question des communaux, de la vaine pâture. En Normandie, dans l'Ile-de-France, en Flandre, les paysans peu aisés font souvent prévaloir leurs réclamations contre la "réunion des fermes » la constitution de grandes fermes, qui leur porte un si grand préjudice.

Les vœux d'ordre économique. - En matière industrielle, il y a, nous le savons, conflit d'intérêts entre la classe des négociants et di- 
recteurs de manufactures et celle des maîtres des métiers. Dans les cahiers des bailliages et des sénéchaussées, c'est l'influence de la première qui prédomine, malgré le petit nombre de ses membres ; elle fait insérer des articles contre la réglementation industrielle et le régime des corporations de métiers. Mais, dans les cahiers des corporations qui nous ont été conservés, les maîtres assemblés demandent le maintien de l'ancien régime corporatif, de leurs privilèges, s'élèvent souvent contre l'emploi des métiers mécaniques, contre l'extension de l'industrie rurale, qui nuisent si fort à leurs intérêts, et ils prétendent se réclamer, à cet égard, de l'intérêt public. Quant aux compagnons, ils peuvent rarement faire entendre leur voix, car ils ne figurent pas aux assemblées des corporations. Ils ont parfois cependant rédigé des cahiers particuliers, comme ceux qui nous ont été conservés pour Marseille et pour Troyes. S'ils manifestent la même aversion que leurs maîtres pour les métiers mécaniques, ils se trouvent en opposition avec eux sur les questions du travail et des salaires; ils demandent le droit de former des associations, d'avoir des confréries particulières.

En matière commerciale, ce sont les vœux de la bourgeoisie commerçante qui l'emportent le plus souvent, lorsque les cahiers demandent l'abolition des douanes intérieures, des péages et des octrois, qui nuisent si fort aux transactions, la libre exportation des produits manufacturés et des denrées agricoles. Les gros négociants se montrent partisans de la liberté économique, sous toutes ses formes; mais ils se plaignent souvent que leur cause ne soit qu'insuffisamment représentée aux élections pour les États Généraux. Contre le traité de commerce avec l'Angleterre, de 1786, c'est une réprobation presque unanime. Cependant, grâce aux progrès du capitalisme, — au moins sous sa forme commerciale - des conflits commencent à se dessiner entre la classe des hommes d'affaires, des spéculateurs, et la masse des consommateurs, conflits qui s'aggraveront singulièrement à l'époque de la Révolution, et dont les luttes politiques ne seront souvent que la manifestation. 
Cahiers de doléances pour les États Généraux, et, notamment, les recueils publiés dans la Collection des Documents économiques de la Révolution (C. BLOCH, Cahiers du bailliage d'Orléans; H. SÉE et A. LESORT, Cahiers de la sénéchaussée de Rennes; BRIDREY, Cahiers du bailliage de Cotentin; J. FOURnIER, Cahiers de la sénéchaussée de Marseille; J.-J. VERnIER, Cahiers du bailliage de Troyes; Gustave LAURENT, Cahiers de la généralité de Châlons-sur-Marne, etc.).

LAVISSE Ernest, Histoire de France, t. IX.

CHAMPION Edme, La France d'après les cahiers de 1789, $2^{\mathrm{e}}$ éd., 1904.

CHÈREST, La Chute de l'ancien régime, 1884-1887.

BLOCH C., Études d'histoire économique de la France, Paris, 1900.

PICARD Roger, Les Cahiers de 1789 au point de vue industriel et commercial, Paris, 1910 (thèse de doctorat en droit).

Mourlot F., La Fin de l'Ancien Régime et les débuts de la Révolution dans la généralité de Caen (1787-1790), Paris, 1913.

Voir Béatrice F. HysLOP, Répertoire critique des Cahiers des États généraux de 1789, Paris, 1933. Guide à travers les publications de Cahiers entreprises par le Comité d'Histoire économique de la Révolution, ainsi qu’à travers les cahiers publiés ailleurs. 


\section{Conclusion}

A considérer dans leur ensemble la vie économique et l'état social de la France au XVIII siècle, on voit clairement que notre pays présente à peu près le même aspect qu'au siècle précédent.

C’est toujours la propriété foncière qui joue un rôle prépondérant, et ses traits distinctifs ne se sont que peu modifiés. Le régime seigneurial a pu s’atténuer ; il s'est maintenu cependant jusqu’à la Révolution. La propriété paysanne s'est conservée et même fortifiée. Ce sont les paysans qui, comme tenanciers ou comme fermiers, sont les seuls à exploiter le sol, nourrissant de leur travail les classes privilégiées. Aussi, en 1789, est-ce la question paysanne qui se pose, et ce sont les paysans qui en imposeront la solution aux assemblées révolutionnaires.

En ce qui concerne le travail industriel, c'est toujours l'ancien régime de la petite industrie qui prédomine. Les corporations de métiers sont tombées de plus en plus en décadence longtemps avant que la réforme de Turgot n’ait menacé leur existence ; elles gardent cependant leur caractère de corps fermés, aux tendances conservatrices, et dans lesquels il est de plus en plus difficile de pénétrer, si l'on n'est pas fils de maître. La réglementation industrielle est battue en brèche, elle n'a pas disparu, bien qu'à la fin de l'ancien régime on tende à la laisser tomber en désuétude.

Il semble aussi que des barrières juridiques de plus en plus hautes se dressent entre les classes sociales. C'est ainsi que la noblesse, bien que continuant à se recruter, en une certaine mesure, dans la classe des enrichis, tend à devenir par certains côtés une caste fermée. Les réformations de cette classe, accomplies à l'époque de Louis XIV, bien qu'ayant été surtout des mesures fiscales, ont retranché de la noblesse les familles de récente extraction, surtout les familles qui continuent à se livrer au commerce, les magistrats des sièges secondaires, les gen- 
tilshommes enfin qui sont trop pauvres pour faire valoir leurs droits. Ainsi, au XVIII ${ }^{\mathrm{e}}$ siècle, les sièges parlementaires sont fermés aux roturiers, et le fossé se creuse de plus en plus entre les nobles et les roturiers, tandis que la noblesse n'a plus guère d'autre ressource ou d'autre occupation que les charges militaires.

Mais c’est précisément à la même époque que se préparent de profondes transformations économiques, qui auront pour effet de donner aux classes sociales un aspect tout nouveau. Le capitalisme, sous sa forme commerciale du moins, a pris une remarquable extension au $\mathrm{XVIII}^{\mathrm{e}}$ siècle, et voici qu'il commence à exercer son emprise sur l'industrie. La classe des négociants et directeurs de manufactures prend une importance de plus en plus grande. Ils en arrivent, en bien des cas, à " contrôler " l'industrie rurale, ouvrant ainsi la voie à la grande industrie capitaliste. Dans les métiers urbains de l'industrie textile, — notamment dans l'industrie lyonnaise de la soie —, les maîtres marchands soumettent à leur domination les maîtres ouvriers, les transformant en véritables salariés. Ainsi se constitue de plus en plus forte cette classe, essentiellement capitaliste, des négociants, qui se trouve directement en lutte avec les métiers d'artisans, avec les organisations corporatives, au cadre desquelles elle a pu échapper. Elle donnera naissance à la classe des grands patrons industriels du $\mathrm{XIX}^{\mathrm{e}}$ siècle, et elle nous apparaît déjà comme singulièrement entreprenante, novatrice, révolutionnaire, du moins au sens économique du mot, ennemie de la réglementation, des règles et privilèges juridiques. Cette première poussée du capitalisme contribua grandement à la transformation sociale que la Révolution va accomplir.

La Révolution aura précisément pour effet de détruire toutes les distinctions juridiques qui existaient entre les classes sociales, d'établir l'égalité de droit.

$\mathrm{Au} \mathrm{XIX}^{\mathrm{e}}$ siècle, la notion de classes sociales et la conscience qu'en prennent les individus s'affirmeront de plus en plus nettement. C'est que l'abolition des privilèges de classes juridiques et les progrès du capitalisme auront eu pour effet d'établir une nouvelle répartition des classes sociales, fondée sur leur rôle économique. La classe du haut négoce, des patrons et de la grande industrie prendra une importance croissante. Le fossé se creusera de plus en plus profond entre les employeurs et les ouvriers qu'ils font travailler. Tandis qu'au XVIII ${ }^{\mathrm{e}}$ siè- 
cle, les compagnons n’ont pas une idée bien claire de leur solidarité - et c'est pourquoi on ne saurait parler encore d'une question ouvriè$r e-$ au $\mathrm{XIX}^{\mathrm{e}}$ siècle, au contraire, la classe ouvrière prendra vraiment conscience de ses intérêts collectifs. Remarquons que cette nouvelle conception des classes sociales se lie très étroitement avec l’organisation individualiste de la société.

Voilà ce qui distingue profondément la vie économique et sociale du XIX ${ }^{\mathrm{e}}$ siècle de celle que nous avons essayé de décrire pour le XVIII ${ }^{\mathrm{e}}$. En l'espace de cinquante ans, la transformation aura été plus profonde qu'elle ne l'avait été pendant les trois siècles qui se sont écoulés depuis la fin du moyen âge.

Cependant, dès le XVIII ${ }^{\mathrm{e}}$ siècle, pour qui scrute les réalités économiques, les classes sociales sont déjà infiniment plus diversifiées qu'on ne serait tenté de le penser, lorsque l'on consulte les documents officiels ou les textes juridiques. On a vu, par exemple, que les classes paysannes ne forment pas un bloc uniforme, que propriétaires et nonpropriétaires ont des intérêts très souvent antagonistes, que, parmi les fermiers, il y a bien des conditions diverses. Tous les nobles, en droit, paraissent jouir des mêmes privilèges ; en réalité, la noblesse de cour et la noblesse provinciale se distinguent profondément par leur condition et leur genre de vie. Dans le clergé, distinction radicale aussi entre les dignitaires séculiers et les prêtres des paroisses, entre le clergé séculier et le clergé régulier. Sous le nom global de tiers état des villes, combien diffèrent les maîtres des métiers, les directeurs des manufactures, les négociants ! Le financier côtoie le monde de la noblesse et même l'éclabousse souvent de son luxe. Les magistrats municipaux, anoblis par leurs charges, forment, avec les riches rentiers, une haute bourgeoisie, beaucoup plus éloignée des classes populaires que des ordres privilégiés. Le patriciat urbain, en 1789, entre en conflit violent avec les gens des " communes ", la moyenne et la petite bourgeoisie, hommes de loi, médecins, marchands et artisans, qui constitueront les cadres de la république démocratique de l'An I et de l’An II.

Enfin, la prédominance de la propriété rurale, de la production agricole constitue un trait permanent de la civilisation française, qui subsistera encore au XIX ${ }^{\mathrm{e}}$ siècle, malgré les progrès de l'industrie. La conséquence, c’est que l'équilibre ne sera jamais rompu, comme en 
Angleterre ou dans l'Allemagne contemporaine, au profit de la production industrielle, au détriment des campagnes. L'exode vers les villes ne se produira qu'avec modération ; la France restera essentiellement un pays agricole et elle n'est pas encore sur le point de perdre son caractère de démocratie rurale. L'on pourrait encore, dans une certaine mesure du moins, appliquer à la France contemporaine le mot de Chaptal, en 1819 : « De toutes les nations de l'Europe, c'est encore la France qui, réduite à ses propres ressources, éprouverait le moins de privations. " 


\section{Bibliographie générale}

Henri SÉE, Histoire économique de la France, t. I. Le moyen âge et l'ancien régime, Paris, 1939, in-8 ${ }^{\circ}$ (texte français, publié avec le concours de R. SCHNERB, de l'ouvrage paru en allemand Französische Wirtschaftsgeschichte, Jena, 1930.

Fr. SimiAnD, Recherches anciennes et nouvelles sur le mouvement général des prix du XVI $\mathrm{C}^{\mathrm{e}}$ au XIX $\mathrm{e}^{\mathrm{e}}$ siècle, Paris, 1932, in-8 .

LABROUSSE, Esquisse du mouvement des prix et des revenus en France au XVIII ${ }^{\mathrm{e}}$ siècle, Paris, 1933, 2 vol. in-8 ${ }^{\circ}$.

Henri HAUSER, Recherches et documents sur l'histoire des prix en France de 1500 à 1800, Paris, 1936, in-4 .

Consulter les ouvrages de:

SAINT-LÉGER et Ph. SAGNAC, La prépondérance française (1650-1715), et Pierre MurET, La prépondérance anglaise (1115-1163), (t. X et XI de la collection «Peuples et civilisations »).

H. HAUSER, Les crises de crédit et de spéculation en France et en Angleterre au lendemain de la paix d'Utrecht (Revue d'histoire moderne, 1934).

Achille Viallatte, L'activité économique de la France de la fin du XVIII siècle à nos jours, Paris, 1937, in- ${ }^{\circ}$.

\section{APPENDICE BIBLIOGRAPHIQUE}

\section{Chapitre II.}

A. Aulard, La Révolution française et le régime féodal, Paris, 1919.

Ch. Leroy, Paysans normands au XVIII ${ }^{\mathrm{e}}$ siècle, Rouen, 1929, 2 vol. in-8 ${ }^{0}$.

H. SÉE, Études sur la vie économique en France. 1772-an III, Paris, 1930, in-8º

Marc BLOCH, Les caractères originaux de l'histoire rurale française, Oslo et Paris, 1931. 
Arthur Young, Voyages en France en 1781, 1788 et 1789, traduits et annotés par Henri Sée, Paris, Armand Colin, 1931, 3 vol. in-8 ${ }^{\circ}$.

\section{Chapitre VI.}

René NigeON, État financier des corporations parisiennes d'Arts et Métiers au XVIII siècle (Doc. d'hist. de la Révolution, 1934, in- ${ }^{\circ}$ ).

Em. CoORnAert, L'organisation corporative du Moyen Age à la fin de l'ancien régime, Louvain [Recueil de Travaux de l'Université), 1939 , in-8 .

\section{Chapitre VII.}

VIGNON, Étude historique sur l'administration des voies publiques en France, Paris, 1863, 3 vol. in- $8^{\circ}$.

Marcel VIgNe, La Banque à Lyon du XV $\mathrm{XV}^{\mathrm{e}}$ au XVII ${ }^{\mathrm{e}}$ siècle, 1902.

Henry WEBER, La Compagnie française des Indes, 1904.

Turgot, Euvres, éd. Schelle, Paris, 1913-1923, 5 vol. in-8º

H. SÉE, Documents sur le commerce de Cadix, Paris, 1927 (extr. de la Revue d'histoire des colonies). — Les origines du capitalisme moderne, Paris, 1926.

Gaston MARTIN, L'administration de Gérard Mellier, 1709, 1720, 1739, Toulouse et Nantes, 1908, in-8 ${ }^{\circ}$. - Négriers et bois d'ébène, Grenoble, 1928, in-8 ${ }^{\circ}$. Nantes et la Compagnie des Indes, 1664-1789. - Capital et travail à Nantes au XVIII ${ }^{\mathrm{e}}$ siècle, Paris, 1931, in-8 ${ }^{\circ}$. - Nantes au XVIII ${ }^{\mathrm{e}}$ siècle : l'ère des négriers 1714-1772, 1931, in- ${ }^{0}$.

HUBERT, Structure et condition juridique des Compagnies de navigation de l'Ancien régime, Paris, 1929, in-8 .

Henri SÉE et Léon Vignols, Documents sur les relations commerciales entre la France et la Hollande au début du XVIII ${ }^{\mathrm{e}}$ siècle (Economisch Historisch Jaarboek, 1929).

P. Charliat, Trois siècles d'économie maritime française, Paris, 1931, in-8º .

Albert GIRARD, Le commerce français à Séville et à Cadix au temps des Habsbourg, Paris, 1932.

Henri LÉVY-BRUHL, Histoire de la lettre de change en France aux XVII ${ }^{\mathrm{e}}$ et XVIII ${ }^{\mathrm{e}}$ siècles, Paris, 1933, in- $8^{\circ}$. - Un projet de Code de Commerce à la veille de la Révolution : le projet Miromesnil 1778-1780, Paris, 1932, in-8º 
J. RICOMMARD, La lieutenance générale de police à Troyes au XVIII ${ }^{\mathrm{e}}$ siècle, Paris, 1934, in- ${ }^{\circ}$.

Léon CAHEN, Le prétendu pacte de famine (Revue historique, 1933). L'approvisionnement en pain de Paris au XVIII ${ }^{\mathrm{e}}$ siècle (Cahiers de la Révolution française, 1934).

\section{Chapitre VIII.}

De l'ouvrage classique de Paul MANTOUX, une réédition remaniée, mais en anglais, The industrial Revolution in the eightenth century, Londres, 1928, in-8 ${ }^{\circ}$. Quoiqu'il s'agisse de l'Angleterre, l’ouvrage est à consulter.

Paul Harsin, De quand date le mot « industrie »? (Annales d'histoire économique et sociale, 1930).

Jos. KulISCHER, La grande industrie aux XVII et XVIII ${ }^{\mathrm{e}}$ siècles. France, Allemagne, Russie (Annales d'histoire économique et sociale, 1931).

Paul BAUD, L'industrie chimique en France, Paris, 1932, in-8 ${ }^{\circ}$.

H. DEPORS, Recherches sur l'industrie des cuirs en France pendant le XVIII et le début du XIX siècle (Doc. écon. de la Révolution), Paris, 1932, in-8 ${ }^{\mathrm{e}}$.

Yvonne Lefranc, Essai sur l'industrie textile de la Ferté-Macé, Alençon, 1934, in- $8^{\circ}$.

J. RiCOMMARD, La bonneterie à Troyes, Paris, 1934, in-8 ${ }^{\circ}$.

J. Chevalier, Le Creusot, Paris, 1935, in-8 . 